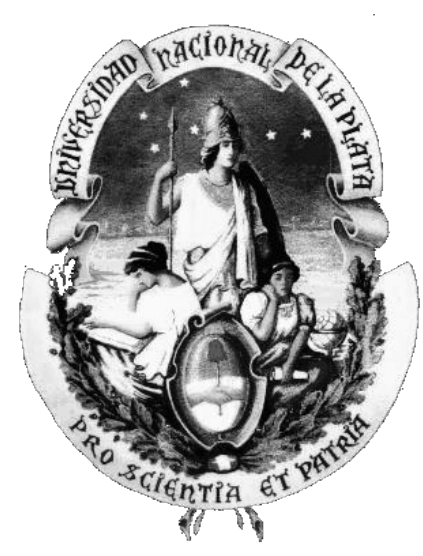

UNIVERSIDAD NACIONAL DE LA PLATA

FACULTAD DE CIENCIAS EXACTAS

DEPARTAMENTO DE CIENCIAS BIOLÓGICAS

Tesis Doctoral

\title{
ESTUDIO DE LA FORMACIÓN DE COMPLEJOS LIGANDO-RECEPTOR MEDIANTE SIMULACIONES COMPUTACIONALES
}

\section{EL CASO ALBÚMINA SÉRICA HUMANA - ASPIRINA}

\author{
Hugo Ariel Alvarez
}

Director: J. Raúl Grigera 



\section{A Lautaro y Martina.}

Hoy es siempre todavía, toda la vida es ahora. Y ahora, ahora es el momento de cumplir las promesas que nos hicimos. Porque ayer no lo hicimos, porque mañana es tarde...

Proverbios y Cantares VIII - Antonio Machado | Ismael Serrano 



\section{Agradecimientos}

La elaboración de una Tesis es un proyecto que insume un tiempo y una dedicación que muchas veces, más allá de la obvia satisfacción personal de poder trabajar en lo que uno desea, quita lugar a otros proyectos personales y colectivos y, por qué no decirlo, a los tiempos compartidos con los afectos. Por eso mi principal agradecimiento es a todos aquellos que han visto mermar mi aporte a los proyectos que compartimos por dedicarme a este proyecto personal, y a los familiares y amigos que no he acompañado como quisiera.

También quiero agradecer a quienes disfrutaron conmigo de mis aciertos (aunque siempre sean menos de los que uno desearía) y a quienes sufrieron o toleraron mis desaciertos. A todos y cada uno, GRACIAS, sobre todo por ayudarme a CRECER en todo aspecto que esta palabra indique, y porque en todo este camino transitado lo que me queda son las manos amigas que han sido tendidas y posibilitaron que los escollos se vuelvan sólo piedras en el zapato.

\section{A Silvina}

Por el aguante de todos estos años y por la felicidad que compartimos al ver crecer a nuestros hijos... tan rápido.

\section{A Raúl}

Por haberme acompañado en mi crecimiento profesional.

\section{A mis Padres, Hermanos, Cuñados y Sobrinos}

Porque simplemente, siempre están, y porque la palabra alegría siempre está presente cuando pienso en ustedes.

\section{A mis Suegros}

Por ser Familia.

\section{A Manuel Carlevaro}

Por todo lo que me has ayudado y por hacerme descubrir la UTN-FRBA.

\section{A Osvaldo Chara}

Espero honrar la oportunidad que me brindaste y no hacértela tan difícil.

\section{A mis amigos}

Por bancarse mis tiempos y ausencias.

\section{A la gente del IFLYSIB}

El hecho de que uno sienta su lugar de trabajo como un segundo hogar depende en gran medida de quienes lo habitan y su calidad humana. Muy especialmente a Ricardo, Ramiro, Ariel, Guillermo, Gastón, Nara, Celeste, Marisa, Ivana, Eduardo Howard, Andrés Salvay y a las Autoridades del Instituto.

\section{A Lola}

Por el amor que tienen esas empanadas caseras, y que espero retribuir. 


\section{A mis Compañeros Docentes}

Especialmente a Tati Prieto.

\section{Al Departamento de Cs. Biológicas y a los Directivos del CEQUINOR}

Por ayudarme a finalizar esta Tesis.

\section{A la Facultad de Ciencias Exactas y su gente}

Alguien dijo alguna vez que las instituciones son mucho más que la gente que las transita, y en ese tránsito hemos compartido muchas experiencias, diferencias y momentos vitales.

\section{A los compañeros de CCyP}

Por el compromiso y el trabajo constante. Porque seguimos construyendo ladrillo sobre ladrillo, desde el Pie.

\section{A los Scouts}

Por mostrarme día a día que la verdadera manera de ser felices es haciendo felices a los demás. Por hacerme feliz. 


\section{ÍNDICE GENERAL}

\section{Capítulo 1 - INTRODUCCIÓN}

pg 1

Objetivos con los que se ha desarrollado esta Tesis Doctoral

pg 3

Descripción de la problemática y el sistema utilizado para estudiarla

pg 3

Sobre la Técnica utilizada

pg 4

Albúmina y Aspirina

pg 4

La relación de Jarzynski

pg 8

Cálculo de $\Delta G$ a partir de la constante de afinidad entre proteína y ligando

pg 10

Caracterización de los modelos de solvente utilizados

pg 11

Comparación de los modelos de agua actualmente más utilizados en Simulaciones Computacionales

pg 11

El agua como combinación de estructuras

pg 14

El agua deuterada

pg 16

\section{Capítulo 2 - DINÁMICA MOLECULAR}

pg 21

1. La Dinámica Molecular Aproximaciones

pg 23

a. Las simulaciones son Clásicas

pg 24

b. Los electrones se encuentran en el estado energético fundamental

pg 24

c. Los Campos de Fuerza son efectivos

pg 24

d. EI Campo de Fuerzas es aditivo y analiza sólo interacciones de a pares

pg 24

e. Las interacciones de largo alcance son tratadas con radios de corte

pg 25

f. Tratamiento de las Condiciones de Contorno pg 25

2. Algoritmo general utilizado en Dinámica Molecular pg 27

3. El Campo de Fuerzas $\quad$ pg 28

Potenciales no-enlazantes $\quad$ pg 28

Potenciales enlazantes $\quad$ pg 31

Potenciales especiales $\quad$ pg 36

4. Generalidades del cómputo de fuerzas p 39

a. Condiciones iniciales pg 39

b. Búsqueda de vecinos $\quad$ pg 42

c. Cómputo de interacciones $\quad$ pg 43

d. Actualización de la configuración $\quad$ pg 44

e. Acoplamiento térmico $\quad$ pg 45

f. Acoplamiento de presión $\quad$ pg 47 
5. Algoritmos de restricciones topológicas pg 48

6. Potenciales de Fuerza media - El "Pull Code" pg 50

7. Otras Herramientas de análisis utilizadas pg 52

Algoritmo completo de actualización $\quad$ pg 54

Capítulo 3 - ALBÚMINA Y ASPIRINA pg 55

Estabilización $\quad$ pg 58

Estudios de la estabilidad del Complejo HSA-ASA pg 59

a. Estudios en agua (modelo SPC/E) pg 59

b. Estudios en agua deuterada (modelo SPC/HW) pg 59

c. Efectos de la Presión Hidrostática pg 60

d. Análisis del Radio de Giro pg 61

e. Superficie Accesible al Solvente pg 61

Simulación de Umbrella Pulling $\quad$ pg 63

Hacia la elección de Caminos $\quad$ pg 66

Mutantes K199A y K199M de Albúmina Sérica Humana pg 69

\section{$\begin{array}{lr}\text { CONCLUSIONES } & \text { pg } 71\end{array}$}

REFERENCIAS BIBLIOGRÁFICAS pg 77

$\begin{array}{ll}\text { APÉNDICE } & \text { pg } 87\end{array}$

\section{ÍNDICE DE FIGURAS}

Figura 1-1: Dos representaciones esquemáticas de la Albúmina Sérica Humana.

pg 6

$\begin{array}{ll}\text { Figura 1-2 Dos representaciones esquemáticas de la Aspirina. } & \text { pg } 7\end{array}$

$\begin{array}{ll}\text { Figura 1-3 Dos representaciones esquemáticas del Ácido Mirístico. } & \text { pg } 7\end{array}$

Figura 1.4. Representación esquemática de algunos de los modelos moleculares planos más populares de agua.

pg 11

Figura 1.5. Representación de la Descomposición $\mathrm{G}$ de la Función de Distribución Radial para el modelo de agua SPC/E a T $=300 \mathrm{~K}$ y p $=1$ bar.

pg 15

Figura 1.6. Parámetro de Orden Pr en función de la presión hidrostática ejercida sobre el sistema para el modelo de agua SPC/E.

pg 16

Figura 1.7. Función de Distribución Radial para el modelo de agua pesada SPC/HW entre 1bar (gráfica superior) y 10kbar (gráfica inferior). 
Figura 1.8. Gráfica comparativa del Parámetro de Orden Pr en función de la presión hidrostática ejercida sobre el sistema para los modelos de agua SPC/E y de agua pesada SPC/HW a $300 \mathrm{~K}$.

Figura 1.9. Gráficas de la Presión de crossover para los modelos estudiados.

Figura 1.10. Gráfica comparativa de la Presión de crossover para ambos modelos estudiados en función de la temperatura del sistema.

Figura 2-1. Condiciones periódicas de contorno en dos dimensiones

Figura 2-2: Curva potencial para la interacción repulsión-dispersión de Lennard-Jones.

Figura 2-3: Un ejemplo de curva potencial para la interacción Coulombiana entre cargas de igual signo, con y sin Campo de reacción.

Figura 2-4: Principio del estiramiento de enlace (izquierda), y el correspondiente potencial armónico de enlace (derecha).

Figura 2-5: El pozo potencial de Morse, para una longitud de enlace de 0.15 nm.

Figura 2-6: Principio de vibración de enlace (izquierda) y función potencial de ángulo de enlace (derecha).

Figura 2-7: Diferentes tipos de ángulos diedros impropios. Distorsiones de anillos fuera del plano (izquierda), sustituyentes de anillos (centro) y distorsión del tetraedro (derecha). El ángulo diedro impropio se define para todos los casos como el ángulo entre los planos $(i, j, k) \mathrm{y}(j, k, l)$.

Figura 2-8: Función potencial para diedros impropios.

Figura 2-9: Principio para el ángulo diedro propio (izquierda, en configuración trans) y el potencial periódico para el diedro propio (derecha).

Figura 2-10: Función potencial para diedro propio de Ryckaert-Bellemans.

Figura 2-11: Función potencial para la restricción de posición.

Figura 2-12: Función potencial para la restricción de distancias. 
Figura 2-14: Representación esquemática del funcionamiento de la convención de la 'imagen más cercana'.

Figura 2-15: Método de integración de "leap-frog" o salto de rana. Recibe este nombre debido a que $r$ y $v$ saltan uno sobre el otro alternadamente al estilo del salto de rana.

Figura 2-16: Las tres actualizaciones de posición requeridas para cada paso de integración. La línea punteada representa el viejo enlace de longitud $d$, mientras que las líneas llenas representan $\operatorname{los}$ nuevos enlaces. $l=d \cos \theta$ y $p=\left(2 d^{2}-l^{2}\right)^{1 / 2}$

Figura 2-17: Representación esquemática de la acción de Umbrella Pulling.

Figura 2-18: Representación de la aplicación del algoritmo para obtener la $S A S$.

Figura 3-1: Raíz de la Desviación Cuadrática Media (RMSD) de las posiciones de los Carbonos $\alpha$ de la proteína en una corrida de simulación de $80 \mathrm{~ns}$ en agua $\mathrm{SPC} / \mathrm{E}$.

Figura 3-2: RMSD de las posiciones de los Carbonos $\alpha$ de la proteína en una corrida de simulación de 80ns en agua SPC/E (curva negra) y en una corrida de simulación de 40ns en agua pesada SPC/HW a partir de los 40ns (curva azul).

Figura 3-3: RMSD de las posiciones de los Carbonos $\alpha$ de la proteína en una corrida de simulación de 80ns (curva negra) y en dos corridas de simulación a $3 \mathrm{kbar}$ (curvas verdes) en agua SPC/E.

Figura 3-4: Radio de Giro $\mathrm{R}_{\mathrm{g}}$ de la proteína en una corrida de 80ns (curva negra), en dos corridas a $3 \mathrm{kbar}$ (curvas verdes) en agua SPC/E y una corrida en agua pesada SPC/HW (curva azul).

Figura 3-5: Fracción promedio de superficie hidrofóbica expuesta al solvente en las condiciones estudiadas.

Figura 3-6: Ejemplo de gráficas de las Componentes $x, y$ y $z$, respectivamente de la Fuerza aplicada en función del tiempo. Aquí puede observarse que el desplazamiento según el eje $\mathrm{z}$ fue en el sentido negativo del eje mientras que para $\mathrm{x}$ e y se tiró en el sentido positivo.

Figura 3-7: Ejemplo de gráfica de componente de la fuerza aplicada en función de la misma componente de la posición de la molécula de la cual se tira.

Figura 3-8: Dependencia de la magnitud de la fuerza media aplicada sobre el centro de masas del ASA como función de la magnitud del desplazamiento del resorte (coordenada de tirado o Pull Coordinate), tanto para el sistema en presencia (líneas negras) y ausencia (líneas rojas) del complejo de HSA. Estos valores medios representan la fuerza media en cada paso en treinta corridas de DM para ambos sistemas. Las barras de error son la desviación estándar de los valores (sólo 80 se muestran para una mejor visión). 
Figura 3-9: Representación en histogramas del trabajo mecánico, tanto para el sistema en presencia (barras negras) como en ausencia (barras rojas) del complejo de HSA. Las líneas continuas son las distribuciones gaussianas para los valores correspondientes de la desviación estándar y el valor medio de cada histograma.

Figura 3-10. Tres representaciones de la Proteína en Superficie (celeste) y del ácido acetilsalicílico en diferentes posiciones sobre la trayectoria de tirado (rojo)

Figura 3-11. Grafícas de Fuerza Media en función de la coordenada de tracción para los sistemas HSA-ASA (negro), Trabajo Viscoso (rojo) y para HSA-ASA tirando en una dirección alternativa (verde).

Figura 3.12. Representación del sitio específico de unión del complejo HSAASA y mutaciones por sustitución puntual de aminoácido K199A y K199M

Figura 3.13. Gráficas de Fuerza en función de la coordenada de tracción para los sistemas HSA-ASA (negro), Trabajo Viscoso (rojo), K199A- ASA (azul) y K199M-ASA (verde).

Figura 3-14. Representación de la superficie proteica, y de la Aspirina (rojo) ubicada en el sitio específico de unión y vista en la dirección de tirado para la proteína "silvestre" y sus mutantes.

Nombres asignados a los diferentes átomos del ácido acetilsalicílico

\section{ÍNDICE DE TABLAS}

Tabla 1.1. Parámetros de los modelos de agua descriptos

Tabla 1.2. Propiedades físicas de los modelos de agua presentados y sus respectivos valores experimentales

(Todos los datos son a 298K y $1 \mathrm{~atm}$, excepto * a 300K y \# a 293K).

Tabla 1.3. Parámetros del modelo SPC/HW.

Tabla 2.1. Tipos de Cajas utilizables en Simulaciones con PBC.

Distribución de las cargas asignadas a cada átomo en la construcción de la topología del ácido acetilsalicílico.

Distribución de las cargas asignadas a cada átomo en la construcción de la 

Capítulo 1

\section{INTRODUCCIÓN}


Página $\mid 2$ 


\section{Objetivos con los que se ha desarrollado esta Tesis Doctoral}

A continuación, se detallan los objetivos iniciales con los que fue desarrollada esta Tesis. Lejos de pretender haberlos alcanzado totalmente, los presento para dejar claro el camino recorrido al respecto y los pasos futuros para aproximarme a ellos.

\section{Objetivo general}

En esta Tesis se propone profundizar en la comprensión del mecanismo de interacción entre una proteína y un ligando. En particular, en este estudio se desarrolla un método computacional cuantitativamente eficiente para la caracterización de la interacción Receptor-Ligando de diferentes complejos, contrastable con medidas experimentales de Microcalorimetría.

\section{Objetivos específicos}

1) Desarrollar una herramienta computacional que permita el cálculo de paisajes tridimensionales de energía libre de interacción en Complejos Receptor-Ligando.

2) Calibrar esta herramienta utilizando medidas experimentales de sistemas simples mediante microcalorimetría.

3) Utilizar la herramienta para obtener características de posibles inhibidores específicos de enzimas de interés farmacológico.

\section{Descripción de la problemática y el sistema utilizado para estudiarla}

Son bien conocidas las interacciones que generan la conformación de complejos Enzima-Sustrato como el que se estudia en el presente trabajo, sin embargo, a pesar de los diversos avances que se han hecho al respecto, todavía no se encuentra una técnica efectiva (pero sobre todo eficiente) para una caracterización global de esta interacción. Esto permitiría, por ejemplo, un entendimiento más profundo de la acción catalizadora de la Enzima y de los mecanismos que regula, así como también el desarrollo de inhibidores de su actividad específica.

Hoy en día, las técnicas utilizadas para el estudio de conformación tridimensional de macromoléculas biológicas, tales como Difracción de Rayos X $(X R D)$, Difracción de Neutrones $(N D)$, y Resonancia Magnética Nuclear $(N M R)$, han evolucionado notablemente, y esto ha permitido contar con copiosa información accesible a toda la comunidad científica mundial a través de las bases de datos de proteínas $(P D B)^{1}$, con acceso libre a través de internet. Asimismo, las técnicas de simulación computacional permiten el modelado $\mathrm{y}$ análisis detallado de la estructura microscópica $\mathrm{y}$ las

\footnotetext{
${ }^{1}$ http://www.rcsb.org
} 
propiedades dinámicas de estas macromoléculas, como también de su interacción con otras sustancias.

Con este trasfondo es que se inicia un estudio de la interacción de una enzima (la Albúmina Sérica Humana en este caso) con su sustrato. El sustrato utilizado, elegido de entre la gran variedad de pequeñas moléculas hidrofóbicas que interactúan con la Albúmina, fue el Ácido Acetil Salicílico. Con el propósito de desarrollar un método de estudio de la interacción enzima-sustrato, se describen en la presente Tesis los pasos dados en pos de este objetivo.

\section{Sobre la Técnica utilizada}

La técnica empleada para el estudio de este sistema es la simulación computacional por Dinámica Molecular. En particular se utiliza el paquete GROMACS (sigla en inglés para GROningen MAchine for Chemical Simulations) 5, 6, 7, 8, herramienta de acceso libre y gratuito, de probada eficiencia en este campo, y ampliamente utilizada en todo el mundo. Dentro de las facilidades de este paquete se encuentra el programa denominado Pull Code que permite la implementación de Potenciales de Fuerza Media actuando sobre el sistema a estudiar. En particular, para este trabajo se utiliza la opción Umbrella Pulling, que simula la acción de la palanca (en inglés la palabra utilizada sería cantilever) de un microscopio de fuerza atómica, el cual tira de una molécula y cuantifica la fuerza empleada para realizar este proceso.

Mediante el cálculo del trabajo mecánico externo ${ }^{2}$ empleado en liberar al sustrato del sitio activo de la proteína, se calcula una cota superior para la variación de energía libre de Gibbs asociada a dicho proceso, que es un parámetro de equilibrio. Para esto se utiliza la corrección de muestreo finito para la llamada Igualdad de Jarzynski 1, 2, 3, 4, que provee el valor de esta cota superior para un número finito de medidas del trabajo realizado.

\section{Albúmina y Aspirina}

La Albúmina Sérica Humana ( $H S A$ ) es, probablemente, junto con la Hemoglobina, y la Fibrina, una de las primeras proteínas del cuerpo humano en ser estudiadas. El médico griego Hipócrates de Cos (460-370 A.C.) señaló en sus 'Aforismos' que una orina espumosa, con toda probabilidad causada por la presencia de Albúmina, indica enfermedad renal crónica.

Su nombre procede de un término más general, albumen, la palabra utilizada en Alemán antiguo para nombrar a las proteínas. Ésta, a su vez, se origina en el Latín albus (blanco), que es el color de la clara de huevo, la cual posee una alta concentración de ovo-albúmina. Hoy en día, uno debe ser consciente de que varias proteínas comparten este nombre pero no están ni estructural ni funcionalmente relacionadas con la albúmina sérica. Por ejemplo, la ovo-albúmina y la pre-albúmina. Por lo tanto, se debe tener cuidado de distinguir albumen, que se refiere al conjunto de proteínas presentes, por ejemplo, en las claras de huevo, de la albúmina o albúmina sérica 9.

\footnotetext{
${ }^{2}$ Proceso realizado fuera del equilibrio.
} 


\section{CAPITULO 1}

Se trata de una proteína de cadena simple que posee 585 aminoácidos y un peso molecular de $67 \mathrm{kDa}$. El $67 \%$ de este polipéptido se encuentra en estado de hélice $\alpha$ y no posee hojas $\beta$. Está compuesta de tres dominios homólogos (I a III), que, a su vez poseen dos subdominios (A y B) cada uno. Es sintetizada en el hígado, y es la proteína soluble más abundante en todos los organismos vertebrados, incluido el ser humano 10. Está presente en prácticamente todos los tejidos pero sobre todo en la piel y los músculos. Puede encontrarse en cualquier fluido corporal, como por ejemplo en el sudor, en las lágrimas, en la saliva, y en el plasma sanguíneo, siendo la proteína más abundante en la sangre. Su principal función es actuar como vehículo de transporte y distribución de sustancias endógenas y exógenas a través de la sangre, así como mantener el pH y la presión osmótica del plasma 11. Ejemplo de ello es el transporte de fármacos (influyendo así, en su farmacocinética y distribución), de ácidos grasos aniónicos de cadena larga, ácidos biliares, hormonas, vitaminas, etc. 12.

La concentración normal de albúmina sérica en la sangre humana oscila entre 3,5 y 5,0 gramos por decilitro, y supone un 54\% de la proteína plasmática. Cuenta con 17 puentes disulfuro, los cuales le proveen enlaces cruzados entre regiones distantes de la cadena polipeptídica, que estabilizan la estructura terciaria, más allá de su conocida flexibilidad. Los mismos son exclusivamente intra-subdominios, y contribuyen a su impresionante estabilidad térmica. Además, posee un tiol libre (Cisteína 34 - Cys34) y un único triptófano (Triptófano 214 - Trp214), que se utiliza para parte de los estudios de Extinción de la Fluorescencia (a falta de una más adecuada traducción para Quenching Fluorescence) que permiten obtener información de interés sobre la interacción de esta proteína con diferentes ligandos 13.

Entre las características de la $H S A$ que resultan de importancia para el funcionamiento de nuestro organismo, podemos destacar las siguientes:

- Estabilización de volumen: la $H S A$ es una molécula muy hidrofílica. Esta característica hace que tenga un rol fundamental en el mantenimiento del volumen de sangre intravasal en el organismo.

- Función de transporte: Su fuerte carga neta negativa, le provee la capacidad de transportar entre otras cosas agua, calcio, sodio, cobre, y también sustancias no solubles en agua, como ácidos biliares, ácidos grasos, bilirrubina, fenoles, aminoácidos aromáticos y sus derivados, monóxido de nitrógeno (NO) y muchas otras sustancias, como, por ejemplo, el Ácido Acetil Salicílico (la aspirina). La $H S A$ es la molécula decisiva para el transporte de metabolitos hidrofóbicos y tóxicos de todo el organismo al hígado, debido a que presenta una importante cantidad de bolsillos hidrofóbicos cercanos a la interface con el solvente. Mientras estos metabolitos permanecen unidos a la albúmina, no tienen ningún efecto nocivo sobre el organismo, por lo que podemos decir que la albúmina tiene también un efecto neutralizante de toxinas, actuando, en ocasiones, como un "almacén" de las mismas, como cuando transporta la bilirrubina hasta el hígado para su excreción biliar.

Debido a la función de transporte de esta proteína, y a la gran variedad de posibles ligandos que posee, resulta de mucho interés el estudio de la formación de complejos con $H S A$. Una gran cantidad de drogas se transportan a través del torrente sanguíneo complejadas con Albúmina. Esta proteína resulta un verdadero depósito de drogas en el organismo, y las protege de ser modificadas por el metabolismo. 
En forma más general, más allá del organismo del que provengan, las albúminas son proteínas flexibles que pueden adaptar su estructura para interaccionar con una gran variedad de sustratos en sus distintos sitios de unión. Entre los compuestos con mayor grado de unión se encuentran, como ya se ha mencionado, aniones orgánicos hidrofóbicos, como ácidos grasos de cadena larga, bilirrubina, etc. Esta interacción puede generar cambios en la albúmina que provoquen un aumento en su estabilidad, una mayor afinidad hacia otros sustratos, etc. 14, 15, 16.

En la figura 1-1 se observan dos representaciones (tipo "New Cartoon") de la Albúmina Sérica Humana.

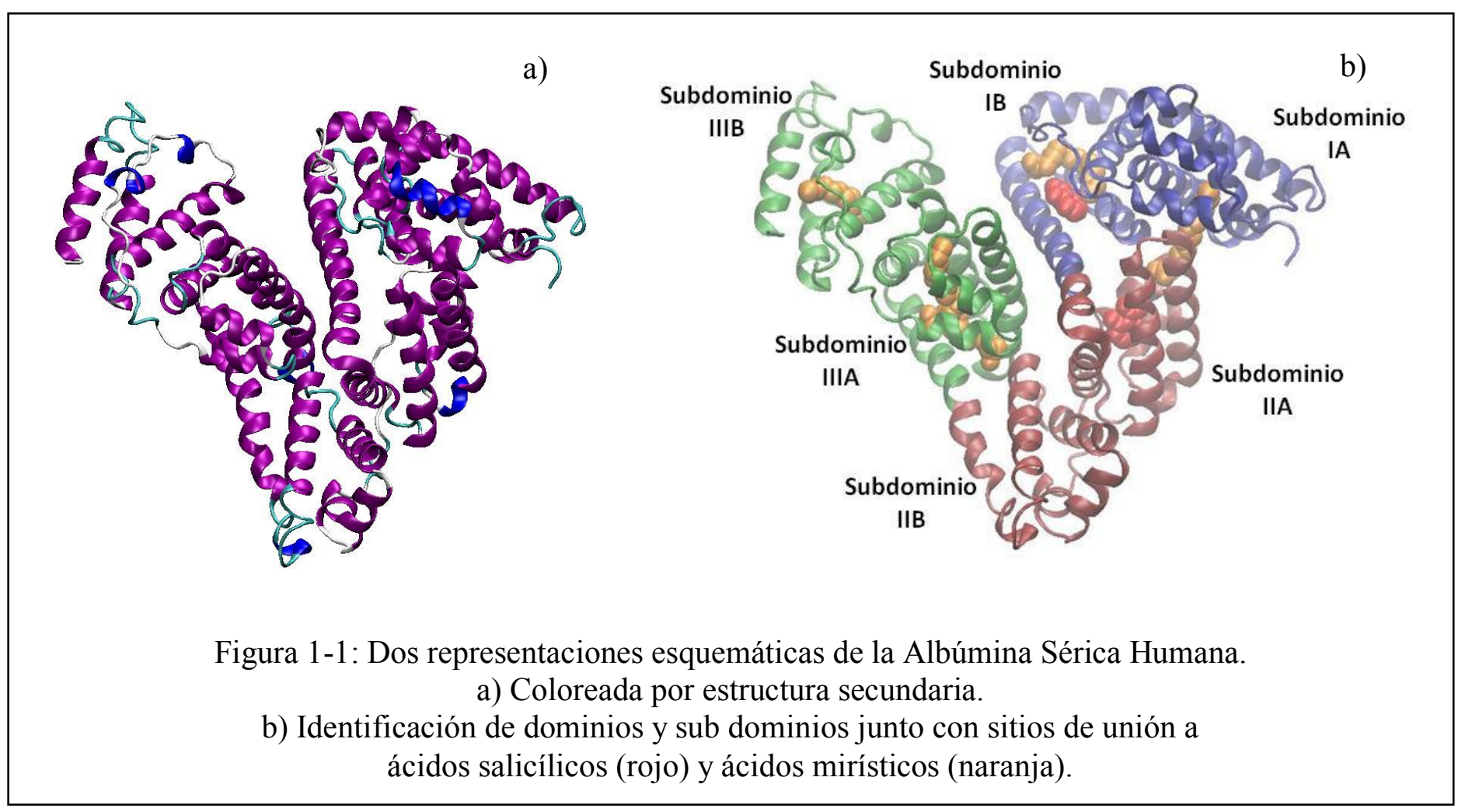

Además, la interacción de sustratos con albúmina puede originar un incremento en la solubilidad de éstos en la sangre (como es el caso de los ácidos grasos), así como una disminución de su toxicidad o una protección frente a la oxidación (como es el caso del daño peroxidativo al ácido linoléico) 17.

Por su lado, el ácido acetil-salicílico (ácido 2-etanoatobenzoico) más comúnmente conocido por su nombre comercial, aspirina, es un antiinflamatorio no esteroide de la familia de los salicilatos, usado frecuentemente como analgésico, antipirético y antiagregante plaquetario.

$\mathrm{Su}$ fórmula molecular es $\mathrm{C}_{9} \mathrm{H}_{8} \mathrm{O}_{4}$, y su peso molecular de 180,16 Da.

Se lo utiliza en bajas dosis y a largo plazo para la prevención del infarto agudo de miocardio y la prevención de la formación de coágulos en los vasos sanguíneos en grupos de riesgo para estas afecciones. 


\section{CAPITULO 1}

En la siguiente figura (figura 1-2) se observan dos representaciones de la aspirina, una en dos y otra en tres dimensiones.

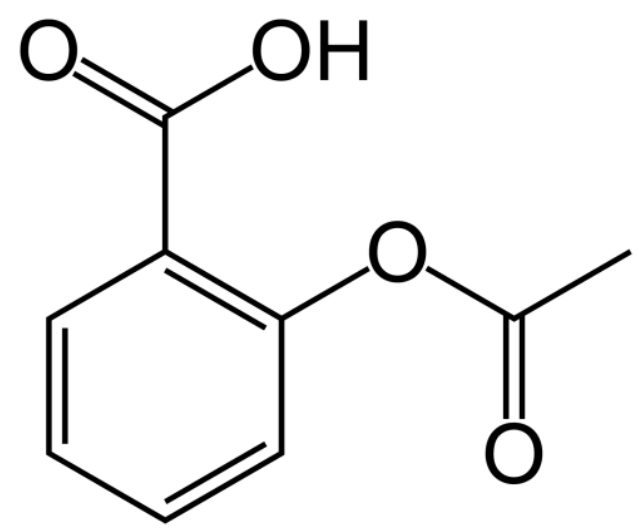

a) Representación bidimensional

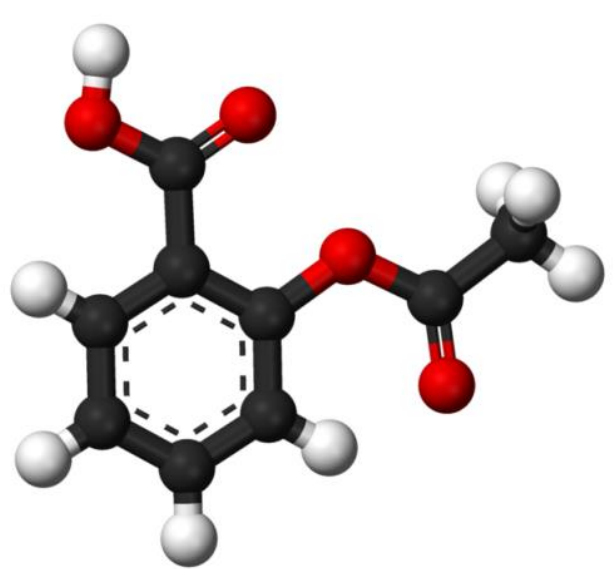

b) Representación tridimensional

Figura 1-2 Dos representaciones esquemáticas de la Aspirina.

Además de la aspirina, la estructura utilizada de la proteína poseía en su conformación cinco ácidos mirísticos (Ácido Tetradecanóico), que son ácidos grasos saturados, cuya fórmula molecular es $\mathrm{C}_{14} \mathrm{H}_{28} \mathrm{O}_{2}$ y su peso molecular 228,36 Da. Se cree que poseen una función reguladora de la afinidad de la Albúmina hacia diferentes drogas, entre ellas la aspirina [9]. En la Figura 1-3 se observan dos representaciones del ácido mirístico en dos y tres dimensiones.

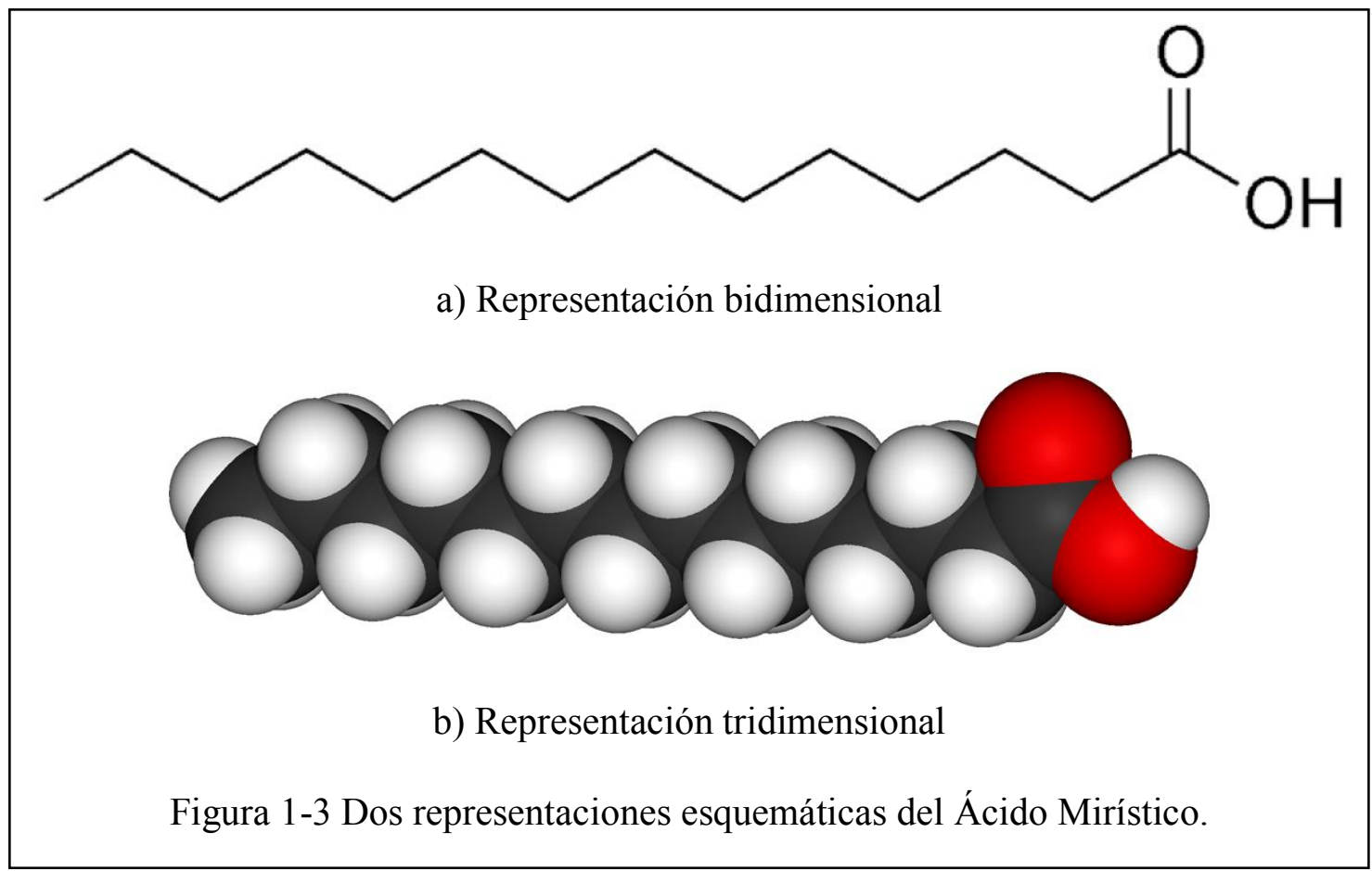




\section{La relación de Jarzynski}

A continuación se describe brevemente el desarrollo que conduce a la llamada igualdad de Jarzynski, que provee la relación entre la variación de energía libre ${ }^{3}$ que describe un cambio de estado del sistema y el trabajo, promediado adecuadamente, que se realiza para llevar al sistema de un estado al otro en un tiempo finito (y, por lo tanto, fuera del equilibrio). También se describirá la cota superior para la variación de energía libre que puede obtenerse a partir de un número finito de medidas del trabajo y la estimación del error cometido.

Consideremos un sistema finito clásico, que depende de un parámetro externo $\lambda$, inicialmente en equilibrio con un reservorio térmico a la temperatura $T$. Si cambiamos el parámetro $\lambda$ infinitesimalmente, desde un valor inicial $\lambda_{0}$ hasta un valor final $\lambda_{t}$, el sistema permanecerá en equilibrio con el reservorio durante este proceso, y el trabajo total realizado sobre el sistema será igual a la variación de energía libre de Gibbs involucrada en dicho proceso:

$$
W_{t \rightarrow \infty}=G\left(\lambda_{t}\right)-G\left(\lambda_{0}\right)=\Delta G
$$

Donde $G\left(\lambda_{t}\right)$ representa la energía libre de equilibrio del sistema a la temperatura $T$ para un valor determinado de $\lambda\left(\lambda=\lambda_{t}\right)$. Este resultado sólo es válido para una variación infinitesimal del parámetro $\lambda$.

Si cambiamos el valor de $\lambda$ a un paso finito, y realizamos un número muy grande o ensamble de estas medidas, obtendremos una distribución de valores del trabajo $W$. Llamaremos $\rho\left(W, t_{s}\right)$ a esta distribución de valores del trabajo, donde $t_{s}$ es el tiempo empleado en cambiar el valor de $\lambda$ entre $\lambda_{0} y \lambda_{t}$.

La magnitud $\rho\left(W, t_{s}\right) d W$ será la probabilidad de que el trabajo realizado en pasar de $\lambda=\lambda_{0}$ a $\lambda=\lambda_{t}$ en un tiempo $t_{s}$ se encuentre entre $W$ y $W+d W$.

En el límite para $t_{s} \rightarrow \infty$ obtenemos $W=\Delta G$ y por lo tanto $\rho=\delta(W-\Delta G)$ en este límite.

Para tiempos finitos sin embargo, observamos dos condiciones importantes:

1. La distribución $\rho$ adquiere un ancho finito reflejando las fluctuaciones en el trabajo realizado.

2. Su centroide se mueve hacia la derecha debido a la disipación:

$$
\langle W\rangle=\int W \rho\left(W, t_{s}\right) d W \geq \Delta G
$$

La ecuación (1-1) presenta a la variación de energía libre $\Delta G$ en términos del trabajo realizado durante un único proceso cuasiestático infinitesimal. En cambio la ecuación (1-2) provee una cota superior sobre $\Delta G$ a partir de un ensamble de repeticiones del proceso a tiempo finito. Jarzynski mostró que en lugar de esta cota superior puede

\footnotetext{
${ }^{3}$ de Gibbs, en el caso de trabajar a temperatura $\mathrm{T}$ y p constantes - Ensamble Isobárico-Isotérmico.
} 


\section{CAPITULO 1}

obtenerse directamente el valor de $\Delta G$ a partir de la información contenida en la distribución $\rho$, para cualquier tiempo $t_{s}$, mediante la siguiente relación que recibe su nombre:

$$
\left\langle e^{-\frac{W}{k_{B} T}}\right\rangle \equiv \int W \rho\left(W, t_{s}\right) e^{-\frac{W}{k_{B} T}} d W=e^{-\frac{\Delta G}{k_{B} T}}
$$

Este resultado provee el valor de una magnitud de equilibrio, como lo es la variación de la energía libre de Gibbs, en términos de un ensamble de medidas fuera del equilibrio realizadas en un tiempo finito.

Si en lugar de un ensamble de medidas se realiza un número finito $N_{s}$ de ellas y se llama $W_{i}$ al trabajo realizado en el i-ésimo proceso, el promedio de los trabajos estará dado por:

$$
W^{a} \equiv \frac{1}{N_{s}} \sum_{i=1}^{N_{s}} W_{i}
$$

Podemos pensar a los trabajos $W_{i}$ como un muestreo aleatorio de números a partir de la distribución $\rho(W)$, que satisfacen la ecuación (1-3). Luego, el valor esperado de $W^{a}$ nos dará una cota rigurosa sobre $\Delta G$.

$$
\left\langle\left\langle W^{a}\right\rangle\right\rangle=\langle W\rangle \equiv \int W \rho(W) d W \geq \Delta G
$$

Donde el doble "bracket" indica el valor esperado de $W^{a}$, mientras que el simple denota el promedio en el ensamble de $W$.

La ecuación (1-3) sugiere que en realidad la cantidad más adecuada para estimar $\Delta G$ no es $W^{a}$ sino la siguiente magnitud:

$$
W^{x} \equiv-k_{B} T \ln \left[\frac{1}{N_{s}} \sum_{i=1}^{N_{s}} e^{-\frac{W_{i}}{k_{B} T}}\right]
$$

La expresión (1-6) es la llamada Corrección de muestreo finito a la Igualdad de Jarzynski 3, 4.

Para $N_{s}=1, W^{x}$ y $W^{a}$ serán idénticas y el valor esperado de ambas será $\langle W\rangle$.

Para $N_{s} \rightarrow \infty, W^{x}$ tenderá a $\Delta G$, mientras que $W^{a}$ tenderá a $\langle W\rangle$. Para valores intermedios de $N_{s}$ se satisface la siguiente inecuación:

$$
\Delta G \leq\left\langle\left\langle W^{x}\right\rangle\right\rangle \leq\left\langle\left\langle W^{a}\right\rangle\right\rangle
$$

Donde los promedios son tomados sobre las $N_{s}$ medidas del trabajo.

En otras palabras el "promedio exponencial" $W^{x}$ tiene una desviación estadística mucho menor que el promedio ordinario $W^{a}$ para $N_{s}>1$.

La fluctuación del trabajo realizado, suele ser una medida de la aplicabilidad de la igualdad de Jarzynski al sistema. Sólo si esta fluctuación es comparable con $k_{B} T$, la 
igualdad será aplicable en la práctica. Esta magnitud se calcula, como toda fluctuación, de la siguiente manera:

$$
\sigma^{2}=\left\langle W^{2}\right\rangle-\langle W\rangle^{2}
$$

Si $\sigma>k_{B} T$, el promedio en el ensamble de $\exp (-\beta W)$ estará dominado por valores de $\mathrm{W}$ que se encuentran varias desviaciones standard por debajo de $\langle W\rangle$. Como estos valores del trabajo representan eventos estadísticamente poco frecuentes, se requeriría en este caso un número muy grande de medidas del trabajo $W$ para determinar con exactitud $\langle\exp (-\beta W)\rangle$.

\section{Cálculo de $\Delta G$ a partir de la constante de afinidad experimental entre proteína y ligando}

La constante de afinidad entre una proteína y su ligando se define de la siguiente manera:

$$
K_{a}=\frac{[\text { Complejo }]}{[\text { Proteína }][\text { Ligando }]}
$$

Donde [Complejo] es la concentración molar del Complejo formado por la Proteína y su Ligando, mientras que [Proteína] y [Ligando] son las concentraciones molares de ambas especies no ligadas.

La constante de Afinidad está relacionada con la variación de Energía libre involucrada en el proceso de ligadura entre la proteína y su sustrato mediante la siguiente relación:

$$
\Delta G=k_{B} T \ln \left(K_{a}\right)
$$




\section{Caracterización de los modelos de solvente utilizados}

\section{Comparación de los modelos de agua actualmente más utilizados en Simulaciones Computacionales ${ }^{4}$}

En la actualidad, existe una gran cantidad de modelos moleculares de agua 18, que incluyen geometrías planas o tetraédricas, con topologías rígidas o flexibles, cargas fijas o polarizables, con tres, cuatro, cinco o seis cargas puntuales.

Analizaremos las propiedades de los cuatro modelos planos rígidos más populares de agua, es decir, SPC 19, SPC/E 20, TIP3P 21 y TIP4P 21, 22.

Las características generales de estos cuatro modelos se muestran en la Figura (1.4). Sus parámetros se presentan en la Tabla 1.1, donde $\sigma \mathrm{y} \boldsymbol{\varepsilon}$ son, respectivamente, el diámetro de colisión de Lennard-Jones y la profundidad del pozo de potencial (centrado en el átomo de oxígeno), y $\mathbf{L}$ es la distancia entre los centros de masa (COM) del oxígeno y de los átomos de hidrógeno.

En todos estos modelos, la carga positiva $\mathbf{q}_{\mathbf{H}}$ se encuentra en los átomos de hidrógeno. En el caso de los modelos de tres sitios (es decir SPC, SPC/E y TIP3P), la carga negativa qo se coloca sobre el oxígeno.

El ángulo HÔH se llama $\boldsymbol{\theta}^{\circ}$. En el modelo de TIP4P, I es la distancia entre el sitio virtual (D) donde se coloca la carga negativa (cerca del oxígeno a lo largo de la bisectriz de $\boldsymbol{\theta}^{\circ}$ ) y el centro de masas del oxígeno, y $\varphi^{\circ}$ es el ángulo entre el segmento $\mathbf{O H}$ y el segmento OD de diámetro exterior (es decir, $\boldsymbol{\theta}^{\circ}=2 \varphi^{\circ}$ ). Este sitio virtual $\mathbf{D}$ (usualmente llamado dummy atom o más recientemente virtual site), sólo está presente en modelos de cuatro puntos (en los casos que analizamos, sólo en TIP4P).

a)
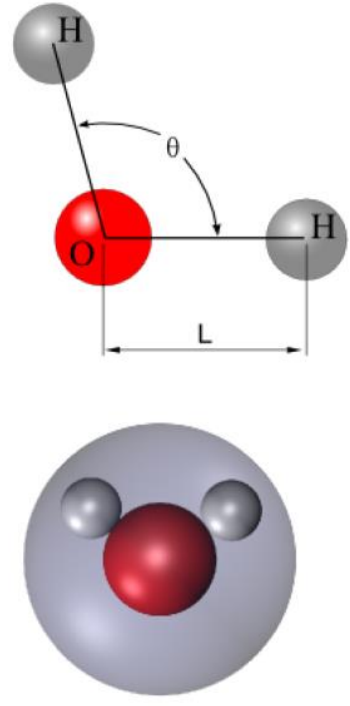

b)
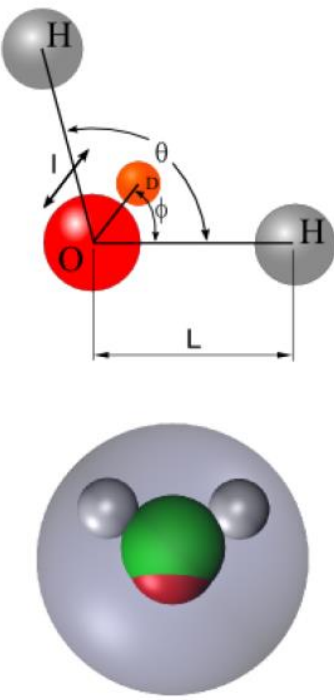

Figura 1.4. Representación esquemática de algunos de los modelos moleculares planos más populares de agua.

a) Modelos de tres puntos (es decir SPC, TIP3P y SPC/E).

b) Modelo de cuatro puntos (TIP4P).

En las Figuras, la esfera grande representa el diámetro de colisión de Lennard-Jones.

${ }^{4}$ Este análisis comparativo de los modelos de agua planos rígidos forma parte de la siguiente publicación: Ozu, M.*, Alvarez, H. A.*, McCarthy, A. N., Grigera, J. R., \& Chara, O. Molecular dynamics of water in the neighborhood of aquaporins. European Biophysics Journal, 2013. 42(4): p. 223-239.

* Comparten primera autoría 
A partir de un análisis de los datos presentados en la Tabla 1.1 puede verse fácilmente que el modelo SPC/E es una re-parametrización del modelo de SPC. La misma se realiza teniendo en cuenta la corrección a la auto-energía debida al momento dipolar eficaz de la molécula de agua en fase líquida. Significativamente, los modelos SPC y $\mathrm{SPC} / \mathrm{E}$ muestran un ángulo $\boldsymbol{\theta}^{\circ}$ más amplio que la molécula real, siendo la distribución de carga eléctrica la única diferencia entre estos dos modelos. Por otro lado, el modelo TIP4P introduce un cuarto punto, un sitio virtual (sin masa), donde se encuentra la carga negativa. También difiere de TIP3P en la distribución de carga y en los parámetros de Lennard-Jones. Curiosamente, las pequeñas diferencias entre estos modelos de agua pueden inducir diferencias significativas en los valores de las propiedades físicas calculadas para cada uno. Por ejemplo, el modelo SPC/E presenta mejores valores que el modelo SPC para la densidad y el coeficiente de difusión.

\begin{tabular}{|c|c|c|c|c|c|c|c|c|}
\hline \multirow[b]{2}{*}{ Modelo } & \multicolumn{2}{|c|}{ Parámetros de L-J } & \multirow{2}{*}{$\begin{array}{c}\mathrm{L} \\
{\left[10^{-10} \mathrm{~m}\right]}\end{array}$} & \multirow{2}{*}{$\begin{array}{c}1 \\
{\left[10^{-10} \mathrm{~m}\right]}\end{array}$} & \multirow[b]{2}{*}{$\begin{array}{c}\mathrm{q}_{\mathrm{H}} \\
{\left[\mathrm{e}^{-}\right]}\end{array}$} & \multirow[b]{2}{*}{$\begin{array}{l}\text { qo } \\
{\left[e^{-}\right]}\end{array}$} & \multirow[b]{2}{*}{$\theta^{\circ}$} & \multirow[b]{2}{*}{$\varphi^{\circ}$} \\
\hline & $\begin{array}{c}\sigma \\
{\left[10^{-10} \mathrm{~m}\right]}\end{array}$ & $\begin{array}{c}\varepsilon \\
{\left[\mathrm{kJ} \mathrm{mol}^{-1}\right]}\end{array}$ & & & & & & \\
\hline SPC & 3,166 & 0,650 & 1,0000 & - & $+0,410$ & $-0,8200$ & 109,47 & - \\
\hline SPC/E & 3,166 & 0,650 & 1,0000 & - & $+0,4238$ & $-0,8476$ & 109,47 & - \\
\hline TIP3P & 3,15061 & 0,6364 & 0,9572 & - & $+0,4170$ & $-0,8340$ & 104,52 & - \\
\hline TIP4P & 3,15365 & 0,6480 & 0,9572 & 0,15 & $+0,5200$ & $-1,0400$ & 104,52 & 52,26 \\
\hline
\end{tabular}

Tabla 1.1. Parámetros de los modelos de agua descriptos.

La Tabla 1.2 muestra algunas de las magnitudes calculadas para estos modelos, a saber: Densidad, Momento Dipolar, Permitividad Dielectrica estática ("constante" dieléctrica), Coeficiente de Auto-difusión, Energía configuracional media (Energía Potencial por mol), Temperatura de máxima Densidad y Coeficiente de Expansión Térmica.

Tal como aparece marcado en negritas en la Tabla 1.2, el modelo SPC/E presenta mejores valores de densidad, momento dipolar, coeficiente de auto-difusión, energía potencial por mol y constante dieléctrica, mientras que el modelo TIP4P proporciona mejores valores de la temperatura de máxima densidad, y coeficiente de expansión térmica. Todos estos modelos muestran baja concordancia en lo que respecta al punto de fusión del agua (los puntos de fusión de estos modelos son: $190 \mathrm{~K}$ para SPC, $215 \mathrm{~K}$ para SPC/E, $146 \mathrm{~K}$ para TIP3P y $232 \mathrm{~K}$ para TIP4P 23).

A partir de estas observaciones se puede concluir que, cuando se estudia una propiedad física particular, el uso de un solo modelo podría ser la mejor opción. Por ejemplo, si el estudio se basa en la temperatura a la cual la densidad alcanza su máximo, entonces probablemente debe ser elegido el modelo TIP4P. Sin embargo, es evidente que el modelo SPC/E presenta un mejor rendimiento promedio en cuanto a las propiedades físicas antes mencionadas, a un menor coste computacional. 


\begin{tabular}{|c|c|c|c|c|c|}
\hline Modelo & SPC & SPC/E & TIP3P & TIP4P & Experimental \\
\hline $\begin{array}{l}\text { Densidad, } \rho \\
{\left[\mathrm{kg} / \mathrm{m}^{3}\right]}\end{array}$ & $970 * 20$ & $998 * 20$ & 100224 & $1001^{24}$ & 99724 \\
\hline $\begin{array}{l}\text { Momento Dipolar, } \mu \\
{\left[D^{5}\right]}\end{array}$ & 2,2725 & $\mathbf{2 , 3 9 2 5}$ & 2,3525 & $2,18^{25}$ & $2,95^{34}$ \\
\hline $\begin{array}{l}\text { Constante Dieléctrica, } \varepsilon \\
\text { [adimensional] }\end{array}$ & 6526 & 6826 & 9726 & $\begin{array}{l}53 \# 32 \\
29 * 33\end{array}$ & 78,3935 \\
\hline $\begin{array}{l}\text { Coeficiente de Auto-Difusión, D } \\
{\left[10^{-5} \mathrm{~cm}^{2} / \mathrm{s}\right]}\end{array}$ & 3,8527 & 2,4927 & 5,1927 & 3,3127 & 2,3036 \\
\hline $\begin{array}{l}\text { Energía Configuracional Media, U } \\
{\left[\mathrm{kJ} \mathrm{mol}^{-1}\right]}\end{array}$ & $-37,720$ & $-41,420$ & $-41,124$ & $-42,1^{24}$ & $-41,5^{37}$ \\
\hline $\begin{array}{l}\text { Temperatura de máxima densidad, } \mathrm{T}_{\mathrm{TMD}} \\
{[\mathrm{K}]}\end{array}$ & 22828 & $235^{30}$ & 18228 & $253^{28}$ & $277,13^{38}$ \\
\hline $\begin{array}{l}\text { Coeficiente de Expansión Térmica, } \alpha_{\mathrm{p}} \\
{\left[10^{-4}{ }^{\circ} \mathrm{C}^{-1}\right]}\end{array}$ & $7,3^{* 29}$ & $5,14^{31}$ & 9,224 & $4,4^{24}$ & 2,5339 \\
\hline
\end{tabular}

Tabla 1.2. Propiedades físicas de los modelos de agua presentados y sus respectivos valores experimentales (Todos los datos son a $298 \mathrm{~K}$ y 1 atm, excepto * a $300 \mathrm{~K}$ y \# a $293 \mathrm{~K}$ ).

Independientemente de la perspectiva de modelado antes mencionada, las propiedades físicas reales de agua, como se obtienen a partir del experimento, pueden distinguirse claramente de las observadas para líquidos no asociados, y son notoriamente susceptibles de modificación por cambios en las condiciones de temperatura y presión, como se ha demostrado ampliamente a través de diversos enfoques experimentales 40 50. Estos resultados muestran que las denominadas "anomalías" de agua se pierden gradualmente a medida que aumentan la temperatura y la presión, moviéndose hacia un régimen similar al de un líquido simple. Estas propiedades físicas peculiares han sido ampliamente reconocidas y, en general, han sido asociadas a la particular estructura que posee el agua.

Si comparamos el comportamiento de los modelos de tres puntos fijos tipo SPC claramente podemos observar que el modelo SPC/E arroja mejores resultados para agua "bulk". Cuando analizamos este comportamiento en presencia de diferentes solutos o interfases, el análisis se vuelve más complejo y las opiniones se dividen, aunque ninguna se expresa de manera concluyente. De este modo, podemos encontrar publicaciones en las que se considera al modelo SPC como más adecuado para este tipo de sistemas y otras en las que sucede lo contrario, muy posteriores $\mathrm{y}$, a nuestro entender, más exhaustivas 51, 52, 53. Obviamente en este análisis se vuelve relevante la elección del campo de fuerzas a utilizar para cada estudio a emprender. Siendo SPC/E el modelo de tres puntos fijos que mejor se ajusta al comportamiento experimental del agua líquida, llama la atención la escasez de desarrollos de campos de fuerza optimizados utilizando este modelo de agua. Como excepción podemos mencionar el campo de fuerzas propuesto por Cheng et al. 54, para componentes de la interfase aire/Dodecil Sulfato de Sodio/agua.

Por otro lado, según indican Zhang \& Duan 55, analizando las propiedades PVT de los modelos SPCE, TIP4P, TIP5P y EP 0, el modelo SPC/E muestra en general mejores predicciones que los otros tres modelos, ligeramente mejores a las de TIP4P, pero mucho más precisas que las de EP y TIP5P, en un amplio rango de temperaturas y

\footnotetext{
${ }^{5} 1 \mathrm{D}=1$ Debye $=3,34 \cdot 10^{-30} \mathrm{C} . \mathrm{m}$
} 
presiones. Recientemente, Braun y colaboradores 57 comparan las propiedades dieléctricas y de tranporte de los modelos TIP3P y SPC/E con el modelo BMW (coarsegrained big multipole water), con amplia ventaja a favor del modelo SPC/E.

\section{El agua como combinación de estructuras}

Considerando al agua en estado líquido como una combinación de estructuras de baja y alta densidad estrechamente entrecruzadas, como se propuso originalmente en el trabajo de Bernal y Fowler 58, pueden definirse diferentes parámetros de orden que permitan caracterizar una transición líquido-líquido entre ambas configuraciones estadísticas límite. Estas estructuras se corresponden con una conformación abierta (tetraédrica) y una conformación cerrada (hexagonal), respectivamente. En particular, desde nuestro grupo de investigación se ha propuesto un parámetro de orden, $P_{r}$, que permite esta caracterización mediante el análisis de la Función de Distribución Radial ( $R D F$, por sus siglas en inglés, o simplemente $\mathrm{g}(\mathrm{r})$ ) de ese líquido, tanto para sistemas experimentales como para cálculos computacionales 59. $P_{r}$ es capaz de evaluar la estructura más allá de la primera esfera de coordinación a diferencia de la gran mayoría de los parámetros de orden existentes en literatura. Además, su cálculo requiere solamente de la información proporcionada por la $\mathrm{g}(\mathrm{r})$ oxígeno-oxígeno.

El parámetro de orden $\operatorname{Pr}$ se calcula mediante la realización de un procedimiento que se dio en llamar descomposición-G. Éste consiste en el ajuste de la Función G a la Función de Distribución Radial en estudio. La Función G se construye mediante la superposición de 7 funciones: dos funciones Freundlich $\left(f_{t} \mathrm{y} f_{h}\right)$ - correspondientes a la primera capa de hidratación de las contribuciones tetraédrica y hexagonal respectivamente-, cuatro funciones Gaussianas $\left(g_{t}^{1}, g_{t}^{2}, g_{h}^{1}\right.$ y $\left.g_{h}^{2}\right)$ - correspondientes a la segunda y tercera capa de hidratación de las contribuciones tetraédrica y hexagonal respectivamente- y una función Sigmoidea $(s)$ - correspondiente a las cuarta $\mathrm{y}$ posteriores capas hidratación de ambas contribuciones -.

La función $\mathrm{G}$ se define entonces de la siguiente manera:

$$
\mathrm{G}(\mathrm{r} / \sigma)=f_{t}+f_{h}+g_{t}{ }^{l}+g_{t}^{2}+g_{h}{ }^{1}+g_{h}^{2}+s
$$

Con

$$
\begin{gathered}
f_{i}(z)=a \cdot z^{b \cdot z^{-c}} \operatorname{con} \begin{cases}z=r & \forall r \geq 0 \\
z=r_{0} & \forall r<0\end{cases} \\
g_{i}(r)=\frac{A_{i}^{j}}{\omega_{i}^{j} \sqrt{\pi / 2}} e^{-2 \frac{(r-\mu)^{2}}{\omega_{i}^{j}}} \\
s(r)=\frac{V \cdot r^{n}}{K^{n}+r^{n}}
\end{gathered}
$$

En este caso $a, b, c, A_{i}^{j}, \omega_{i}^{j}, \mu, V, K$ y $n$ son parámetros ajustables (con $i=t, h y$ $j=1,2)$. 


\section{CAPITULO 1}

El primer paso para realizar este ajuste es la normalización del dominio de la función $\mathrm{g}(\mathrm{r})$ por medio de la posición del máximo de la función, que representa el diámetro de impenetrabilidad de las moléculas (diámetro molecular $\sigma$ ), dividiendo esta función por $\sigma$. Una vez normalizada la Función de Distribución Radial, se procede al ajuste.

A partir de estos parámetros de ajuste, $P_{r}$ se define como:

$$
P_{r}=\frac{C_{t}-C_{h}}{C_{t}+C_{h}}
$$

donde $C_{t}$ y $C_{h}$ son las contribuciones tetraédrica y hexagonal que se obtienen de la siguiente manera:

$$
C_{t}=\frac{A_{t}^{1}}{\omega_{t}^{1}}+\frac{A_{t}^{2}}{\omega_{t}^{2}} \quad \text { y } \quad C_{h}=\frac{A_{h}^{1}}{\omega_{h}^{1}}+\frac{A_{h}^{2}}{\omega_{h}^{2}}
$$

donde, para cada contribución, el primer término corresponde a la función Gaussiana de los segundos vecinos y el segundo término corresponde a los terceros vecinos. Por tanto, podemos decir que el parámetro de orden $P_{r}$ se construye a partir de las contribuciones tetraédrica y hexagonal de los segundos y terceros vecinos.

En la siguiente Figura (Figura 1.5) se presentan las diferentes contribuciones a la Función G, utilizada para calcular el mencionado parámetro de orden para el modelo de agua SPC/E a una temperatura de $300 \mathrm{~K}$ y una presión de 1 bar.

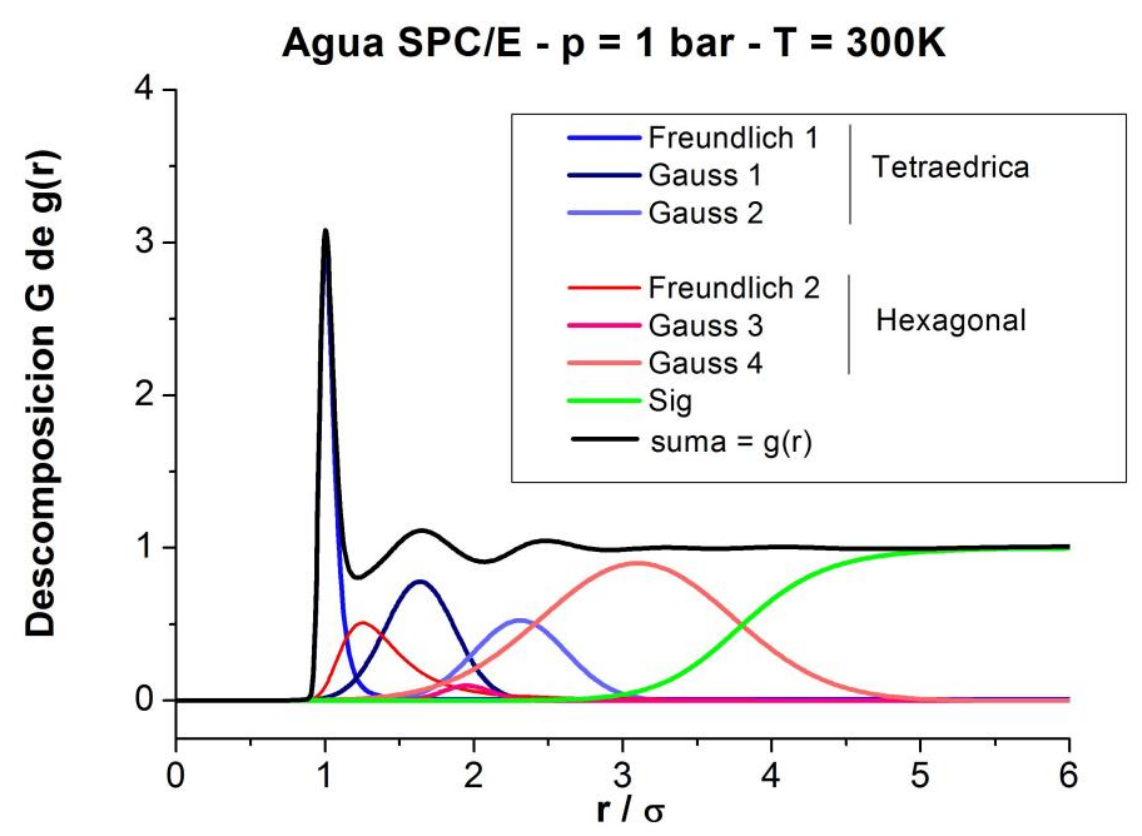

Figura 1.5. Representación de la Descomposición G de la Función de Distribución Radial para el modelo de agua SPC/E a T $=300 \mathrm{~K}$ y $\mathrm{p}=1$ bar.

Puede verse que el rango de valores del parámetro $P_{r}$ será: 


$$
-1 \leq P_{r} \leq 1
$$

Correspondiendo $P_{r}=-1$ a una estructura puramente hexagonal y $P_{r}=1$ a una estructura puramente tetraédrica.

Utilizando simulaciones por Dinámica Molecular bajo diversas condiciones de temperatura y presión se demostró que, para $\mathrm{SPC} / \mathrm{E}, P_{r}$ sigue un comportamiento monótonamente decreciente con la presión. Este resultado puede interpretarse aduciendo que la presión "perturba" la red de puentes de hidrógeno que une las moléculas de agua, obligando a algunas de ellas, que antes se encontraban en una conformación tetraédrica, a pasar a una conformación hexagonal. De esta manera puede identificarse una presión a la cual no existe prevalencia de ninguna de las contribuciones estructurales (es decir $P_{r}=0$ ), a la que se ha denominado crossover estructural.

En la Figura 1.6 puede verse representado el parámetro $P_{r}$ en función de la presión hidrostática en un rango entre 1 bar y $10 \mathrm{kbar}$. Aquí puede observarse el mencionado crossover, que para el modelo SPC/E se encuentra a los 2,3 kbar.

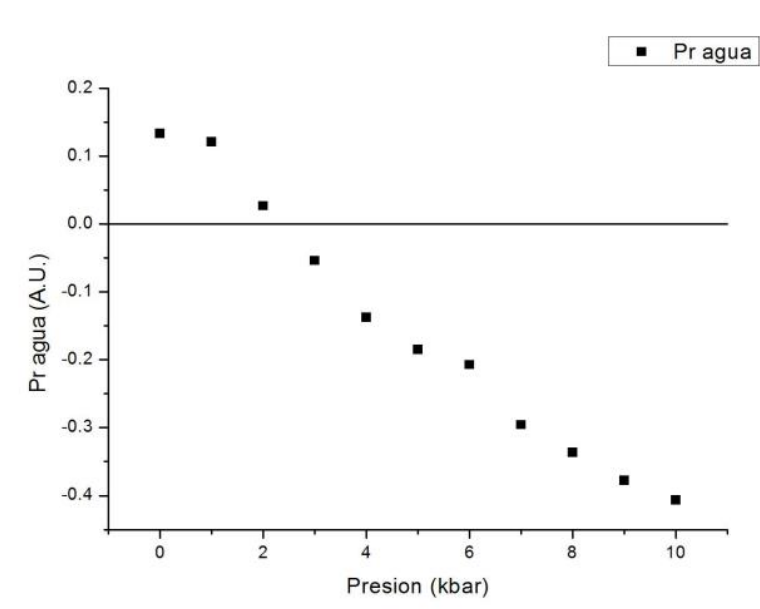

Figura 1.6. Parámetro de Orden $\operatorname{Pr}$ en función de la presión hidrostática ejercida sobre el sistema para el modelo de agua SPC/E.

Este parámetro de orden es capaz de establecer el punto en el que se produce el cambio en la predominancia de una contribución estructural por sobre la otra, en referencia a los cambios de la presión y de la temperatura. Utilizándolo fue posible demostrar que tanto el aumento de la presión como de la temperatura inducen un incremento de la contribución estructural hexagonal en el agua, en detrimento de la contribución tetraédrica.

\section{El agua deuterada}

Si el hecho de poseer características estructurales tan particulares provee al agua de esas propiedades que hemos históricamente considerado como "anómalas", qué decir del agua pesada $\left(\mathrm{D}_{2} \mathrm{O}\right.$ en su variedad más abundante), que tiene la peculiaridad de reforzar esta estructura. A partir de esto, considerando su amplia utilización experimental, y su conocido efecto desnaturalizante en sistemas proteicos 60 , 61, es que se vuelve relevante estudiar el comportamiento de complejos formados por proteínas globulares 


\section{CAPITULO 1}

en presencia de este solvente. El objeto de tal tarea es elucidar un posible mecanismo que genere el mencionado efecto desnaturalizante.

A partir de esta premisa se inicia el estudio de propiedades estructurales del modelo molecular de agua pesada SPC/HW 62 en un amplio rango de presiones y temperaturas, lo cual permite un análisis más detallado de cómo afecta su comportamiento a la estabilidad de sistemas proteicos.

En la Tabla 1.3 se detallan los parámetros del Modelo SPC/HW.

\begin{tabular}{|c|c|c|c|c|c|c|}
\hline \multirow{3}{*}{ Modelo SPC/HW } & \multicolumn{2}{|c|}{ Parámetros de L-J } & \multirow{2}{*}{$\begin{array}{c}\mathbf{L} \\
{\left[10^{-10} \mathrm{~m}\right]}\end{array}$} & \multirow{2}{*}{$\begin{array}{l}\mathrm{q}_{\mathrm{D}} \\
{\left[\mathrm{e}^{-}\right]}\end{array}$} & \multirow{2}{*}{$\begin{array}{c}\mathrm{qo} \\
{\left[\mathrm{e}^{-}\right]}\end{array}$} & \multirow[b]{2}{*}{$\theta^{\circ}$} \\
\hline & $\begin{array}{c}\sigma \\
{\left[10^{-10} \mathrm{~m}\right]}\end{array}$ & $\begin{array}{c}\varepsilon \\
{\left[\mathrm{kJ} \mathrm{mol}^{-1}\right]}\end{array}$ & & & & \\
\hline & 3,166 & 0,650 & 1,0000 & $+0,435$ & $-0,870$ & 109,47 \\
\hline
\end{tabular}

Tabla 1.3. Parámetros del modelo SPC/HW.

De la tabla anterior podemos notar que lo que diferencia al modelo de agua SPC/E con el de agua pesada SPC/HW, no es sólo la obvia diferencia de masas (dada por el hecho que el Deuterio duplica en masa al Hidrógeno), sino también en las cargas. Debido a la geometría y la distribución de cargas del modelo, su momento dipolar resulta $\mu_{\mathrm{SPC} / \mathrm{HW}}=8,048.10^{-30}$ C.m, que es mayor que el valor experimental en la fase gaseosa $\mu_{\text {gas }}=6,171 \cdot 10^{-30}$ C.m (el mismo que el agua "liviana"). Esto último se debe a que se trata de modelos efectivos y en ellos se vuelve necesario incrementar el valor del momento dipolar para la fase líquida, para, de ese modo, incluir la polarización. Podemos comparar este valor con el del modelo SPC/E $\left(\mu_{\mathrm{SPC} / \mathrm{E}}=7,841.10^{-30} \mathrm{C} . \mathrm{m}\right)$ y observar que el cociente entre las contribuciones de ambos al momento dipolar debidas a la polarización $(\Delta \mu)$ debería tener un valor cercano al cociente de polarizabilidades. De este modo, resulta $\Delta \mu_{\mathrm{SPC} / \mathrm{HW}} / \Delta \mu_{\mathrm{SPC} / \mathrm{E}}=1,12$, mientras que el cociente de polarizabilidades tiene un valor experimental de 1,05 . Podemos remarcar también que el modelo SPC/HW posee idénticos coeficientes de Lennard-Jones que los modelos SPC y SPC/E.

En la Figura 1.7 se grafica el cambio en el ordenamiento estructural del modelo SPC/HW con la presión a la temperatura de $300 \mathrm{~K}$, utilizando para este análisis la Función de Distribución Radial g(r).

En esta gráfica puede observarse, como es de esperar, la pérdida gradual de estructura tetraédrica de este modelo de agua pesada con el aumento de la presión. Ese efecto es mucho menos pronunciado que para el caso de agua SPC/E, de modo que se verán valores superiores del parámetro de orden $\boldsymbol{P}_{\boldsymbol{r}}$ para el caso de agua $\mathrm{SPC} / \mathrm{HW}$ en comparación con SPC/E (Figura 1.8), diferenciación que se pierde a altas presiones, a las cuáles ambos sistemas tienen un comportamiento análogo al de un líquido simple.

Es de destacar, de igual modo, en la Figura 1.8, la discontinuidad observada en el parámetro $P_{r}$ en las cercanías del crossover estructural. Esta discontinuidad característica, aparentemente, también se observa para el modelo SPC/E, pero a menores temperaturas, lo cual concuerda con el análisis de que el agua pesada posee un mayor ordenamiento estructural que el agua "liviana". 


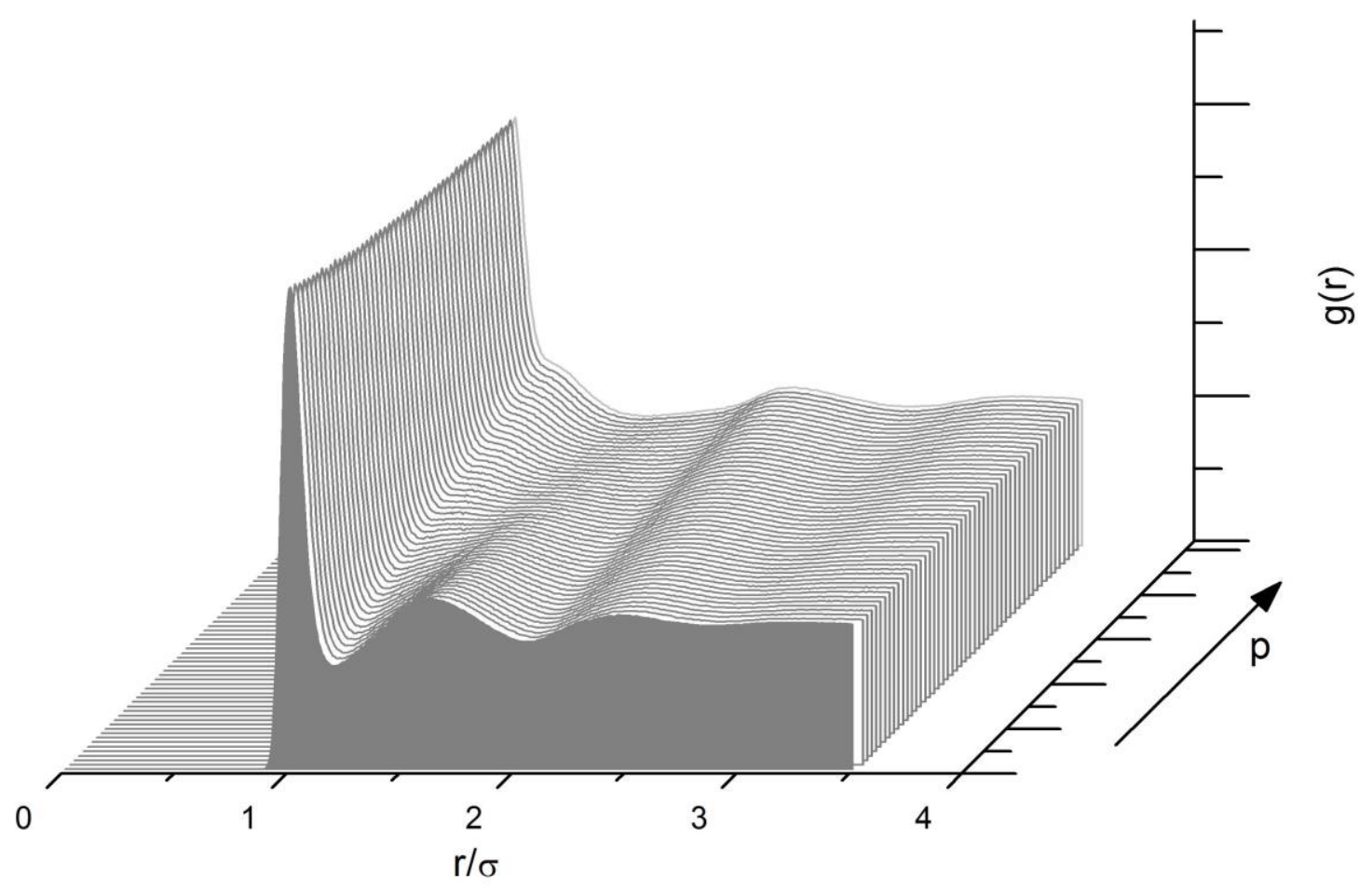

Figura 1.7. Función de Distribución Radial para el modelo de agua pesada SPC/HW entre 1 bar (gráfica inferior) y 10kbar (gráfica superior).

Continuando este estudio, se analiza el valor de la presión a la cual se produce el crossover estructural en función de la temperatura del sistema, comparando los resultados obtenidos con los previamente publicados por nuestro grupo para agua SPC/E 59 (Figura 1.9 a) y b) y Figura 1.10). Aquí puede observarse que la presión de crossover siempre será mayor para el caso de agua pesada. Estas curvas separarán una región de alta densidad del líquido ( $H D L$ por sus siglas en inglés) por encima de ellas, y una región de baja densidad $(L D L)$ y constituirán por tanto un diagrama de fases con una transición líquido-líquido. Del mismo modo que para agua SPC/E, se identifica una línea de Widom en este diagrama de fases, que permite determinar un punto crítico secundario en la transición $H D L \rightarrow L D L$ que corresponde aproximadamente a $\mathrm{T}_{\mathrm{c}}=268 \mathrm{~K}$ y $\mathrm{p}_{\mathrm{c}}=3,5 \mathrm{kbar} 59$ para agua $\mathrm{SPC} / \mathrm{E}_{\mathrm{y}} \mathrm{T}_{\mathrm{c}}=171 \mathrm{~K}$ y $\mathrm{p}_{\mathrm{c}}=8,6 \mathrm{kbar}$ para agua pesada $\mathrm{SPC} / \mathrm{HW}$ [valores obtenidos en el marco de este trabajo de Tesis - Manuscrito en preparación]. 


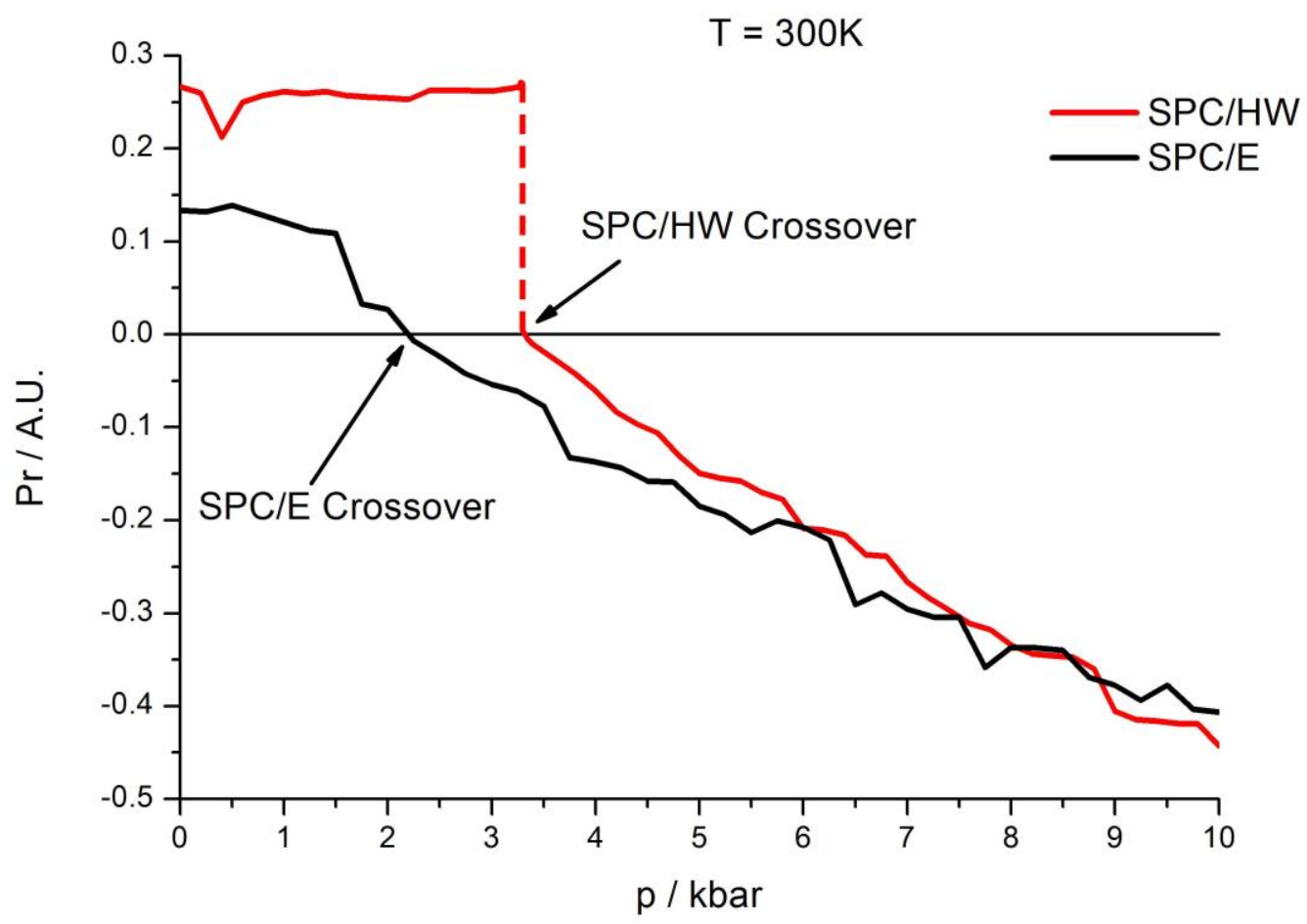

Figura 1.8. Gráfica comparativa del Parámetro de Orden Pr en función de la presión hidrostática ejercida sobre el sistema para los modelos de agua SPC/E y de agua pesada SPC/HW a $300 \mathrm{~K}$.
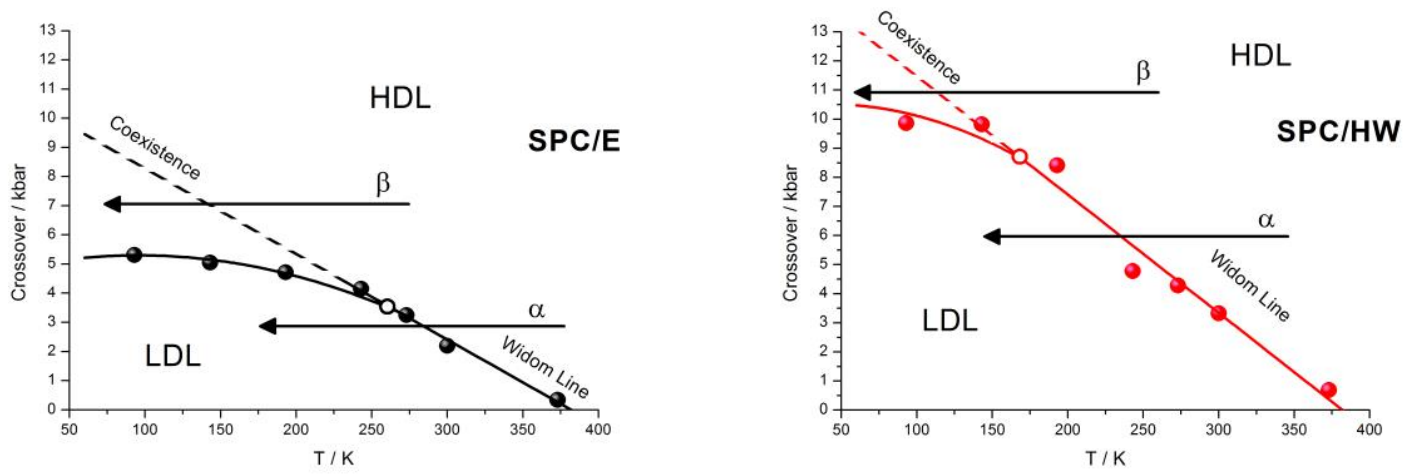

Figura 1.9. Gráficas de la Presión de crossover para los modelos estudiados, a) Agua SPC/E y b) Agua pesada SPC/HW, en función de la temperatura del sistema. Pueden apreciarse aquí los puntos críticos de la transición Líquido-Liquido para ambos modelos (señalados como puntos sin relleno). 


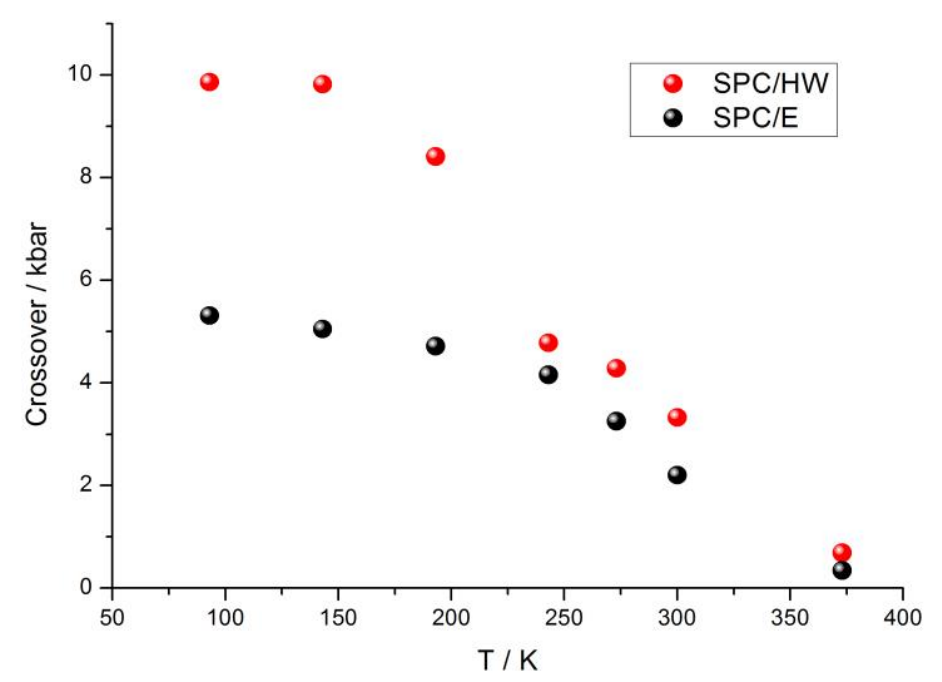

Figura 1.10. Gráfica comparativa de la Presión de crossover para ambos modelos estudiados en función de la temperatura del sistema.

Teniendo en cuenta lo antes descripto, se estudia el sistema Albúmina-Aspirina solvatado con ambos modelos (SPC/E y SPC/HW). También se analiza el comportamiento del sistema en agua SPC/E por encima y por debajo de las presiones correspondientes al crossover estructural. El objeto de estos análisis es profundizar el entendimiento de la estabilidad del complejo en estas condiciones. 
Capítulo 2

\section{DINÁMICA MOLECULAR}


Página $\mid 22$ 


\section{CAPÍTULO 2}

A continuación se describe la técnica de Dinámica Molecular y sus fundamentos, como así también las ventajas y limitaciones que presenta en la actualidad. Se desarrollan principalmente las herramientas necesarias para la realización del presente trabajo.

\section{La Dinámica Molecular:}

Las simulaciones por Dinámica Molecular consisten en un método de cálculo numérico mediante el cual se resuelven las ecuaciones de la dinámica de Newton para un sistema de $\mathrm{N}$ partículas que interaccionan entre sí:

$$
m_{i} \frac{\partial^{2} \vec{r}_{i}}{\partial t^{2}}=\vec{F}_{i}, \quad i=1 \ldots \mathrm{N}
$$

donde $\vec{F}_{i}$ es la fuerza resultante que actúa sobre la i-ésima partícula, $\mathrm{m}_{\mathrm{i}}$ su masa y $\vec{r}_{i} \mathrm{su}$ posición. Las fuerzas son los gradientes cambiados de signo de los potenciales $V\left(\vec{r}_{1}, \vec{r}_{2}, \ldots, \vec{r}_{N}\right)$ de interacción que actúan sobre las diferentes partículas del sistema:

$$
\vec{F}_{i}=-\vec{\nabla}_{i} V
$$

Las ecuaciones (2.1) y (2.2) se resuelven simultáneamente en pasos de tamaño establecido. El sistema evoluciona durante algún tiempo, manteniendo la temperatura y la presión dentro de un rango estipulado alrededor de los valores requeridos (para esto el paquete cuenta con sus respectivos termostatos y barostatos ${ }^{6}$ ), registrando también las coordenadas atómicas a intervalos regulares. Estas últimas en función del tiempo representan la trayectoria del sistema.

Luego de los cambios iniciales, el sistema normalmente tenderá a alcanzar un estado de equilibrio, en el que minimice su energía. Muchas propiedades macroscópicas pueden entonces extraerse de los datos de salida, cuando se promedia sobre una trayectoria de equilibrio. Asimismo, valiosa información puede obtenerse de estos sistemas cuando las simulaciones se realizan fuera del equilibrio.

En este punto resulta apropiado considerar las aproximaciones de las simulaciones realizadas con esta técnica:

\section{Aproximaciones}

a. Las simulaciones son Clásicas.

b. Los electrones se encuentran en el estado energético fundamental.

c. Los Campos de Fuerza son aproximados.

d. El Campo de Fuerzas es aditivo y analiza sólo interacciones de a pares.

e. Las interacciones de largo alcance son tratadas con radios de corte.

f. Las condiciones de contorno no resultan naturales.

\footnotetext{
${ }^{6}$ Con esto nos referimos a programas que simulan la acción de un baño termoestatizante y la de una presión hidrostática sobre el sistema en estudio, respectivamente. Más adelante (Secciones 4.f. y 4.g. del presente Capítulo) se detallan los más utilizados y en particular los usados para las simulaciones descriptas en esta Tesis.
} 
Desarrollemos estos puntos:

\section{a. Las simulaciones son Clásicas:}

El uso de las ecuaciones de movimiento de Newton implica automáticamente el empleo de la "Mecánica Clásica" en la descripción del movimiento de los átomos. Esto es correcto para la mayoría de los átomos a temperaturas normales, pero existen excepciones. Los átomos de hidrógeno, al ser de masa tan pequeña, poseen movimiento de carácter esencialmente mecánico-cuántico. Por ejemplo, un protón puede moverse a través de una barrera de potencial por efecto túnel, lo cual constituye una transferencia de protón a través de un puente de hidrógeno.

Tal proceso no puede ser descripto por la mecánica clásica.

En la simulación por Dinámica molecular se soluciona este problema tratando a los enlaces covalentes $\mathrm{y}$ sus respectivos ángulos como restricciones topológicas $\mathrm{o}$ "constraints" (en el caso de los hidrógenos, se adsorben al átomo pesado al que están unidos). Un motivo práctico para dicho tratamiento resulta del eventual aumento en el paso de integración, lo cual resulta esencial a la hora de permitir movimientos realistas, además de un recorrido completo del espacio configuracional.

\section{b. Los electrones se encuentran en el estado energético fundamental:}

En la Dinámica Molecular utilizamos campos de fuerzas conservativos, los cuales son solamente función de las posiciones de los átomos. Esto significa que los movimientos electrónicos no son tomados en cuenta: se supone que los electrones ajustan su dinámica instantáneamente al cambiar las posiciones atómicas (aproximación de BornOppenheimer), además de permanecer en un estado cuántico no excitado. Esto constituye una buena aproximación en la mayoría de los casos. Aunque, por supuesto, quedan excluidos los procesos de transferencia electrónica, como así también aquellos con estados electrónicos excitados. Por lo tanto las reacciones químicas en general se encuentran fuera del alcance de ésta técnica. Las mismas pueden estudiarse localmente con el empleo de herramientas híbridas como QM/MM, con las que cuentan la mayoría de los paquetes de DM. En estos casos, se estudia la región de interés con técnicas mecánico-cuánticas y el resto del sistema clásicamente.

\section{c. Los Campos de Fuerza son efectivos:}

Las fuerzas son calculadas a partir de los Campos de Fuerza. Los mismos están compuestos por los potenciales de interacción interatómica y los parámetros que caracterizan a las mismas. Éstos no son verdaderamente parte del método de Dinámica Molecular y son susceptibles de modificaciones según se necesite, o bien se actualicen los conocimientos en la materia. Todos los campos de fuerzas disponibles poseen limitaciones (en general no se pueden incorporar polarizaciones y no poseen ajuste fino para los parámetros de enlace, entre otras). La existencia de un gran número de campos de fuerza permite la utilización de diferentes parametrizaciones de acuerdo al tipo de sistema a estudiar.

\section{d. El Campo de Fuerzas es aditivo y analiza sólo interacciones de a pares:}

Esto significa que todas las fuerzas no-enlazantes resultan de la suma lineal de pares de interacciones no-enlazantes. 


\section{CAPÍTULO 2}

Las interacciones no-enlazantes que no pueden describirse por interacciones de a pares de átomos, cuyo ejemplo más importante lo constituye la interacción a través de la polarización atómica, son representadas a través de los potenciales efectivos de pares. Los mismos incorporan sólo contribuciones promedio a las interacciones no-enlazantes, no descriptibles por interacciones de a pares. Esto también significa que las interacciones de a pares no son puras; en otras palabras que no resultan válidas para pares aislados o para situaciones que difieran demasiado de aquellas para las cuales dichos sistemas fueron parametrizados. Por ejemplo, el momento dipolar de los modelos de agua con los que mejores resultados se obtienen es superior al de la molécula individual, debido a que se tiene en cuenta la contribución a la polarización debida a la presencia de las otras moléculas de solvente.

En la práctica, los potenciales efectivos de pares resultan ser una muy buena aproximación, siempre que esta última precaución sea debidamente considerada.

\section{e. Las interacciones de largo alcance son tratadas con radios de corte:}

En general se utilizan radios de corte o "cut-off", tanto para las interacciones de Lennard-Jones como para las interacciones Coulómbicas. Debido a la convención de la mínima imagen (sólo una imagen de cada partícula en las condiciones periódicas de contorno es considerada para la interacción de a pares), el radio de corte utilizado no puede exceder la mitad de la dimensión más pequeña del sistema (del lado más pequeño de la caja de simulación). Si no es tratado adecuadamente, esto puede presentar problemas para el tratamiento de las interacciones Coulómbicas, tales como la acumulación de cargas en la frontera del radio de corte y/o errores muy groseros en los valores de energía.

\section{f. Tratamiento de las Condiciones de Contorno:}

¿Qué debemos hacer en los límites de nuestro sistema de simulación? Una posibilidad es no hacer nada en especial, es decir el sistema simplemente termina, y los átomos en la cercanía de los límites tendrán menos vecinos que los átomos en el interior. En otras palabras, la muestra estaría rodeada por las superficies. Esta no es una situación realista, dado que, no importa cuán grande sea el sistema simulado, el número de átomos $\mathrm{N}$ sería insignificante en comparación con el número de átomos contenidos en una porción macroscópica de materia (del orden de $10^{23}$ ), y la relación entre el número de átomos en la superficie y el número total de átomos sería mucho más grande que la que la existente en un sistema macroscópico, haciendo que los efectos de superficie sean mucho más importantes de lo que deberían.

Para minimizar los efectos producidos en la frontera, en una simulación finita de una porción de un sistema extenso, se utilizan las Condiciones Periódicas de Contorno $(P B C)$. Los átomos del sistema a simular son colocados en una caja poliédrica. Este poliedro debe cumplir con la condición de que el espacio normal de tres dimensiones pueda ser particionado en cajas que sean copias idénticas trasladadas de la original. De este modo se eliminan las fronteras del sistema.

Esto permite remover los problemas indeseados en los bordes que posee un sistema aislado, pero introduce una periodicidad inexistente en el sistema original. Esta característica es beneficiosa para el estudio de sistemas cristalinos, por ejemplo sólidos, donde también son utilizadas.

Por el contrario, si se desea simular sistemas no periódicos tales como líquidos o soluciones, se deberá tener en cuenta la aparición de errores debidos a la imposición de 
la periodicidad. Una manera de evaluar estos errores es estudiar el efecto de la variación del tamaño del sistema (generalmente caracterizado por el número de partículas $\mathrm{N}$ ). Usualmente estos efectos son sustancialmente menores que los que aparecen en las simulaciones $\sin P B C$.

Si una de las partículas que componen el sistema se encuentra en una posición $\vec{r}$ en la caja de simulación, se supone que esta partícula representa un conjunto infinito de partículas localizadas en posiciones $\overrightarrow{\mathrm{r}}^{\prime}=\overrightarrow{\mathrm{r}}+l \breve{\mathrm{b}}_{1}+m \breve{\mathrm{b}}_{2}+n \breve{\mathrm{b}}_{3}$ (con $l, m$ y $n$ enteros y pertenecientes al intervalo $(-\infty, \infty)$, y $\breve{b}_{1}, \breve{b}_{2}$ y $\breve{b}_{3}$ versores correspondientes a las directrices de la caja de simulación). Todas estas partículas se mueven juntas, y de hecho, sólo una de ellas está representada en el programa de simulación.

El punto clave es que ahora cada partícula $i$ en la caja debe ser pensada como interactuando no sólo con otras partículas $j$ en la caja, sino también con sus imágenes en cajas cercanas. Es decir, las interacciones pueden sobrepasar los límites de la caja.

De hecho, se puede ver fácilmente que:

(a) Hemos eliminado la superficie en nuestro sistema.

(b) La posición de los límites de la caja no tiene efectos sobre el comportamiento del sistema (es decir, un traslado de la caja con respecto a las partículas no produce cambios en sus interacciones).

Al parecer, el número de pares de partículas que interactúan aumenta enormemente con el uso de $P B C$. En la práctica, esto no es cierto porque los potenciales de interacción suelen ser de corto alcance. La convención de la 'imagen más cercana', que detallaremos más adelante, simplifica el cálculo, reduciendo aún más la complejidad introducida por el uso de $P B C$.

Para el tratamiento de las interacciones de largo alcance (en general las electroestáticas), se utilizan otras estrategias tales como el uso de radios de corte, Campos de Reacción o sumas de Ewald, entre otras.

Hay varias opciones para la forma de la caja, tales que llenen completamente el espacio. Ellas son: Las cajas cúbicas, que son las de mayor sencillez aunque no las de menor costo computacional.

Las cajas con forma de dodecaedro rómbico son las de tamaño más reducido y las que completan el espacio tridimensional más regularmente.

También pueden mencionarse las cajas octaédricas truncadas entre otras cajas de tipo triclínico, que es en definitiva la clasificación que engloba a todas las posibles celdas unitarias que completan el espacio 63

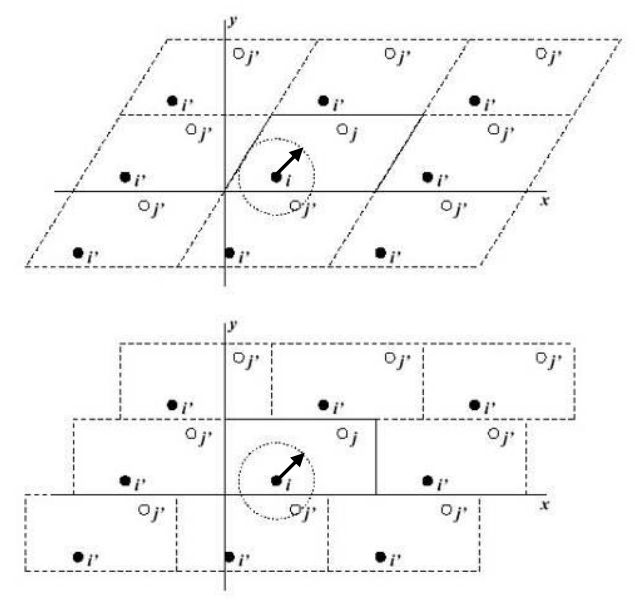

Figura 2-1. Condiciones periódicas de contorno en dos dimensiones 
2. Algoritmo general utilizado en Dinámica Molecular: 64

\section{ALGORITMO GLOBAL PARA DM}

\section{Condiciones iniciales}

Potencial de interacción $V$ como función de las posiciones atómicas

Posiciones $r$ de todos los átomos en el sistema

Velocidades $v$ de todos los átomos en el sistema

$\Downarrow$

Repetir 2, 3 y 4 el número requerido de veces

\section{Cálculo de fuerzas}

La fuerza sobre cualquier átomo

$$
\vec{F}_{i}=-\vec{\nabla}_{i} V
$$

Se computa a través del cálculo de la fuerza entre los pares de átomos no-enlazados:

$$
\vec{F}_{i}=\sum_{i} \vec{F}_{i j}
$$

Más las fuerzas debidas a interacciones enlazantes (las cuales pueden depender de 1, 2, 3 o 4 átomos), más las fuerzas de restricción y/o externas.

Se computan las energías cinética y potencial y el tensor de presión

$$
\Downarrow
$$

\section{Actualización de la configuración}

Se simula el movimiento de los átomos resolviendo numéricamente las ecuaciones de movimiento de Newton

$$
\begin{gathered}
\frac{\partial^{2} \vec{r}_{i}}{\partial t^{2}}=\frac{\vec{F}_{i}}{m_{i}} \\
\text { O bien } \\
\frac{\partial \vec{r}_{i}}{\partial t}=\vec{v}_{i} ; \frac{\partial \vec{v}_{i}}{\partial t}=\frac{\vec{F}_{i}}{m_{i}} \\
\Downarrow
\end{gathered}
$$

4. Si se requiere: Paso de Salida

Escribir posiciones, velocidades, energías, temperatura, presión, etc. 


\section{El Campo de Fuerzas 64}

Un campo de fuerzas se compone de dos elementos claramente distinguibles:

- El conjunto de ecuaciones (las funciones potenciales) utilizadas para generar las energías potenciales y sus derivadas, las fuerzas.

- Los parámetros utilizados en este conjunto de ecuaciones.

Dentro de un conjunto de ecuaciones pueden utilizarse varias combinaciones distintas de parámetros. Debe tenerse cuidado de que la combinación de ecuaciones y parámetros constituyan un conjunto auto-consistente. En general debe tenerse mucho cuidado al hacer modificaciones ad-hoc de algún subconjunto de parámetros, ya que las distintas contribuciones a la fuerza total son normalmente interdependientes.

Las funciones potenciales pueden subdividirse en tres categorías:

- Potenciales no-enlazantes: de repulsión-dispersión (Lennard-Jones o Buckingham) y electrostáticas (Coulómbicas o Coulómbicas modificadas). Las mismas se calculan basados en listas de vecinos que se actualizan en momentos programados.

- Potenciales enlazantes: sobre los enlaces covalentes, ángulos de enlace, diedros impropios, y diedros propios. Que se calculan a partir de listas fijas.

- Potenciales especiales: restricciones de posición, restricciones de distancia, y restricciones de orientación. Que también se calculan a partir de listas fijas.

Las funciones potenciales utilizadas en el presente trabajo son las siguientes:

\section{Potenciales no-enlazantes:}

Las interacciones no-enlazantes son aditivas de a pares y centro-simétricas:

$$
\begin{gathered}
V\left(\vec{r}_{1}, \ldots, \vec{r}_{N}\right)=\sum_{i<j} V_{i j}\left(\vec{r}_{i j}\right) \\
\vec{F}_{i}=-\sum \frac{d V_{i j}\left(\vec{r}_{i j}\right)}{d r_{i j}} \breve{r}_{i j}=-\vec{F}_{j}
\end{gathered}
$$

Donde $r_{i j}$ es la distancia entre el átomo $i$ y el átomo $j$ de nuestro sistema.

Las interacciones no-enlazantes contienen un término de repulsión, uno de dispersión, y un término Coulombiano. Los términos de repulsión y dispersión (Fuerzas de London, o de van der Waals) se encuentran combinados. Se los puede modelar de diferentes maneras, ya sea mediante el potencial de Lennard-Jones (o interacción 12-6) o con el potencial de Buckingham (o interacción $\mathrm{e}^{-6}$ ), entre otros. Además, átomos cargados (parcialmente) actúan a través del término Coulombiano.

\section{i. Interacción de Lennard-Jones:}

El potencial más utilizado para el modelado de las interacciones de van der Waals es el potencial de Lennard-Jones, propuesto por John Lennard-Jones 65. Éste puede escribirse, para un par de átomos dados, de la siguiente manera: 


\section{CAPÍTULO 2}

$$
V_{\mathrm{LJ}}\left(r_{i j}\right)=\frac{C_{i j}^{(12)}}{r_{i j}^{12}}-\frac{C_{i j}^{(6)}}{r_{i j}^{6}}
$$

Aquí, el término proporcional a $\mathrm{r}^{-12}$ representa la contribución repulsiva, mientras que aquel proporcional a $\mathrm{r}^{-6}$ se refiere a la contribución atractiva.

En la figura 2-2 puede verse una representación gráfica del potencial.

Los parámetros $C_{i j}^{(12)}$ y $C_{i j}^{(6)}$ dependen del par de átomos considerado para la interacción; consecuentemente los mismos se toman de una matriz de parámetros de Lennard-Jones.

En general, los campos de fuerzas cuentan con tablas de estos parámetros de LennardJones para interacción entre átomos del mismo tipo. Por ejemplo, para los átomos $i$ y $j$ cuentan con: $C_{i i}^{(6)}, C_{i i}^{(12)}, C_{j j}^{(6)} y C_{j j}^{(12)}$, mientras que los parámetros cruzados se calculan con las siguientes expresiones (promedio geométrico): $C_{i j}^{(6)}=\sqrt{C_{i i}^{(6)} C_{j j}^{(6)}} \quad \mathrm{y}$ $C_{i j}^{(12)}=\sqrt{C_{i i}^{(12)} C_{j j}^{(12)}}$.

La fuerza derivada de este potencial resulta por lo tanto:

$$
\vec{F}_{i}\left(\vec{r}_{i j}\right)=\left(12 \frac{C_{i j}^{(12)}}{r_{i j}^{13}}-6 \frac{C_{i j}^{(6)}}{r_{i j}^{7}}\right) \breve{r}_{i j}
$$

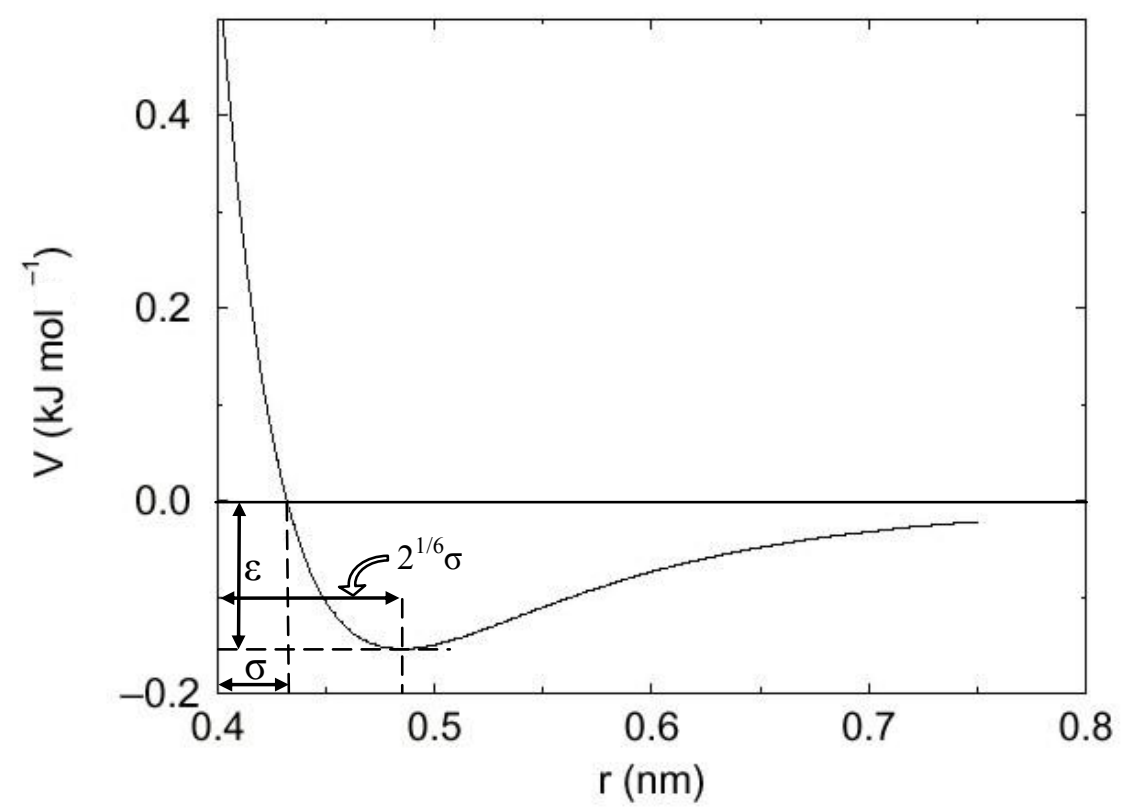

Figura 2-2: Curva potencial para la interacción repulsión-dispersión de Lennard-Jones.

El potencial de Lennard-Jones suele escribirse también de la siguiente manera:

$$
V_{\mathrm{LJ}}\left(r_{i j}\right)=4 \varepsilon_{i j}\left[\left(\frac{\sigma_{i j}}{r_{i j}}\right)^{12}-\left(\frac{\sigma_{i j}}{r_{i j}}\right)^{6}\right]
$$


donde $\varepsilon_{i j}$ es la profundidad del potencial, y $\sigma_{i j}$ es la longitud de penetración (distancia a la cual el potencial vale cero). Del mismo modo que los parámetros $C_{i j}^{(12)}$ y $C_{i j}^{(6)} \mathrm{se}$ obtienen mediante promedios geométricos, podemos calcular $\varepsilon_{i j} \mathrm{y} \sigma_{i j}$ del siguiente modo: $\sigma_{i j}=\frac{1}{2}\left(\sigma_{i i}+\sigma_{j j}\right)$ y $\varepsilon_{i j}=\sqrt{\varepsilon_{i i} \varepsilon_{i j}}$

Pueden relacionarse las expresiones (2.6) y (2.7), obteniendo:

$$
\left.\begin{array}{l}
C_{i j}^{(12)}=4 \varepsilon_{i j} \sigma_{i j}{ }^{12} \\
C_{i j}^{(6)}=4 \varepsilon_{i j} \sigma_{i j}{ }^{6}
\end{array}\right\} \begin{aligned}
& \sigma_{i j}=\left(\frac{C_{i j}^{(12)}}{C_{i j}^{(6)}}\right)^{1 / 6} \\
& \varepsilon_{i j}=\frac{\left(C_{i j}^{(6)}\right)^{2}}{4 C_{i j}^{(12)}}
\end{aligned}
$$

\section{ii. Interacción Coulombiana:}

La interacción Coulombiana entre dos partículas cargadas viene dada por:

$$
V_{\mathrm{C}}\left(r_{i j}\right)=\frac{k}{\varepsilon_{r}} \frac{q_{i} q_{j}}{r_{i j}}
$$

Donde $k=\frac{1}{4 \pi \varepsilon_{0}}, \varepsilon_{o}$ es la permitividad eléctrica del vacío $\varepsilon_{r}$ la permitividad eléctrica relativa del medio, y $q_{i}, q_{j}$ las cargas eléctricas de las especies $i$ y $j$ respectivamente. Dicho potencial se encuentra graficado en la figura 2-3.

La fuerza derivada de este potencial resulta por lo tanto:

$$
\vec{F}_{i}\left(\vec{r}_{i j}\right)=\frac{k}{\varepsilon_{r}} \frac{q_{i} q_{j}}{r_{i j}^{2}} \breve{r}_{i j}
$$

\section{iii. Interacción Coulombiana con Campo de Reacción (RF):}

La interacción Coulombiana puede ser modificada para sistemas relativamente homogéneos, suponiendo la existencia de un medio dieléctrico continuo por fuera de un determinado radio de corte $r_{c}$ con permitividad eléctrica $\varepsilon_{r f}$. Podemos expresar entonces dicha interacción del siguiente modo:

$$
V_{\mathrm{C} \mathrm{RF}}\left(r_{i j}\right)=k \frac{q_{i} q_{j}}{r_{i j}}\left[1+\frac{\varepsilon_{r f}-1}{2 \varepsilon_{r f}+1} \cdot \frac{r_{i j}^{3}}{r_{c}^{3}}\right]-k \frac{q_{i} q_{j}}{r_{c}} \cdot \frac{\varepsilon_{r f}}{2 \varepsilon_{r f}+1}
$$

En la cual el término constante de la derecha lleva el potencial a cero para $r=r_{c}$. En la figura 2-3 puede verse la interacción Coulombiana modificada. La fuerza derivada de este potencial resulta: 
CAPÍTULO 2

$$
\vec{F}_{i j}\left(\vec{r}_{i j}\right)=k q_{i} q_{j}\left[\frac{1}{r_{i j}^{2}}-2\left(\frac{1}{r_{c}^{3}} \frac{\varepsilon_{r f}-1}{\left(2 \varepsilon_{r f}+1\right)}\right) r_{i j}\right] \breve{r}_{i j}
$$

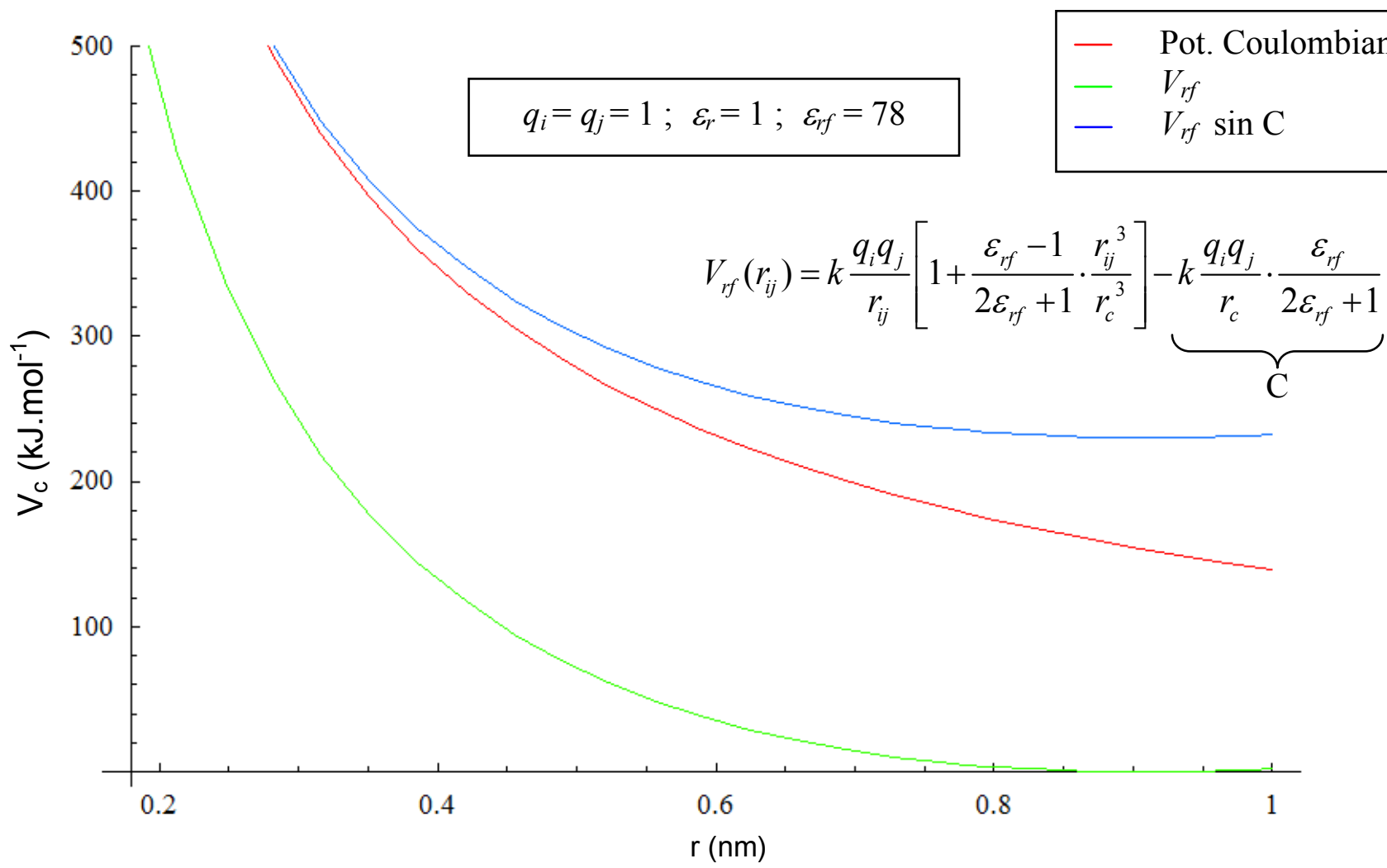

Figura 2-3: Un ejemplo de curva potencial para la interacción Coulombiana entre cargas de igual signo, con y sin Campo de reacción.

\section{Potenciales enlazantes:}

Las interacciones enlazantes se basan en una lista fija de átomos. Estas no están compuestas exclusivamente por interacciones de a pares, sino que incluyen también interacciones de 3 y 4 cuerpos, a saber: Interacciones de estiramiento de la longitud de enlace ( 2 cuerpos), de ángulo de enlace (3 cuerpos) y de ángulo diedro (4 cuerpos). También se utiliza un tipo especial de diedro (llamado diedro impropio) para que los átomos permanezcan en un determinado plano, o bien para prevenir la transición a una configuración de quiralidad opuesta (imagen especular). De esta manera, al diedro habitual se lo llama diedro propio. 


\section{iv. Potencial de estiramiento de la longitud de enlace:}

\section{Potencial de Oscilador armónico:}

El estiramiento (o compresión) del enlace covalente entre dos átomos $i$ y $j$ puede representarse a través de un potencial armónico:

$$
V_{\text {enlace }}=\frac{1}{2} k_{i j}^{\text {enlace }}\left(r_{i j}-b_{i j}\right)^{2}
$$

Donde la fuerza viene dada por:

$$
\vec{F}_{\text {enlace }}\left(\vec{r}_{i j}\right)=-k_{i j}^{\text {enlace }}\left(r_{i j}-b_{i j}\right) \breve{r}_{i j}
$$
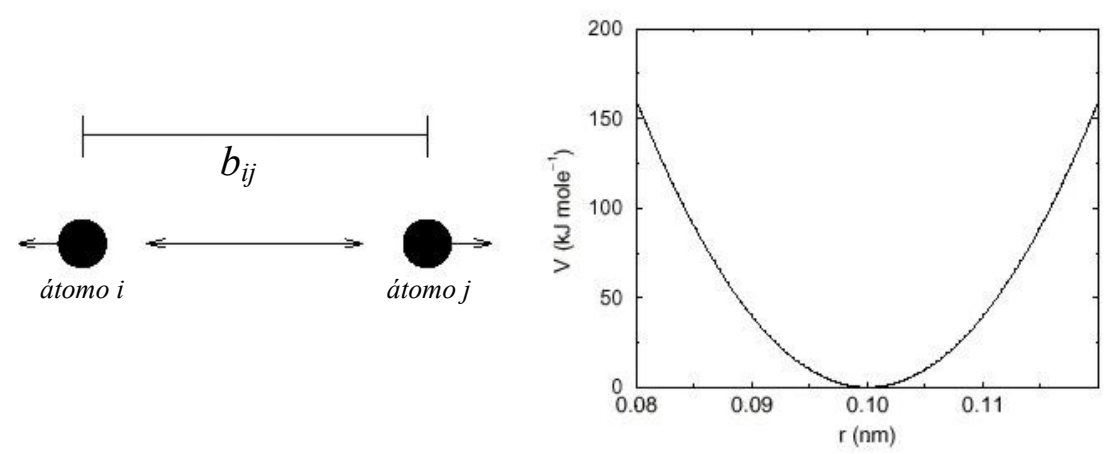

Figura 2-4: Principio del estiramiento de enlace (izquierda), y el correspondiente potencial armónico de enlace (derecha).

\section{Potencial de Morse:}

Para ciertos sistemas donde se requiere un potencial no-armónico de enlace entre los átomos $i \mathrm{y} j$, el potencial de Morse resulta una alternativa muy aceptable 66 . Éste difiere del potencial armónico en que posee un pozo asimétrico además de tener fuerza de enlace cero a distancia infinita. Su forma funcional resulta:

$$
V_{\text {morse }}\left(r_{i j}\right)=D_{i j}\left[1-e^{-\beta_{i j}\left(r_{i j}-b_{i j}\right)}\right]^{2}
$$

Cuya fuerza correspondiente es:

$$
\vec{F}_{\text {morse }}\left(\vec{r}_{i j}\right)=2 D_{i j} \beta_{i j} r_{i j} e^{-\beta_{i j}\left(r_{i j}-b_{i j}\right)}\left[1-e^{-\beta_{i j}\left(r_{i j}-b_{i j}\right)}\right] \breve{r}_{i j}
$$

Donde $D_{i j}$ representa la profundidad del pozo potencial en $\mathrm{kJ} / \mathrm{mol}, \beta_{i j}$ define qué tan agudo es el pozo de potencial $\left(\mathrm{en} \mathrm{nm}^{-1}\right)$ y $b_{i j}$ es la distancia de equilibrio en $\mathrm{nm}$. 


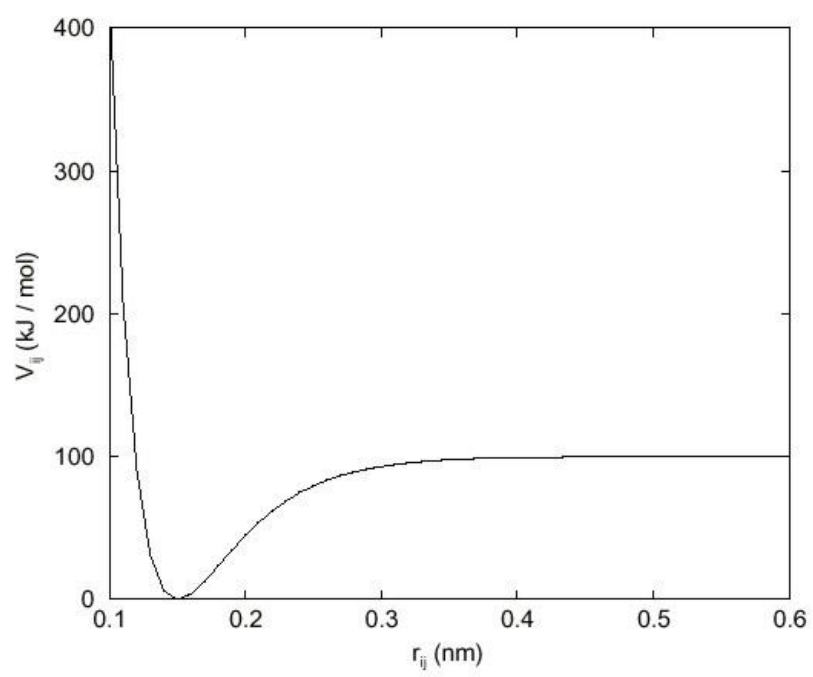

Figura 2-5: El pozo potencial de Morse, para una longitud de enlace de $0.15 \mathrm{~nm}$.

\section{v. Potencial armónico de ángulo de enlace:}

La vibración del ángulo de enlace entre un triplete de átomos $i-j-k$ puede representarse también a través de un potencial de oscilador armónico sobre el ángulo $\theta_{i j k}$ :

$$
V_{\text {angulo }}\left(\theta_{i j k}\right)=\frac{1}{2} k_{i j k}^{\text {angulo }}\left(\theta_{i j k}-\theta_{i j k}^{0}\right)^{2}
$$

Dado que la vibración del ángulo de enlace se representa con un potencial armónico, su forma es la misma que para el potencial de estiramiento de la longitud de enlace (Figura 2-6).
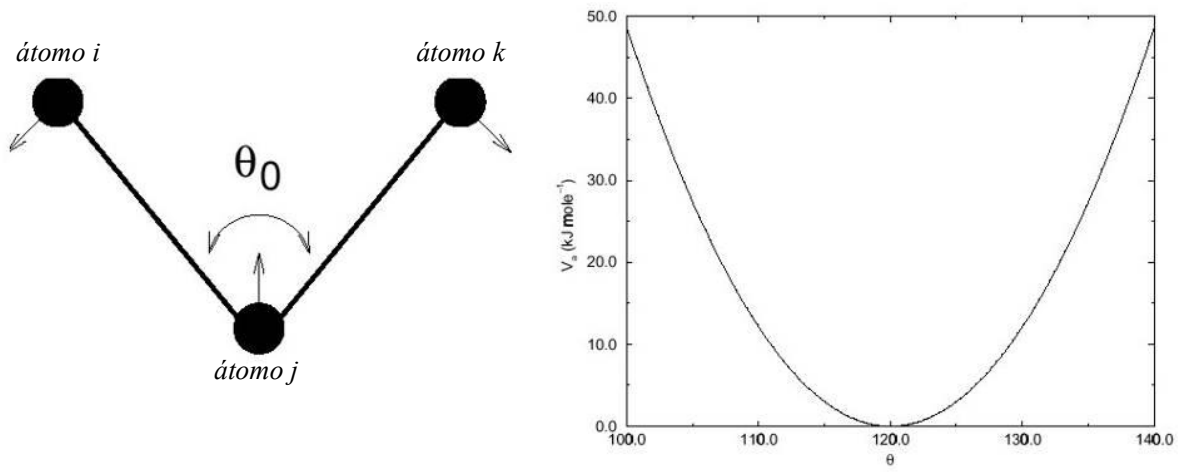

Figura 2-6: Principio de vibración de enlace (izquierda) y función potencial de ángulo de enlace (derecha). 


$$
\begin{aligned}
& \vec{F}_{i}=-\frac{d V_{\text {angulo }}\left(\theta_{i j k}\right)}{d \vec{r}_{i}} \\
& \vec{F}_{k}=-\frac{d V_{\text {angulo }}\left(\theta_{i j k}\right)}{d \vec{r}_{k}} \quad \text { donde } \theta_{i j k}=\arccos \frac{\vec{r}_{i j} \cdot \vec{r}_{j k}}{r_{i j} r_{j k}} \\
& \vec{F}_{j}=-\vec{F}_{i}-\vec{F}_{k}
\end{aligned}
$$

La nomenclatura $i, j, k$ representa la secuencia de enlace de los átomos $i, j, k$ covalentemente enlazados. El átomo $j$ se encuentra en el medio, los átomos $i$ y $k$ están en los extremos (ver Figura 2-6).

\section{vi. Potencial para diedros impropios:}

Los diedros impropios son utilizados para mantener la planaridad en aquellos grupos que así lo requieran (de anillos aromáticos por ejemplo) además de mantener la quiralidad de aquellos grupos que cuenten con algún carbono asimétrico (casi todos los aminoácidos). En la Figura 2-7 se representan dichos casos esquemáticamente.
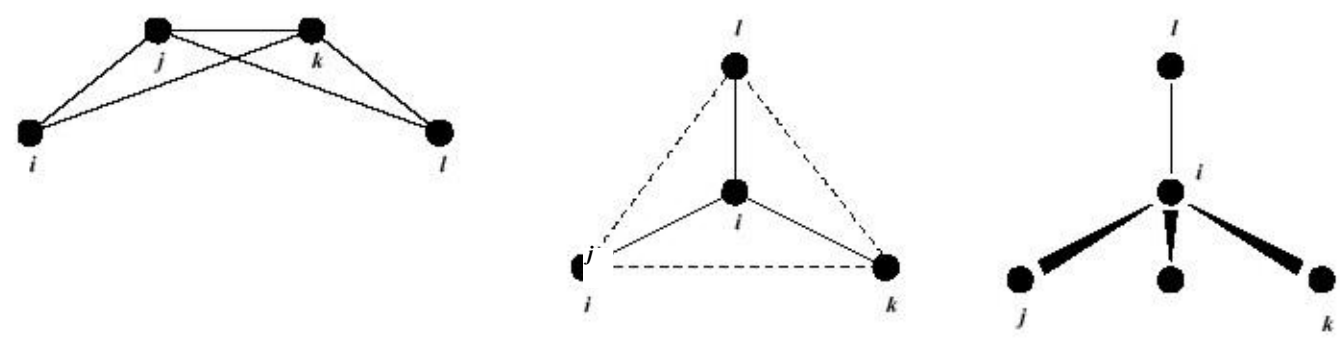

Figura 2-7: Diferentes tipos de ángulos diedros impropios. Distorsiones de anillos fuera del plano (izquierda), sustituyentes de anillos (centro) y distorsión del tetraedro (derecha). El ángulo diedro impropio se define para todos los casos como el ángulo entre los planos $(i, j, k)$ y $(j, k, l)$. expresión:

El potencial que caracteriza esta interacción estará dado por la siguiente

$$
\underset{\text { diedro }}{V_{\text {impropio }}}\left(\xi_{i j k l}\right)=k_{i j k l}^{d i}\left(\xi_{i j k l}-\xi_{0}\right)^{2}
$$

Éste también resulta ser un potencial de oscilador armónico y se encuentra representado en la Figura 2-8. Cabe destacar que, dado que es un potencial de este tipo, la periodicidad no es tomada en cuenta, por lo tanto se recomienda definir un valor de $\xi_{0}$ lo más alejado posible de $\pm 180^{\circ}$. 


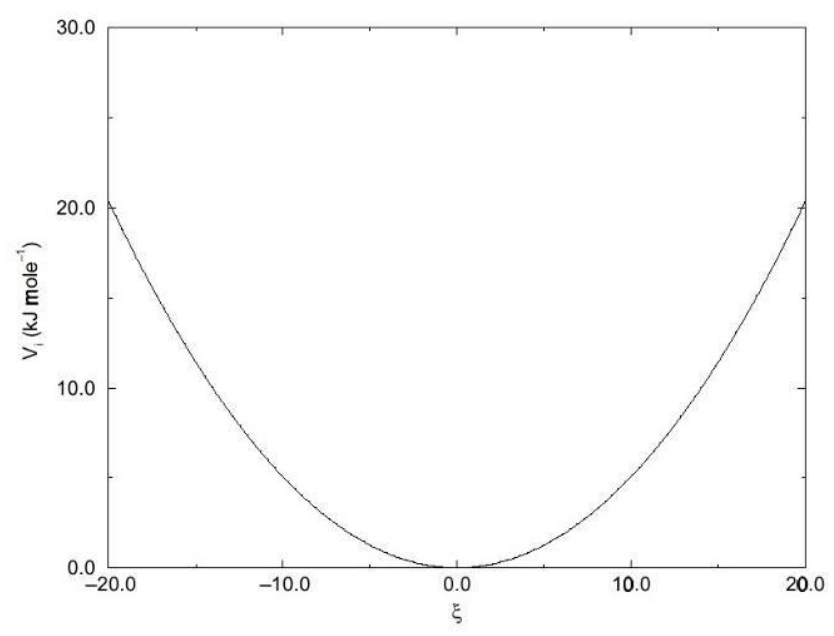

Figura 2-8: Función potencial para diedros impropios.

\section{vii. Potencial para diedros propios:}

La interacción normal para los diedros propios puede ser abordada de dos maneras diferentes; la función periódica clásica o bien una función basada en una expansión de potencias del $\cos \phi$ (el llamado potencial de Ryckaert-Bellemans). Esta elección tiene consecuencias ya que, si se elige la función periódica, debe incluirse una interacción especial entre el $1^{\mathrm{er}}$ y $4^{\text {to }}$ átomo de la tétrada que define al diedro.

\section{Diedros propios: Potencial periódico}

Los ángulos diedros propios de definen de acuerdo a la convención IUPAC/IUB, considerando el ángulo $\phi$ entre los planos $i j k$ y $j k l$, con el cero correspondiente a la configuración cis, en la que los átomos $i$ y $l$ se encuentran del mismo lado (ver figura 2-9).

$$
V_{\text {diedropio }}\left(\phi_{i j k l}\right)=k_{i j k l}^{d}\left[1+\cos \left(n \phi-\phi_{0}\right)\right]
$$

Aquí, $\phi$ es el ángulo diedro, $\phi_{0}$ es un parámetro de corrimiento y $n$ es la multiplicidad del Potencial.
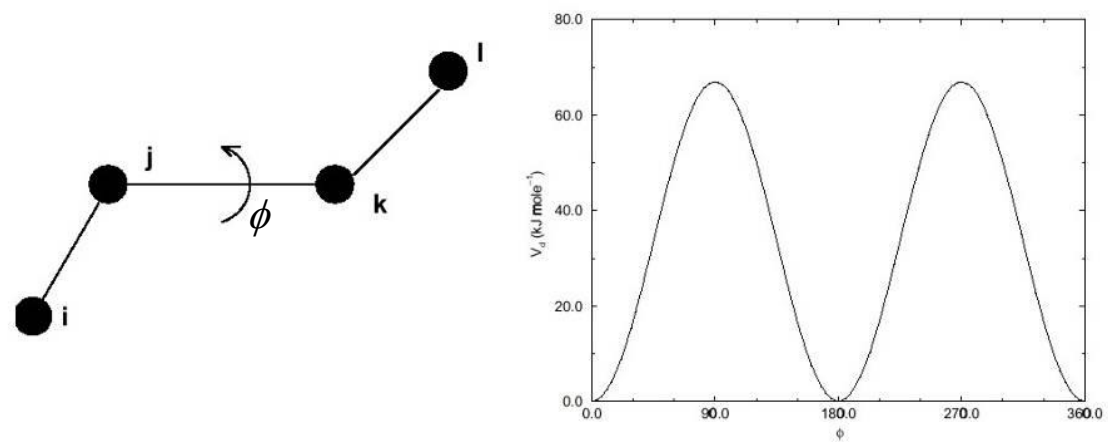

Figura 2-9: Principio para el ángulo diedro propio (izquierda, en configuración trans) y el potencial periódico para el diedro propio (derecha). 


\section{Diedros propios: Potencial de Ryckaert-Bellemans}

Para alcanos suele utilizarse el siguiente potencial (ver Figura 2-10)

$$
V_{R B}=\sum_{n=0}^{5} C_{n}(\cos \psi)^{n}
$$

Donde $\psi=\phi-180^{\circ}$ está definido de acuerdo a la "convención de polímeros" $\left(\psi_{\text {trans }}=0\right)$.

\section{Notas:}

1.- Puede lograrse la conversión de una convención a la otra multiplicando cada coeficiente $C_{n}$ por $(-1)^{n}$.

2.- El uso de este potencial implica la exclusión de las interacciones 1-4 de LennardJones.

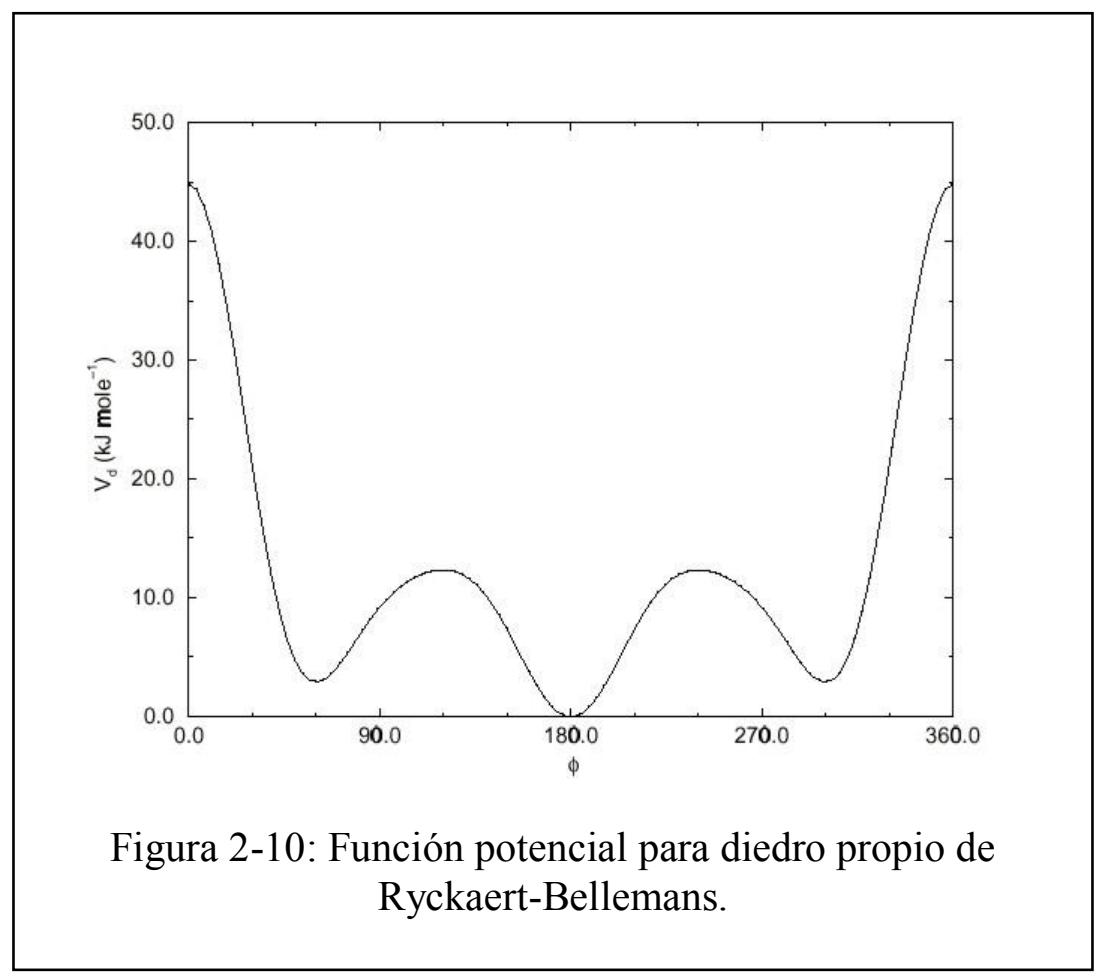

\section{Potenciales especiales:}

Las interacciones especiales son utilizadas para imponer restricciones sobre el sistema, ya sea para evitar desviaciones desastrosas (por Ej. para equilibrar el sistema una vez solvatado), o para incluir el conocimiento de datos experimentales (por Ej. datos provenientes de experimentos de NMR o XRD). En cualquier caso éstas no forman parte del campo de fuerzas y la confiabilidad de sus parámetros no resulta de relevancia.

\section{viii. Restricciones de posición}

Éstas se utilizan para restringir partículas a una posición fija de referencia $\vec{R}_{i}$. Pueden emplearse durante el equilibrado del sistema de manera de evitar el reacomodamiento drástico de zonas críticas (por ejemplo, para restringir el movimiento de una proteína sujeta a fuerzas importantes debidas a un solvente que aún no se encuentra equilibrado). Otra aplicación es la de restringir partículas en una cáscara 


\section{CAPÍTULO 2}

alrededor de una región que se desea simular en detalle, mientras que la cáscara solo es aproximada ya que carece de las interacciones apropiadas por parte de las partículas faltantes que están por fuera de la misma. Las restricciones mantendrán la integridad del interior. Para casquetes esféricos es recomendable utilizar una constante de fuerza para la restricción que dependa del radio, creciendo desde cero para el interior del casquete hasta un valor elevado en el límite exterior del mismo.

Se utiliza la siguiente forma general:

$$
V_{\substack{\text { restricción } \\ \text { deposición }}}\left(\vec{r}_{i}\right)=\frac{1}{2} k^{r p}\left|\vec{r}_{i}-\vec{R}_{i}\right|^{2}
$$

Este potencial se grafica en la Figura 2-11.

El potencial puede ser escrito sin pérdida de generalidad también como:

$$
V_{\substack{\text { restricción } \\ \text { de posición }}}\left(\vec{r}_{i}\right)=\frac{1}{2}\left[k_{x}^{r p}\left(x_{i}-X_{i}\right)^{2} \breve{i}+k_{y}^{r p}\left(y_{i}-Y_{i}\right)^{2} \breve{j}+k_{z}^{r p}\left(z_{i}-Z_{i}\right)^{2} \breve{k}\right]
$$

Donde las componentes de la fuerza sobre la i-ésima partícula son:

$$
\begin{aligned}
& F_{i_{x}}=-k_{x}^{r p}\left(x_{i}-X_{i}\right) \\
& F_{i_{y}}=-k_{y}^{r p}\left(y_{i}-Y_{i}\right) \\
& F_{i_{z}}=-k_{z}^{r p}\left(z_{i}-Z_{i}\right)
\end{aligned}
$$

Las restricciones de posición pueden "apagarse" o "prenderse" para cada dimensión espacial utilizando tres constantes de fuerza diferentes; esto significa que los átomos pueden restringirse armónicamente a un punto, un plano o una recta.

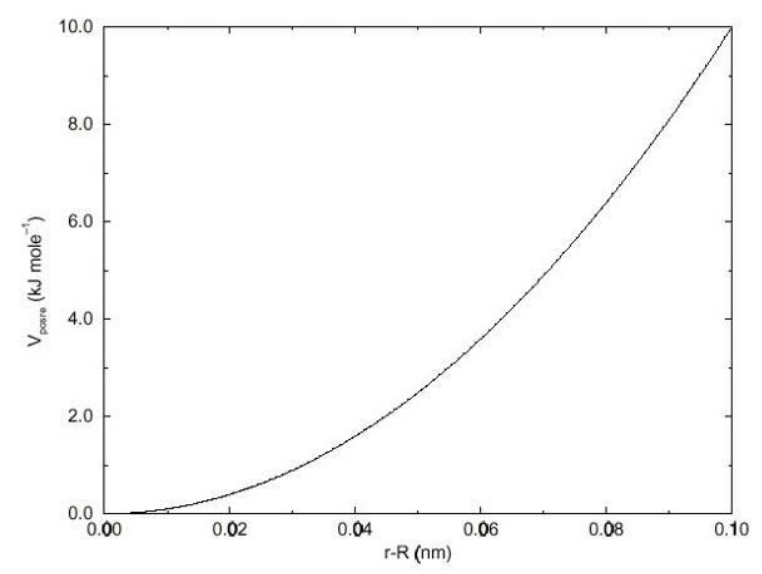

Figura 2-11: Función potencial para la restricción de posición.

\section{ix. Restricciones de ángulo}

Éstas se utilizan para restringir el ángulo entre dos pares de partículas o entre un par de partículas y el eje Z. La forma funcional es similar a la de un diedro propio. Para dos pares de átomos: 


$$
\begin{gathered}
V_{\text {restricción }}\left(\vec{r}_{i}, \vec{r}_{j}, \vec{r}_{k}, \vec{r}_{l}\right)=k^{r a}\left[1-\cos \left(n\left(\phi-\phi_{0}\right)\right)\right] \\
\text { donde } \phi=\arccos \left(\frac{\vec{r}_{j}-\vec{r}_{i}}{\left\|\vec{r}_{j}-\vec{r}_{i}\right\|} \cdot \frac{\vec{r}_{l}-\vec{r}_{k}}{\left\|\vec{r}_{l}-\vec{r}_{k}\right\|}\right)
\end{gathered}
$$

Para un par de átomos y el eje Z:

$$
\begin{gathered}
V_{\begin{array}{c}
\text { restricioin } \\
\text { de angulo }
\end{array}}\left(\vec{r}_{i}, \vec{r}_{j}\right)=k^{r a}\left[1-\cos \left(n\left(\phi-\phi_{0}\right)\right)\right] \\
\text { donde } \phi=\arccos \left(\frac{\vec{r}_{j}-\vec{r}_{i}}{\left\|\vec{r}_{j}-\vec{r}_{i}\right\|} \cdot\left(\begin{array}{l}
0 \\
0 \\
1
\end{array}\right)\right)
\end{gathered}
$$

\section{x. Restricciones de distancia}

Las restricciones de distancia agregan una penalidad al potencial entre pares previamente especificados de átomos, cuando la distancia entre ellos excede un valor límite. Esto se utiliza normalmente para imponer restricciones experimentales sobre el movimiento de un sistema, como en el caso de experimentos de resonancia magnética nuclear $(N M R)$. De este modo la Dinámica Molecular puede utilizarse para el proceso de refinamiento estructural de los datos provenientes de experimentos de $N M R$.

La forma del potencial para las restricciones de distancia es cuadrática por debajo de un valor especificado, como así también entre los dos valores superiores indicados, y lineal por encima del valor del límite superior mayor.

$$
V_{\substack{\text { restrición } \\
\text { de distancia }}}\left(r_{i j}\right)=\left\{\begin{array}{c}
\frac{1}{2} k^{r d}\left(r_{i j}-r_{0}\right)^{2} \text { para } r_{i j}<r_{0} \\
0 \text { para } r_{0} \leq r_{i j}<r_{1} \\
\frac{1}{2} k^{r d}\left(r_{i j}-r_{1}\right)^{2} \text { para } r_{1} \leq r_{i j}<r_{2} \\
\frac{1}{2} k^{r d}\left(r_{2}-r_{1}\right)\left(2 r_{i j}-r_{2}-r_{1}\right) \text { para } r_{2} \leq r_{i j}
\end{array}\right.
$$

Dicho potencial está graficado en la Figura 2-12.

Las fuerzas que derivan de él son

$$
\vec{F}_{i}\left(\vec{r}_{i j}\right)=\left\{\begin{array}{c}
-k^{r d}\left(r_{i j}-r_{0}\right) \breve{r}_{i j} \text { para } r_{i j}<r_{0} \\
0 \text { para } r_{0} \leq r_{i j}<r_{1} \\
-k^{r d}\left(r_{i j}-r_{1}\right) \breve{r}_{i j} \text { para } r_{1} \leq r_{i j}<r_{2} \\
-k^{r d}\left(r_{2}-r_{1}\right) \breve{r}_{i j} \text { para } r_{2} \leq r_{i j}
\end{array}\right.
$$




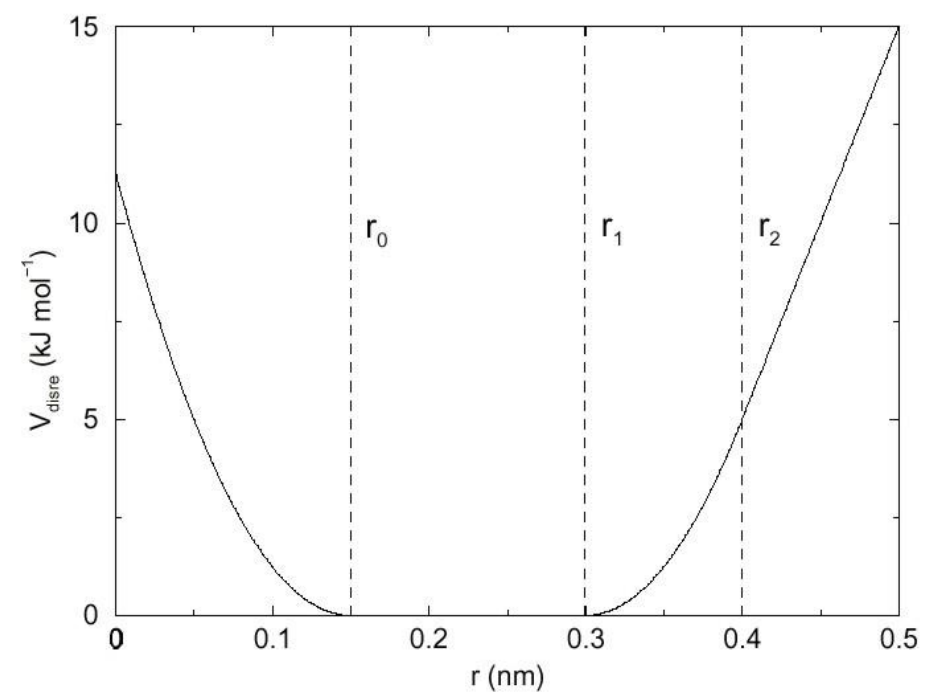

Figura 2-12: Función potencial para la restricción de distancias.

\section{Generalidades del cómputo de fuerzas 64:}

Anteriormente en el presente capítulo dimos un esquema global de flujo para la Dinámica Molecular. Toda simulación en DM requiere como entrada un conjunto de coordenadas y velocidades iniciales para todas las partículas involucradas. Las primeras suelen provenir de datos experimentales (cristalografía de rayos X, Difracción de Neutrones, Resonancia Magnética Nuclear, etc.), sobre todo si se realiza una DM de proteínas, mientras que las últimas suelen ser generadas inicialmente a partir de una distribución de Maxwell-Boltzmann correspondiente a una dada temperatura.

\section{a. Condiciones iniciales:}

\section{La topología y el campo de fuerzas}

La topología, incluyendo la descripción completa del campo de fuerzas, debe ser provista. Estos elementos fueron descriptos en detalle en la sección anterior. Toda esta información es estática y nunca resulta modificada durante la corrida de simulación.

\section{Coordenadas y velocidades}

Antes de comenzar una corrida se requieren las coordenadas y velocidades de las partículas, como así también las dimensiones de la caja de simulación. El tamaño de la caja queda determinado por tres vectores (nueve números) $\vec{a}, \vec{b}, \vec{c}$, los cuales representan los tres vectores que definen la caja periódica.

En la Tabla 2-1 pueden verse los tipos principales de Cajas de Simulación que pueden utilizarse conjuntamente con $P B C$. 


\begin{tabular}{|c|c|c|c|c|c|c|c|}
\hline \multirow{2}{*}{ Tipo de Caja } & \multirow{2}{*}{$\begin{array}{l}\text { Volumen } \\
\text { de la Caja }\end{array}$} & \multicolumn{3}{|c|}{ Vectores de la Caja } & \multicolumn{3}{|c|}{ Ángulos de la Caja } \\
\hline & & $\vec{a}$ & $\vec{b}$ & $\vec{c}$ & $\measuredangle b c$ & $\measuredangle a c$ & $\measuredangle a b$ \\
\hline Cúbica & $d^{3}$ & $\mathrm{~d}$ & $\begin{array}{l}0 \\
\mathrm{~d} \\
0\end{array}$ & $\begin{array}{l}0 \\
0 \\
\text { d }\end{array}$ & $90^{\circ}$ & $90^{\circ}$ & $90^{\circ}$ \\
\hline $\begin{array}{l}\text { Dodecaedro } \\
\text { Rómbico } \\
\text { (cuadrado en } x y \text { ) }\end{array}$ & $0,707 d^{3}$ & $\mathrm{~d}$ & 0 & $\begin{array}{c}\mathrm{d} / 2 \\
\mathrm{~d} / 2 \\
\sqrt{2} / 2 \mathrm{~d}\end{array}$ & $60^{\circ}$ & $60^{\circ}$ & $90^{\circ}$ \\
\hline $\begin{array}{c}\text { Dodecaedro } \\
\text { Rómbico } \\
\text { (hexagonal en xy) }\end{array}$ & $0,707 \mathrm{~d}^{3}$ & 0 & $\begin{array}{c}\mathrm{d} / 2 \\
\sqrt{3} / 2 \mathrm{~d}\end{array}$ & $\begin{array}{c}d / 2 \\
\sqrt{3} / 6 d \\
\sqrt{6} / 3 d\end{array}$ & $60^{\circ}$ & $60^{\circ}$ & $60^{\circ}$ \\
\hline $\begin{array}{l}\text { Octaedro } \\
\text { Truncado }\end{array}$ & $0,770 d^{3}$ & 0 & $\begin{array}{c}\mathrm{d} / 3 \\
2 / 3 \sqrt{2} \mathrm{~d} \\
0\end{array}$ & $\begin{array}{l}-d / 3 \\
\sqrt{2} / 3 d \\
\sqrt{6} / 3 d\end{array}$ & $71,53^{\circ}$ & $109,47^{\circ}$ & $71,53^{\circ}$ \\
\hline
\end{tabular}

Tabla 2.1. Tipos de Cajas utilizables en Simulaciones con PBC.

Si la corrida comienza en $t=t_{0}$, las coordenadas en ese instante deben ser conocidas. El algoritmo "leap-frog" o de salto de rana, utilizado para actualizar el paso de integración $\Delta t$ (ver sección 3-d.- Actualización de la configuración en el presente capítulo), requiere que se conozcan las velocidades en $t=t_{0}+\frac{\Delta t}{2}$. Si las velocidades $v_{i} ; i=1, \ldots, 3 \mathrm{~N}$ no son conocidas, estas pueden generarse a partir de una distribución de Maxwell-Boltzmann para una dada temperatura $T$ : 


\section{CAPÍTULO 2}

$$
p\left(v_{i}\right)=\sqrt{\frac{m_{i}}{2 \pi k_{B} T}} e^{\left(-\frac{m_{i} v_{i}^{2}}{2 k_{B} T}\right)}
$$

Donde $m_{i}$ es la masa de la i-ésima partícula, $p\left(v_{i}\right)$ es la probabilidad de que la i-ésima partícula tenga una velocidad $v_{i}$ y $k_{B}$ es la constante de Boltzmann.

Para obtener esto se generan los números distribuidos normalmente sumando doce números al azar distribuidos uniformemente en el intervalo $[0 ; 1]$, y restando el número 6.0 de su suma. El resultado se multiplica por la desviación estándar de la distribución $\sqrt{k_{B} T / m_{i}}$. Como la energía total resultante no se corresponderá exactamente con la temperatura requerida $T$, se realiza una corrección que consiste en remover el movimiento del centro de masas y luego escalear todas las velocidades de manera que la energía total corresponda exactamente a la temperatura $T$ (ver la expresión 2-13).

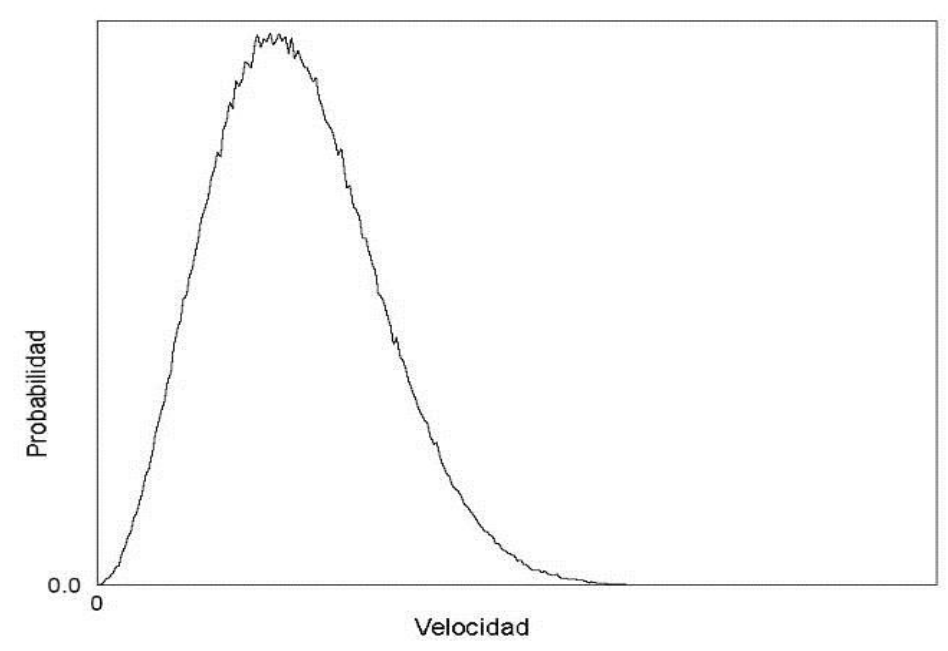

Figura 2-13: Distribución de Maxwell, generada a partir de números aleatorios.

\section{Movimiento del centro de masas}

La velocidad del centro de masas en general se lleva a cero en cada paso. Normalmente no existe ninguna fuerza neta externa actuando sobre el sistema y la velocidad del centro de masas debería permanecer constante. En la práctica, de cualquier manera, el algoritmo de actualización desarrolla un cambio lento en la velocidad del centro de masas, y por lo tanto en la energía cinética total del sistema, especialmente cuando se acopla un baño térmico al mismo. Si estos cambios no se amortiguan, eventualmente se desarrolla un movimiento apreciable del centro de masas para corridas largas, lo cual resultará en una significativa mala interpretación de la temperatura. Lo mismo podría suceder con el movimiento de rotación global, pero solamente cuando se simula un agregado de partículas aislado. En sistemas periódicos con cajas llenas de partículas, el movimiento rotacional global se encuentra acoplado a otros grados de libertad y por lo tanto no ocasiona problemas. 


\section{b. Búsqueda de vecinos:}

Como se mencionó en la sección 1, las fuerzas son generadas, ya sea por listas fijas (estáticas) de átomos, o bien por listas dinámicas. Estas últimas son generadas debido a las interacciones no-enlazantes entre un par de partículas cualesquiera.

\section{Generación de listas de pares}

Las fuerzas entre pares no-enlazantes necesitan calcularse solamente para aquellos pares $i$-j para los cuales la distancia $r_{i j}$ entre la partícula $i$ y la imagen más cercana de la partícula $j$ sea menor que un dado radio de corte $\mathrm{R}_{\mathrm{c}}$ (ver figura 2-14). Algunos de los pares de partículas que satisfacen este criterio deben ser excluidos de la lista, dado que su interacción ha sido totalmente tomada en cuenta por las interacciones enlazantes.

Para realizar dicha lista de vecinos deben hallarse todas las partículas que se encuentran en un entorno (dentro del radio de corte) de una dada partícula. Esta búsqueda involucra condiciones periódicas de contorno y por lo tanto la determinación de la imagen más cercana.

El paquete GROMACS utiliza la convención de la 'imagen más cercana':

- Al calcular las interacciones de corto alcance se tendrá en cuenta solamente la imagen más cercana de todas las correspondientes a una partícula.

- En el caso de las interacciones electrostáticas de largo alcance, esto no siempre es lo suficientemente exacto, y por tanto se utilizan otros métodos de cálculo como Campo de Reacción 67, Sumas de Ewald 68, Particle Mesh Ewald (PME) 69, 70 o ParticleParticle Particle-Mesh (PPPM) 69, 71, 72.

Sin condiciones periódicas de contorno debe usarse un algoritmo simple $O\left(N^{2}\right)$. Con condiciones periódicas de contorno puede aplicarse una búsqueda tipo grilla (gridsearch), la cual resulta $O(N)$, y por lo tanto menos costosa en términos computacionales.

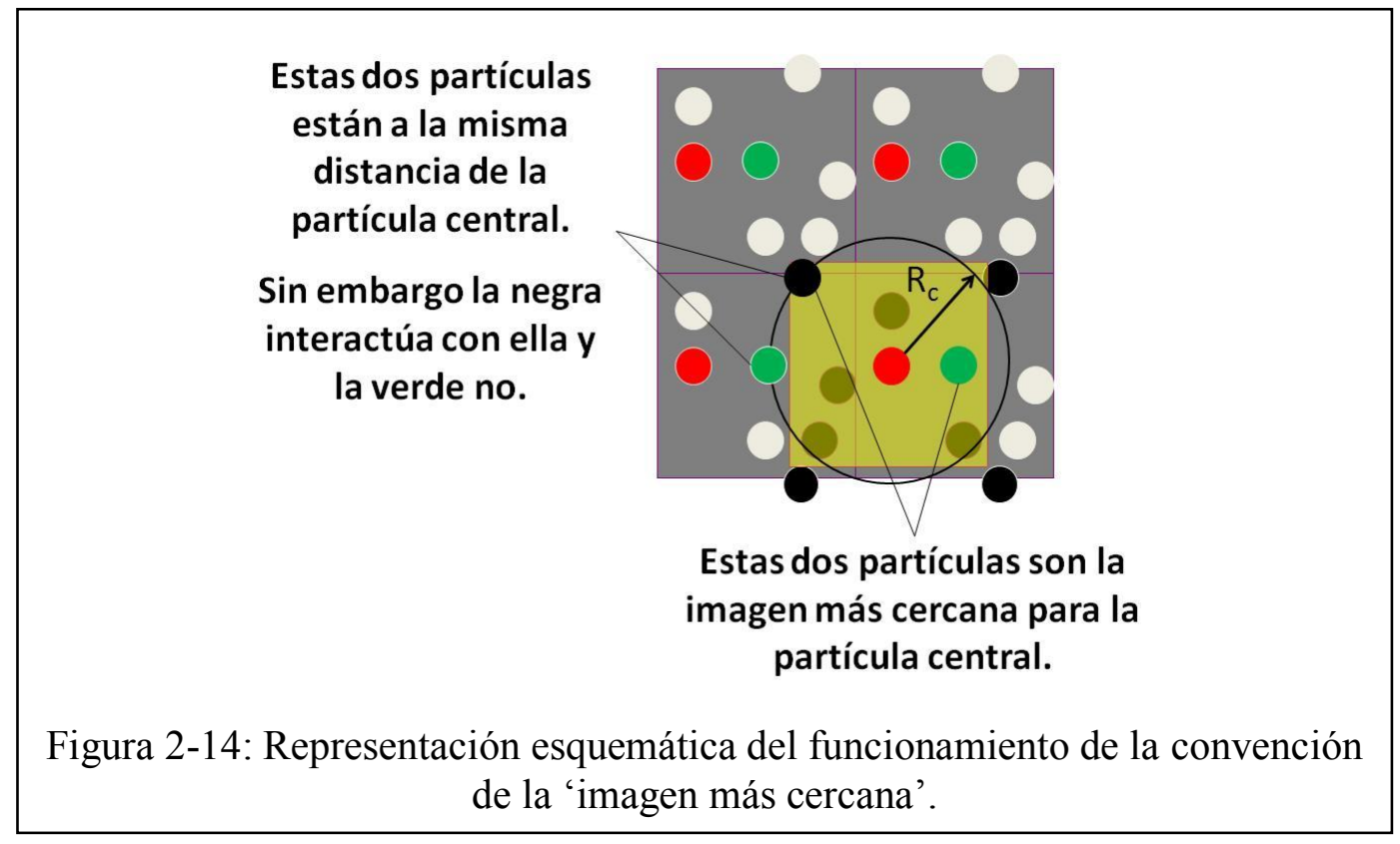




\section{c. Cómputo de interacciones:}

\section{Energía potencial}

Cuando se computan las fuerzas, también se computa la energía potencial para cada término de interacción. Por lo tanto la energía potencial total resulta de la suma de varias contribuciones, tales como las provenientes de las interacciones de LennardJones, las Coulombianas, y las interacciones enlazantes.

\section{Energía cinética y temperatura}

La temperatura del sistema se define a partir de la energía cinética total del sistema de $N$ partículas:

$$
E_{c i n}=\frac{1}{2} \sum_{i=1}^{N} m_{i} v_{i}^{2}
$$

De aquí, la temperatura absoluta $T$ puede ser computada utilizando la siguiente expresión:

$$
\frac{1}{2} N_{g l} k_{B} T=E_{\text {cin }}
$$

Donde $k_{\mathrm{B}}$ es la constante de Boltzmann y $N_{g l}$ es el número total de grados de libertad, los cuales pueden calcularse a partir de:

$$
N_{g l}=3 N-N_{c}-N_{c o m}
$$

Aquí $N_{c}$ es el número de restricciones (constrains) impuestas sobre el sistema. Cuando se realiza una simulación por Dinámica Molecular deben ser restados adicionalmente $N_{\text {com }}=3$ grados de libertad, dado que las tres velocidades del centro de masas son constantes del movimiento, y normalmente se las hace valer cero. Cuando la simulación es realizada en vacío, puede restarse también la rotación alrededor del centro de masas, en este caso $N_{\text {com }}=6$.

Cuando se utiliza más de un grupo de partículas acoplados independientemente al baño de temperatura, el número de grados de libertad para el grupo $i$ es:

$$
N_{g l}^{i}=\left(3 N^{i}-N_{c}^{i}\right) \frac{3 N-N_{c}-N_{c o m}}{3 N-N_{c}}
$$

La energía cinética puede ser escrita también como un tensor, lo cual resulta necesario frecuentemente para el cálculo de la presión, o bien para sistemas en donde se imponen fuerzas de corte:

$$
\mathbf{E}_{\text {cin }}=\frac{1}{2} \sum_{i=1}^{N} m_{i} \vec{v}_{i} \otimes \vec{v}_{i}
$$




\section{La presión y el virial}

El tensor de la presión $\mathbf{P}$ se calcula como la diferencia entre la energía cinética $\mathbf{E}_{\text {cin }}$ y el virial $\Xi$

$$
\mathbf{P}=\frac{2}{V}\left(\mathbf{E}_{c i n}-\mathbf{\Xi}\right)
$$

Donde $V$ es el volumen de la caja de simulación. La presión escalar $P$, la cual puede utilizarse para el acoplamiento al baño de presión para sistemas isotrópicos, puede calcularse según:

$$
P=\frac{\operatorname{Traza}(\mathbf{P})}{3}
$$

El tensor $\boldsymbol{\Xi}$ del virial se define como:

$$
\Xi=-\sum_{i<j} \vec{r}_{i j} \otimes \vec{F}_{i j}
$$

\section{d. Actualización de la configuración:}

El algoritmo utilizado para la integración de las ecuaciones de movimiento es el denominado "leap-frog" o de salto de rana $71{ }^{7}$. Este algoritmo utiliza posiciones $\vec{r}$ a tiempo $t$ y velocidades $\vec{v}$ a tiempo $t-\frac{\Delta t}{2}$; actualiza tanto posiciones como velocidades utilizando las fuerzas $\vec{F}(t)$ determinadas por las posiciones al tiempo $t$ :

$$
\begin{aligned}
\vec{v}\left(t+\frac{\Delta t}{2}\right) & =\vec{v}\left(t-\frac{\Delta t}{2}\right)+\frac{\vec{F}(t)}{m} \Delta t \\
\vec{r}(t+\Delta t) & =\vec{r}(t)+\vec{v}\left(t+\frac{\Delta t}{2}\right) \Delta t
\end{aligned}
$$

El algoritmo puede visualizarse en la Figura 2-15. Es equivalente al algoritmo de Verlet 73:

$$
\vec{r}(t+\Delta t)=2 \vec{r}(t)-\vec{r}(t-\Delta t)+\frac{\vec{F}(t)}{m} \Delta t^{2}+O\left(\Delta t^{4}\right)
$$

Este algoritmo es de $3^{\text {er }}$ orden en $\vec{r}$ y es reversible en el tiempo. Sus ventajas y una comparación con otros algoritmos de integración temporal pueden encontrarse en la referencia 74 .

Las ecuaciones de movimiento se modifican para incorporar el acoplamiento a los baños de presión y temperatura, además de ser extendidas para incluir la conservación de las restricciones, todo lo cual se describe a continuación.

\footnotetext{
${ }^{7}$ Otros algoritmos de actualización pueden verse por ejemplo en el texto de Allen y Tildesley (ref 75)
} 


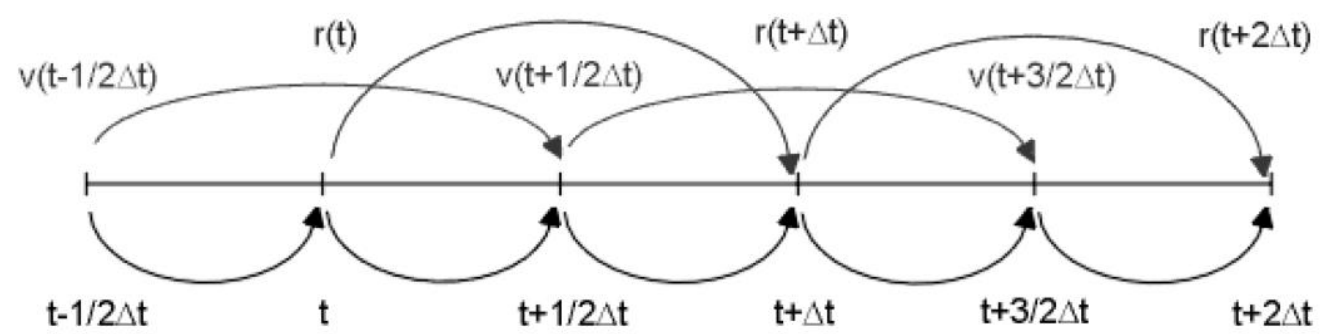

Figura 2-15: Método de integración de "leap-frog" o salto de rana. Recibe este nombre debido a que $r$ y $v$ saltan uno sobre el otro alternadamente al estilo del salto de rana.

\section{e. Acoplamiento térmico:}

Por varios motivos (deriva durante el equilibrado del sistema, deriva como resultado del truncado de fuerzas y errores de integración, calentamiento debido a fuerzas externas o de fricción, entre otras), se vuelve necesario controlar la temperatura del sistema. Para esto puede utilizarse el esquema de acoplamiento débil de Berendsen 76, el acoplamiento conocido como Velocity rescale ( $v$-rescale) 78 , o el esquema de ensamble extendido de Nosé-Hoover 80.

Más allá de la elección del algoritmo, una cuestión importante a considerar es que el acoplar a todo el sistema a un baño térmico suele causar que parte del sistema tenga una temperatura promedio mayor que el resto del sistema. Este efecto suele ser particularmente relevante en sistemas de proteínas en solución acuosa como el que estudiamos, en los que, en general el solvente se estabiliza a una temperatura mayor que la del baño y el soluto a una temperatura menor (se lo suele llamar "problema del solvente caliente y el soluto frío"). Este resultado artificial de la aplicación de un acoplamiento térmico puede evitarse acoplando a solvente y soluto a baños térmicos diferentes.

Por otro lado, tampoco es aconsejable acoplar a un baño térmico por separado a moléculas pequeñas (pequeños ligandos de una proteína por ejemplo), ya que esto les restringe considerablemente su movimiento, generando también una situación artificial. En conclusión, una elección adecuada sería utilizar un baño para la proteína y uno para todo el resto del sistema.

A continuación se encuentra una descripción de los Termostatos de Berendsen y $v$ rescale.

\section{Acoplamiento térmico de Berendsen}

El algoritmo utilizado para la realización del presente Trabajo es el de Berendsen ${ }^{8}$, el cual reproduce un acoplamiento débil a un baño térmico externo de una dada temperatura $T_{0}$, con cinética de primer orden. El efecto de la aplicación de este algoritmo es el de corregir una desviación térmica de $T_{0}$ del sistema según:

$$
\frac{d T(t)}{d t}=\frac{T_{0}-T(t)}{\tau}
$$

\footnotetext{
${ }^{8}$ Para el estudio del modelo SPC/HW de agua pesada se empleó el algoritmo v-rescale.
} 
Lo cual significa que este método brinda un decaimiento exponencial de la temperatura con una constante de tiempo $\tau$. Este método de acoplamiento tiene la ventaja de que la intensidad con la cual se encuentra acoplado el baño puede variarse, adaptándose a las necesidades del sistema: para llevar un sistema al equilibrio puede utilizarse una constante pequeña $(0,01 \mathrm{ps})$, mientras que para lograr corridas confiables de un sistema en equilibrio puede utilizarse una constante mucho mayor $(0,5 \mathrm{ps})$ en cuyo caso prácticamente no se afecta la dinámica conservativa 81 . Típicamente se utiliza una constante de acoplamiento de $0,1 \mathrm{ps}$.

Combinando las expresiones (2.26) y (2.27), obtenemos:

$$
T(t)=\frac{\sum_{i=1}^{N} m_{i} v_{i}^{2}}{N_{g l} k_{B}}
$$

El flujo térmico desde o hacia el sistema es realizado escalando a cada paso las velocidades de cada partícula mediante un factor $\lambda(t)$, resultando, según (2.37), $T(t+\Delta t)=\lambda^{2} T(t)$. De esta manera, el cambio en la temperatura en un paso de integración puede escribirse:

$$
\Delta T=T(t+\Delta t)-T(t)=\lambda^{2} T(t)-T(t)
$$

A partir de (2.36), el cambio en la temperatura en un paso de integración $\Delta t$ será:

$$
\Delta T=\frac{\Delta t}{\tau}\left(T_{o}-T(t)\right)
$$

Combinando (2.38) y (2.39) obtenemos el siguiente valor para $\lambda(t)$ :

$$
\lambda(t)=\left[1+\frac{\Delta t}{\tau}\left\{\frac{T_{0}}{T(t)}-1\right\}\right]^{1 / 2}
$$

Finalmente, teniendo en cuenta que en el algoritmo de integración de salto de rana las velocidades se evalúan para $t-\Delta t / 2, \lambda(t)$ estará dado por:

$$
\lambda(t)=\left[1+\frac{\Delta t}{\tau_{T}}\left\{\frac{T_{0}}{T(t-\Delta t / 2)}-1\right\}\right]^{1 / 2}
$$

El valor del parámetro $\tau_{T}$ es cercano al de la constante de acoplamiento $\tau$, aunque no exactamente igual:

$$
\tau=\frac{2 C_{V} \tau_{T}}{N_{g l} k_{B}}
$$

Donde $C_{V}$ es la capacidad calorífica total del sistema, $k_{B}$ es la constante de Boltzmann y $N_{g l}$ es el número total de grados de libertad. La razón por la cual $\tau \neq \tau_{T}$ es que el cambio en la energía cinética causado por el escalado de las velocidades es parcialmente 


\section{CAPÍTULO 2}

redistribuido entre las energías cinética y potencial, y por lo tanto el cambio en la temperatura resulta menor que el escalado de la energía. En la práctica, el valor de la relación $\tau / \tau_{T}$ va desde 1 (gas) a 2 (sólido armónico) y hasta 3 (agua). El parámetro $\tau_{T}$ es comúnmente llamado "constante temporal de acoplamiento térmico".

El algoritmo de Berendsen resulta estable hasta valores de $\tau_{T} \approx \Delta t$.

\section{Acoplamiento térmico Velocity-rescaling:}

Este acoplamiento térmico re-escala la velocidad de las partículas con un término estocástico. A continuación podemos ver cómo actúa sobre la energía cinética del sistema de partículas

$$
d E_{c}=\left(E_{c}^{0}-E_{c}\right) \frac{d t}{\tau_{T}}+2 \sqrt{\frac{E_{c}^{0} E_{c}}{N_{g l}}} \frac{d W}{\sqrt{\tau_{T}}}
$$

donde $d W$ representa ruido blanco gaussiano y $E_{c}^{0}$ es la Energía Cinética del sistema a la temperatura del baño (Energía Cinética de referencia).

Este termostato utiliza también una constante de acoplamiento $\tau_{T}$, pero el segundo término estocástico asegura un ensamble canónico adecuado. Sin el término estocástico esta ecuación se reduce a la del termostato standard de Berendsen. En el limite $\tau_{T}=0$, la evolución estocástica hace que el sistema termalice instantáneamente. Cuando un sistema está lejos del equilibrio, la parte determinista de la expresión domina, y el algoritmo conduce a un rápido equilibrio térmico como con el termostato de Berendsen. Una vez que el equilibrio se alcanza, el termostato garantiza un muestreo compatible con un ensamble canónico, si en esas condiciones estamos trabajando, a diferencia del de Berendsen.

\section{f. Acoplamiento de presión:}

Del mismo modo que con los termostatos, el sistema puede ser acoplado también a un "baño" de presión.

Para ajustar el valor de la presión del sistema puede utilizarse el algoritmo de Berendsen 76 o el esquema de ensamble extendido de Parrinello-Rahman 77. Ambos pueden combinarse con cualquiera de los algoritmos para el acoplamiento térmico descriptos con anterioridad. A continuación se describe el llamado Baróstato de Berendsen, que es el que se utilizó para realizar este Trabajo.

\section{Baróstato de Berendsen}

El algoritmo de Berendsen re-escala las coordenadas y los vectores de la caja de simulación a cada paso de la integración con la matriz $\boldsymbol{\mu}$, lo cual tiene un efecto sobre la presión de una cinética de relajación de primer orden hacia un valor de referencia dado de presión $\mathbf{P}_{0:}$

$$
\frac{d \mathbf{P}_{\mathbf{0}}}{d t}=\frac{\mathbf{P}_{\mathbf{0}}-\mathbf{P}}{\tau_{p}}
$$

Los elementos de la matriz de escalado $\boldsymbol{\mu}$ vienen dados por:

$$
\mu_{i j}=\delta_{i j}-\frac{\Delta t}{3 \tau_{p}} \beta_{i j}\left[P_{0_{i j}}-P_{i j}(t)\right]
$$


Aquí $\beta_{i j}$ es la compresibilidad isotérmica del sistema. En la mayoría de los casos ésta será una matriz diagonal, con elementos iguales sobre la diagonal, cuyo valor resulta generalmente desconocido. Alcanza con tomar un valor aproximado del mismo, dado que el valor de $\beta_{i j}$ solamente tiene influencia sobre la constante temporal no crítica de la relajación de la presión, sin afectar el valor promedio de la presión.

Cuando el escalado es completamente anisotrópico, el sistema debe ser rotado de manera de cumplimentar con las restricciones de la caja. Esta rotación puede aproximarse en el primer orden del escalado, el cual es normalmente menor que $10^{-4}$. La matriz de escalado $\boldsymbol{\mu}$ 'es:

$$
\boldsymbol{\mu}^{\prime}=\left(\begin{array}{ccc}
\mu_{x x} & \mu_{x y}+\mu_{y x} & \mu_{x z}+\mu_{z x} \\
0 & \mu_{y y} & \mu_{y z}+\mu_{z y} \\
0 & 0 & \mu_{z z}
\end{array}\right)
$$

Las velocidades no se rotan ni se escalan.

El escalado de Berendsen puede también realizarse isotrópicamente, lo cual significa que puede utilizarse una matriz diagonal con elementos de tamaño $\operatorname{Traza}(\mathbf{P}) / 3$ en lugar de la matriz $\mathbf{P}$.

\section{Algoritmos de restricciones topológicas:}

Las restricciones topológicas pueden resolverse utilizando diversos algoritmos desarrollados para este fin. A continuación, se realiza una breve reseña de los más utilizados y los más eficientes en términos de costo computacional.

\section{a. SHAKE}

El algoritmo SHAKE 82 cambia un grupo de coordenadas no-restringidas $\vec{r}^{\prime}$ por otro grupo de coordenadas $\vec{r}$ " que cumplimentan con una serie de restricciones de distancia, utilizando como referencia el conjunto de coordenadas $\vec{r}$ :

$$
\operatorname{SHAKE}\left(\vec{r}^{\prime} \rightarrow \vec{r}^{\prime \prime} ; \vec{r}\right)
$$

Esta acción es consistente con la resolución de un conjunto de multiplicadores de Lagrange en las ecuaciones de movimiento restringidas. En el algoritmo SHAKE se necesita definir un parámetro de tolerancia (TOL); este continuará con las iteraciones hasta que se satisfagan todas las restricciones dentro del valor de tolerancia dada.

Asumiendo que las ecuaciones de movimiento deben cumplir con un conjunto de restricciones holonómicas $K$, expresadas por:

$$
\sigma_{k}\left(\vec{r}_{1}, \vec{r}_{2}, \ldots, \vec{r}_{N}\right)=0 ; \quad k=1, \ldots, K
$$

Entonces las fuerzas quedan definidas por:

$$
-\vec{\nabla}_{i}\left(V+\sum_{k=1}^{K} \lambda_{k} \sigma_{k}\right)
$$




\section{CAPÍTULO 2}

Donde $\lambda_{k}$ son los multiplicadores de Lagrange que deben ser resueltos para satisfacer las ecuaciones de restricción. La segunda parte de esta suma determina las fuerzas de restricción $\vec{G}_{i}$, definidas por:

$$
\vec{G}_{i}=-\sum_{k=1}^{K} \lambda_{k} \vec{\nabla}_{i}\left(\sigma_{k}\right)
$$

El desplazamiento debido a estas fuerzas de restricción en los algoritmos de integración "Leap-frog" o Verlet es igual a $\left(\vec{G}_{i} / m_{i}\right)(\Delta t)^{2}$. La resolución de los multiplicadores de Lagrange (y por lo tanto de los desplazamientos) requiere de resolver un conjunto de ecuaciones acopladas de segundo grado. Este conjunto de ecuaciones es resuelto iterativamente en el algoritmo SHAKE.

Dado que en simulaciones de sistemas hidratados el solvente suele representar más del 80\% del mismo, existen ciertas alternativas para el uso de este algoritmo.

Para el caso de modelos de agua rígidos puede utilizarse una versión optimizada (y simplificada) de este algoritmo, denominado SETTLE 83, el cual consiste en una aplicación de una solución analítica de SHAKE.

\section{b. LINCS}

\section{EI algoritmo LINCS}

LINCS es un algoritmo que reconstituye enlaces a su longitud correcta luego de una actualización no-restringida 84. El método es no-iterativo, dado que siempre se resuelve en dos pasos. Aunque LINCS está basado en matrices, no precisa de la resolución de multiplicaciones entre matrices. El método es más rápido y estable que SHAKE, pero sólo puede utilizarse con restricciones de longitud de enlace y restricciones de ángulos de enlace aislados, tales como el ángulo del protón en el enlace $\mathrm{OH}$.

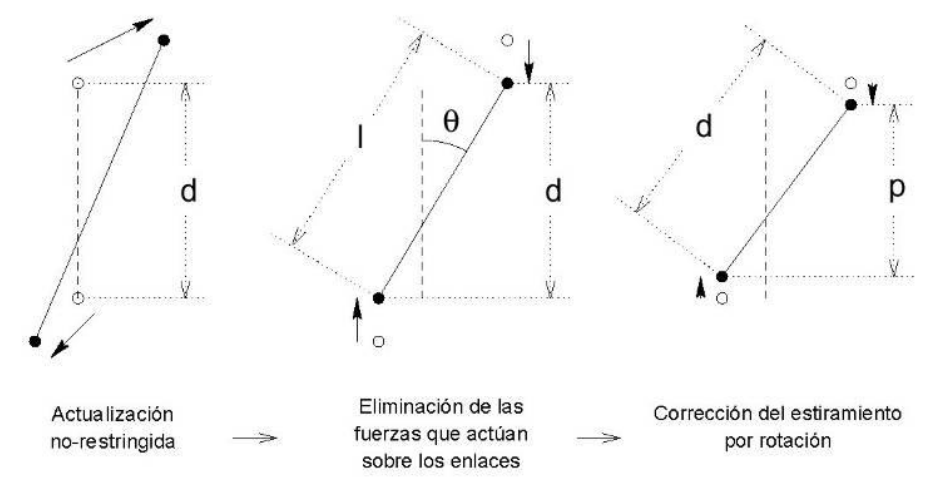

Figura 2-16: Las tres actualizaciones de posición requeridas para cada paso de integración. La línea punteada representa el viejo enlace de longitud $d$, mientras que las líneas llenas representan los nuevos enlaces. $l=d \cos \theta$ y $p=\left(2 d^{2}-l^{2}\right)^{1 / 2}$ 


\section{Las fórmulas de LINCS}

Consideremos un sistema de $N$ partículas, con posiciones dadas por un vector de $3 N$ componentes, denominado $\vec{r}(t)$. Para la Dinámica Molecular las ecuaciones de movimiento vienen dadas por las ecuaciones de Newton:

$$
\frac{\partial^{2} \vec{r}}{\partial t^{2}}=\mathbf{M}^{-1} \vec{F}
$$

Donde $\vec{F}$ es el vector de la fuerza y $\mathbf{M}$ es la matriz diagonal $3 N \times 3 N$, que contiene las masas de las partículas. El sistema se encuentra restringido topológicamente por $K$ ecuaciones de restricción, dependientes del tiempo

$$
g_{i}(\vec{r})=\left|\vec{r}_{i_{1}}-\vec{r}_{i_{2}}\right|-d_{i} \text { donde } i=1, \ldots, K
$$

En el esquema de integración numérica LINCS (al igual que SHAKE) es aplicado luego de una actualización no-restringida. El algoritmo trabaja en dos pasos (ver Figura 2-6). Durante el primer paso se llevan a cero las proyecciones del nuevo enlace sobre el viejo. En el segundo paso se aplica una corrección por estiramiento de enlace debido a la rotación. Puede verse una derivación completa del algoritmo en la referencia 84 .

\section{Potenciales de Fuerza media - El "Pull Code":}

El paquete GROMACS cuenta con una serie de herramientas que permiten realizar fuerzas externas sobre los átomos del sistema que se está estudiando y registrar su valor a cada paso de la simulación. Éstas se denominan en conjunto Pull Code. A partir de estas pueden obtenerse potenciales de fuerza media. Será necesario especificar un grupo de referencia y entre uno y veinte otros grupos sobre los que actuarán estos potenciales. Por el momento, GROMACS cuenta con tres formas diferentes de realizar estas fuerzas:

- Umbrella pulling ${ }^{9}$ : Un potencial armónico se aplica entre los centros de masa de dos grupos. Por lo tanto, la fuerza es proporcional al desplazamiento. Simula la acción de la palanca de un Microscopio de Fuerza Atómica (por eso también se la suele llamar AFM pulling) sobre el átomo o grupo de átomos sobre los que se va a actuar. Consiste en conectar un resorte ideal al grupo del que se tira y mover el otro extremo del resorte a una velocidad constante. Esto tiene el efecto de alejar a este átomo o grupo de ellos de su posición original. La velocidad con que se mueve el extremo libre del resorte (en dirección, sentido y módulo) y su constante de fuerza son parámetros de entrada del programa.

- Fuerzas de restricción de distancia: La variación de la distancia entre los centros de masa de dos grupos de átomos puede restringirse en 1, 2 o 3 dimensiones, monitoreando la fuerza que se realiza. El potencial actúa manteniendo fija la distancia que poseían el grupo de referencia y los demás grupos especificados al comienzo de la simulación. Este método usa el algoritmo SHAKE, y necesita de un único paso de iteración para ser exacto si sólo dos grupos son restringidos.

\footnotetext{
${ }^{9}$ A falta de una expresión castellana que describa adecuadamente estos nombres, se utilizan nuevamente sus expresiones en inglés. Los nombres son los que asignaron los desarrolladores de GROMACS, no los que elegiría el autor de la presente Tesis.
} 


\section{CAPÍTULO 2}

- Fuerza constante: Una fuerza constante se aplica entre los centros de masa de los dos grupos. Por lo tanto, el potencial es lineal.

A continuación, se describe el caso del Umbrella Pulling, que es el potencial utilizado para la realización del presente trabajo:

El programa permite registrar la posición del grupo del que se tira (que llamaremos pull), del grupo de referencia ( $r e f)$ y de la fuerza media que actúa entre paso y paso sobre el grupo del que se tira. La dirección y sentido en las cuales se tira, se establecen a través de un vector llamado pull_vec, mientras que la razón de cambio de la posición del extremo libre del resorte (o velocidad con que se tira) en $\mathrm{nm} / \mathrm{ps}$ se introduce con el nombre pull_rate. También debe ingresarse la coordenada inicial del extremo libre del resorte (pull_init). Para que inicialmente el resorte comience realizando una fuerza nula el valor de pull_init deberá ser la coordenada inicial del grupo del que se tira con respecto a la coordenada inicial del grupo de referencia, o, más específicamente:

$$
\overrightarrow{\text { pull_init }}=\overrightarrow{\text { pull }_{0}}-\overrightarrow{\text { refo }_{0}}
$$

Si pull_init $=0$ se tomará como posición inicial del resorte la posición inicial del grupo del cual se tira, por lo que la fuerza inicial será nula.

La constante del resorte se introduce en $\frac{\mathrm{kJ}}{\mathrm{mol} \cdot \mathrm{nm}^{2}}$.

En la siguiente figura (figura 2-17) se esquematiza la acción del resorte en el caso de Umbrella Pulling:

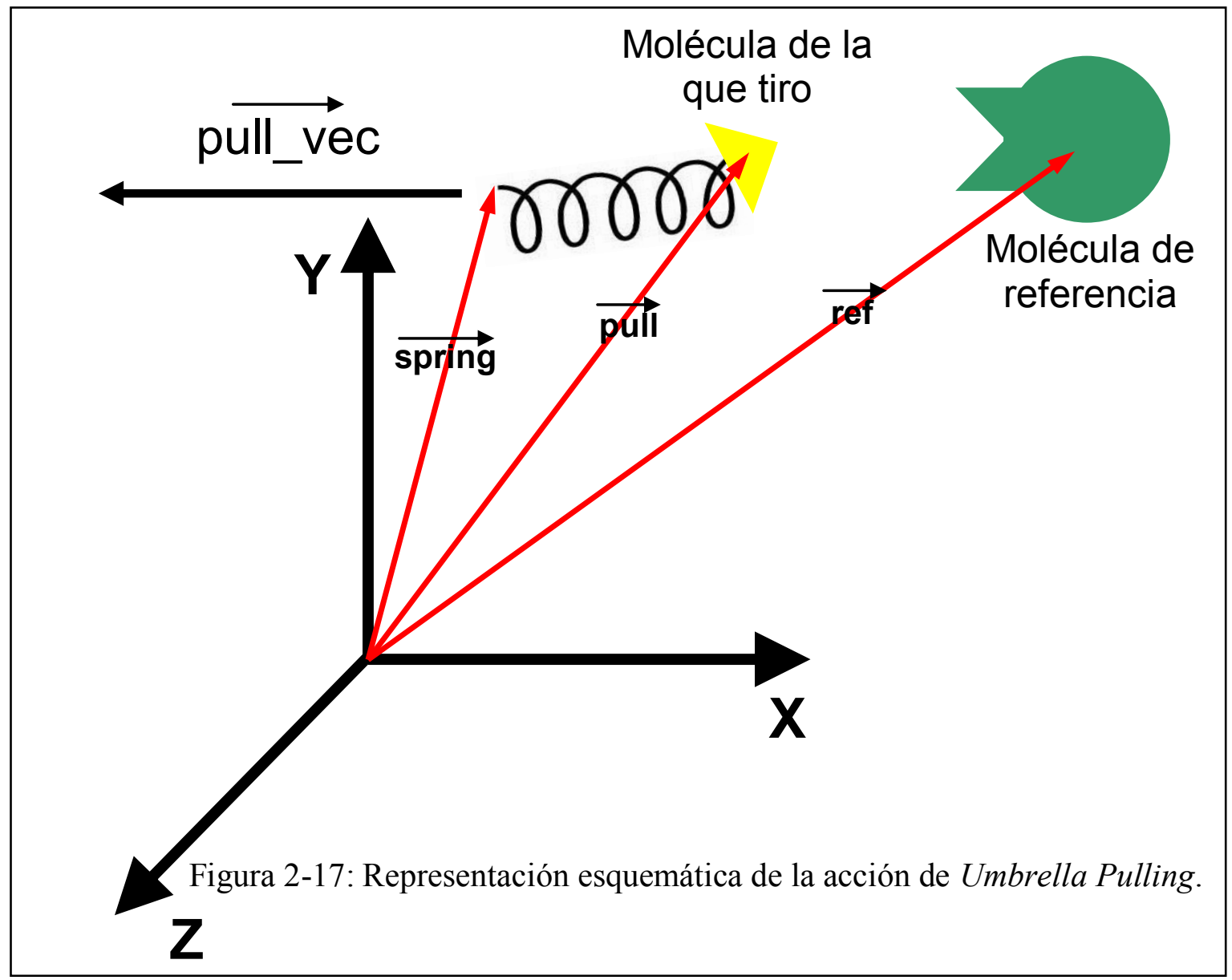




\section{Otras Herramientas de análisis utilizadas:}

\section{a. Cálculo de la Raíz de la desviación Cuadrática Media (RMSD):}

Podemos calcular la Raíz de la Desviación Cuadrática Media (RMSD por sus siglas en Inglés) de ciertos átomos de una molécula con respecto a una estructura de la mencionada molécula que se desea tomar como referencia. Para esto se realiza primero un ajuste por Cuadrados Mínimos de parte de esa estructura a la configuración de referencia y luego, mediante el cálculo del $R M S D$, se estudia la desviación de la estructura respecto de la referencia. Este ajuste inicial se hace para evitar considerar en el análisis el movimiento de traslación y rotación de la molécula estudiada como un todo, y así poder considerar sólo los cambios conformacionales que en ella se producen. Puede calcularse el $R M S D$ de toda la molécula de interés o de parte de ella. Por ejemplo, es muy común el estudio del $R M S D$ de los carbonos $\alpha$ al estudiar la estabilidad de proteínas.

Si el número de átomos a considerar para el cálculo es $N$, obtenemos el $R M S D$ a un dado tiempo $t$, respecto de una estructura de referencia (con posiciones $\vec{r}_{i}(0)$ y masas $\left.m_{i}, i=1, N\right)$ mediante la siguiente expresión:

$$
\operatorname{RMSD}(t)=\left[\frac{1}{M} \sum_{i=1}^{N} m_{i}\left\|\vec{r}_{i}(t)-\vec{r}_{i}(0)\right\|^{2}\right]^{\frac{1}{2}}
$$

donde $M=\sum_{i=1}^{N} m_{i}$ y $\vec{r}_{i}(t)$ son la suma de las masas de los $N$ átomos considerados y sus posiciones al tiempo $t$, respectivamente.

\section{b. Cálculo del Radio de Giro:}

También se puede tener una medida aproximada de cuan compacta es la estructura a estudiar y cómo cambia esa distribución de masa en función del tiempo analizando el radio de giro $R_{g}$ de la molécula definido como:

$$
R_{g}(t)=\left(\frac{\sum_{i=1}^{N}\left\|\vec{r}_{i}(t)\right\|^{2} m_{i}}{M}\right)^{\frac{1}{2}}
$$

donde las distancias $\vec{r}_{i}(t)(i=1, N)$ son las posiciones de los $N$ átomos de la molécula considerados para el análisis, tomadas desde su Centro de Masas, $m_{i}$ es la masa del i-ésimo átomo y $M=\sum_{i=1}^{N} m_{i}$ la suma de las mismas.

\section{c. Superficie Accesible al Solvente:}

El estudio de la Superficie Accesible al Solvente 85, consiste en recorrer la superficie proteica (o de algún otro sistema que se esté estudiando) utilizando una sonda esférica 


\section{CAPÍTULO 2}

de radio igual al del modelo de solvente utilizado. De este modo puede identificarse cuál es esta superficie expuesta, diferenciando a su vez el comportamiento de regiones hidrofílicas e hidrofóbicas. Este último puede estudiarse en función del tiempo, permitiendo la identificación de posibles cambios conformacionales, entre otros efectos observables.

Es pertinente diferenciar entre la Superficie Accesible al Solvente $(S A S)$ y la Superficie de exclusión del mismo (SES) o superficie de Connolly 86, 87. Ambas se construyen recorriendo la superficie con una sonda esférica, sólo que en el caso de la $S A S$, la misma se construye siguiendo la trayectoria del centro de la esfera, mientras que en el caso de la superficie de Connolly, se elabora a partir de los puntos más cercanos a los que llega la esfera respecto de la molécula o grupo de ellas a estudiar (ver Figura 2-18).

Lo habitual es expresar la $S A S$ en unidades de $\AA^{2}$ o $\mathrm{nm}^{2}$. Para el cálculo de la superficie se utilizó una sonda esférica de radio $0,14 \mathrm{~nm}$.

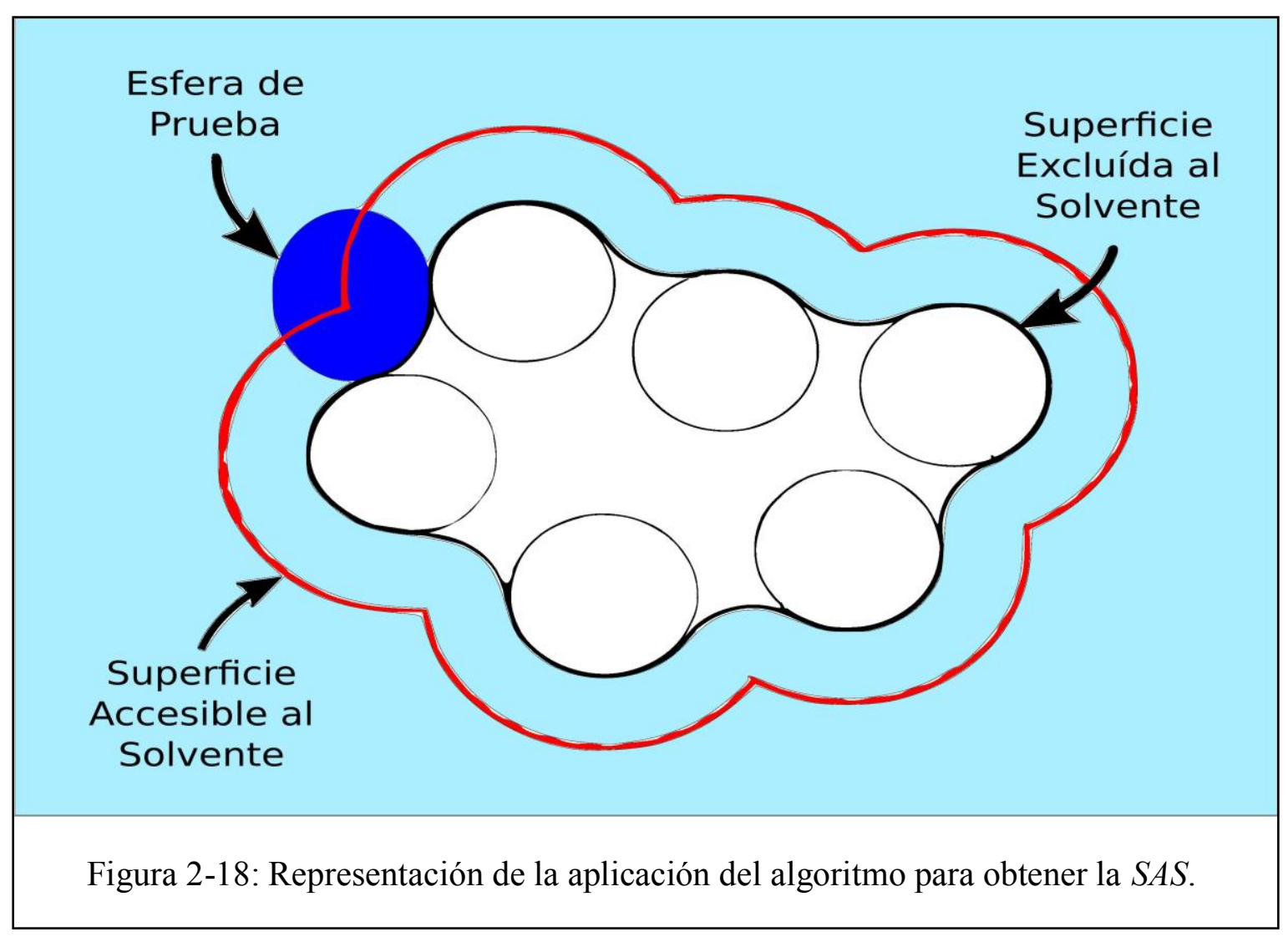


Algoritmo completo de actualización 64:

\section{EL ALGORITMO DE ACTUALIZACION}

Dadas:

Posiciones $\vec{r}$ de todos los átomos a tiempo $t$

Velocidades $\vec{v}$ a tiempo $t-\frac{\Delta t}{2}$

Aceleraciones $\vec{F} / m$ sobre todos los átomos a tiempo $t$.

(Las fuerzas se computan sin tomar en cuenta ninguna restricción)

La Energía Cinética total y el Virial.

$\Downarrow$

1. Cómputo de los factores $\lambda$ y $\boldsymbol{\mu}$ de escalado

(Ecuaciones (2-37) y (2-41))

$\Downarrow$

2. Actualización y escalado de velocidades: $\vec{v}^{\prime}=\lambda(\vec{v}+a \Delta t)$

$\Downarrow$

3. Cálculo de las nuevas coordenadas no-restringidas: $\vec{r}^{\prime}=\vec{r}+\vec{v} \Delta t$

4. Aplicación de algoritmo de restricción a las coordenadas: restringir $(\vec{r} \rightarrow \vec{r} \mid \vec{r})$

$\Downarrow$

5. Corrección de velocidades según restricciones: $\vec{v}=\frac{(\vec{r} "-\vec{r})}{\Delta t}$

$\Downarrow$

6. Escalado de coordenadas y caja: $\vec{r}=\mu \vec{r} " ; \vec{b}=\mu \vec{b}$ 
Capítulo 3

ALBÚMINA Y ASPIRINA 
Página | 56 


\section{CAPÍTULO 3}

Para la realización de la simulación computacional de la interacción entre la Albúmina Sérica Humana y la Aspirina, se empleó el paquete GROMACS 4 5, 6, 7, 8. Se utilizó el campo de fuerzas para átomos enlazados 43a1 de GROMOS96 (ffg43a1) 93, tanto para los procedimientos de estabilización del sistema, como para todos los pasos de simulación por Dinámica Molecular.

Las restricciones topológicas de las moléculas de agua se resolvieron utilizando el algoritmo SETTLE 83. Para el cálculo de las fuerzas electrostáticas se utilizó el método de Campo de Reacción 67. Las interacciones de Lennard-Jones fueron calculadas explícitamente dentro de un radio de corte de $2,5 \mathrm{~nm}$, que corresponde a un valor cercano a la mitad de la dimensión más pequeña de la caja de simulación.

Para todas las simulaciones de este sistema se utilizó un cluster de 54 nodos corriendo bajo GNU/Linux, utilizando para las visualizaciones de trayectorias y estructuras el software de distribución libre Visual Molecular Dynamics (VMD) y Swiss PDB Viewer (SPDBV) respectivamente. Para las representaciones gráficas de resultados se utilizó el programa Microcal Origin 8.

Para los estudios en solvente acuoso se utilizó el modelo de agua SPC/E 20 y para las simulaciones en agua pesada el modelo SPC/HW 62.

Las interacciones de Lennard-Jones fueron calculadas explícitamente dentro de un radio de corte de $1,4 \mathrm{~nm}$.

Se mantuvieron las restricciones topológicas para las longitudes de enlace utilizando el algoritmo LINCS 84.

Para este sistema se utilizó una caja de simulación cúbica. La caja hidratada contenía a la Albúmina, una molécula de Aspirina, cinco Ácidos Mirísticos y 107.430 moléculas de agua.

Se utilizó una estructura resuelta por Difracción de Rayos X, con una precisión de 2,9 94 (código de PDB 2I30), publicada y disponible en el "Protein Data Bank" como estructura de partida.

Una búsqueda de la palabra clave "Human Serum Albumin" en el sitio del PDB arroja 101 resultados positivos, de los cuales 97 corresponden a estructuras resueltas por Difracción de Rayos X. El hecho de no contar con estructuras resueltas en solución por Resonancia Magnética Nuclear se debe probablemente a la alta movilidad de los diferentes residuos de esta proteína.

Debido a la baja resolución con que se obtuvo la estructura, en el archivo .pdb que se obtiene del Protein Data Bank, la proteína se encontraba incompleta (en el extremo N-terminal faltaban los residuos Alanina 2 y Aspártico 1, mientras que en el extremo C-terminal faltaba la Leucina 585). Estos residuos faltantes, que seguramente no pudieron ser resueltos debido a su alta movilidad, fueron incorporados utilizando el programa Swiss PDB Viewer.

Además, la proteína se encontraba acetilada (unida al grupo acetilo de la aspirina) en la Lys199 y la aspirina hidrolizada (sin el grupo acetilo unido a la proteína ácido salicílico).

Utilizando nuevamente el programa Swiss PDB Viewer se quitó el grupo acetilo de la Lisina 199. 
Utilizando el programa PRODRG 95 se reconstruyó la aspirina.

A pesar de que todos los tipos de átomos, las cargas, enlaces, ángulos, ángulos diedros y diedros impropios de la aspirina y el ácido mirístico se encuentran en el campo de fuerzas utilizado, el paquete GROMACS requiere reconocer las moléculas, dado que funciona bajo el concepto de "building blocks". Por lo tanto, se incorporaron los bloques AIN (Aspirina) y MYR (ácido mirístico) al archivo ffg43a1.rtp, el cual identifica los bloques reconocidos por el paquete.

La topología del sistema se generó utilizando la herramienta PDB2GMX, con estados de protonación estándar para todos los aminoácidos ( $\mathrm{pH} 7)$.

Se alineó la proteína en la caja según sus ejes principales y se removió el movimiento de traslación del centro de masas del sistema.

Hecho esto, se procedió a la tarea de estabilizar la proteína, que se llevó adelante en una serie de pasos que se detallan a continuación:

\section{Estabilización}

- Se realizó una corrida en ausencia de solvente (vacío), sin el baño de presión, con restricciones de posición sobre los átomos del Backbone ${ }^{10}$ de la proteína $\left(k_{\begin{array}{c}\text { restricioin } \\ \text { de posición }\end{array}}=1.000 \frac{\mathrm{kJ}}{\mathrm{mol} \cdot \mathrm{nm}^{2}}\right)$, teniendo el cuidado de liberar los residuos que se agregaron, para que puedan explorar una configuración más estable. El baño de temperatura fue de $100 \mathrm{~K}$ y se corrieron $2 \mathrm{ps}$ a pasos de integración de $0,0001 \mathrm{fs}$.

- En las mismas condiciones se corrieron 10 ps con un paso de $0,5 \mathrm{fs}$.

- A estas condiciones se agregó la incorporación de restricciones de longitudes y ángulos de enlace mediante el algoritmo LINCS. Se corrieron 10ps y el paso fue de $0,5 \mathrm{fs}$.

- Se aumentó el paso a 1 fs y se corrió 100ps.

- Se aumentó el paso a 2 fs y la temperatura del baño a $200 \mathrm{~K}$, corriendo durante $100 \mathrm{ps}$.

- Se mantuvieron las condiciones anteriores menos la de la temperatura, que esta vez fue de $300 \mathrm{~K}$. Se corrieron 200ps.

- Se hidrató la caja de simulación y se realizó una corrida con baño de presión a 1 bar, baño de temperatura a $300 \mathrm{~K}$ durante 200 ps a pasos de $2 \mathrm{fs}$.

- Se disminuyó la rigidez de las restricciones de posición, pasando a $200 \frac{\mathrm{kJ}}{\mathrm{mol} \cdot \mathrm{nm}^{2}}$. Se corrió durante 200 ps a un paso de 2 fs.

- Se liberaron las restricciones de posición y se corrió $1 \mathrm{~ns}$ con paso de $2 \mathrm{fs}$ a $300 \mathrm{~K}$ y 1bar.

\footnotetext{
${ }^{10}$ Grupo de los aminoácidos de la proteína que están unidos por enlaces peptídicos. Dicho de otra manera, es la parte de la proteína que no contiene a las cadenas laterales, su esqueleto.
} 


\section{CAPÍTULO 3}

Luego de este proceso, se consideró estabilizado el sistema analizando las gráficas de energía total y cinética del sistema. A partir de este sistema inicial se realizó el estudio de la estabilidad del complejo compuesto por la Proteína y sus ligandos en solución acuosa.

\section{Estudios de la estabilidad del Complejo HSA-ASA}

\section{a. Estudios en agua (modelo SPC/E)}

Se estudió la dependencia temporal de la Raíz de la Desviación Cuadrática Media $(R M S D)$ de las posiciones de los Carbonos $\alpha$ de la proteína en una corrida de simulación de 80ns del sistema completo. En la Figura 3-1 se observa esta dependencia.

Puede verse un crecimiento en el RMSD debido al reacomodamiento de la estructura del cristal a la solución acuosa. En este crecimiento puede apreciarse la conocida flexibilidad de la proteína estudiada. Más adelante analizaremos más información complementaria al respecto.

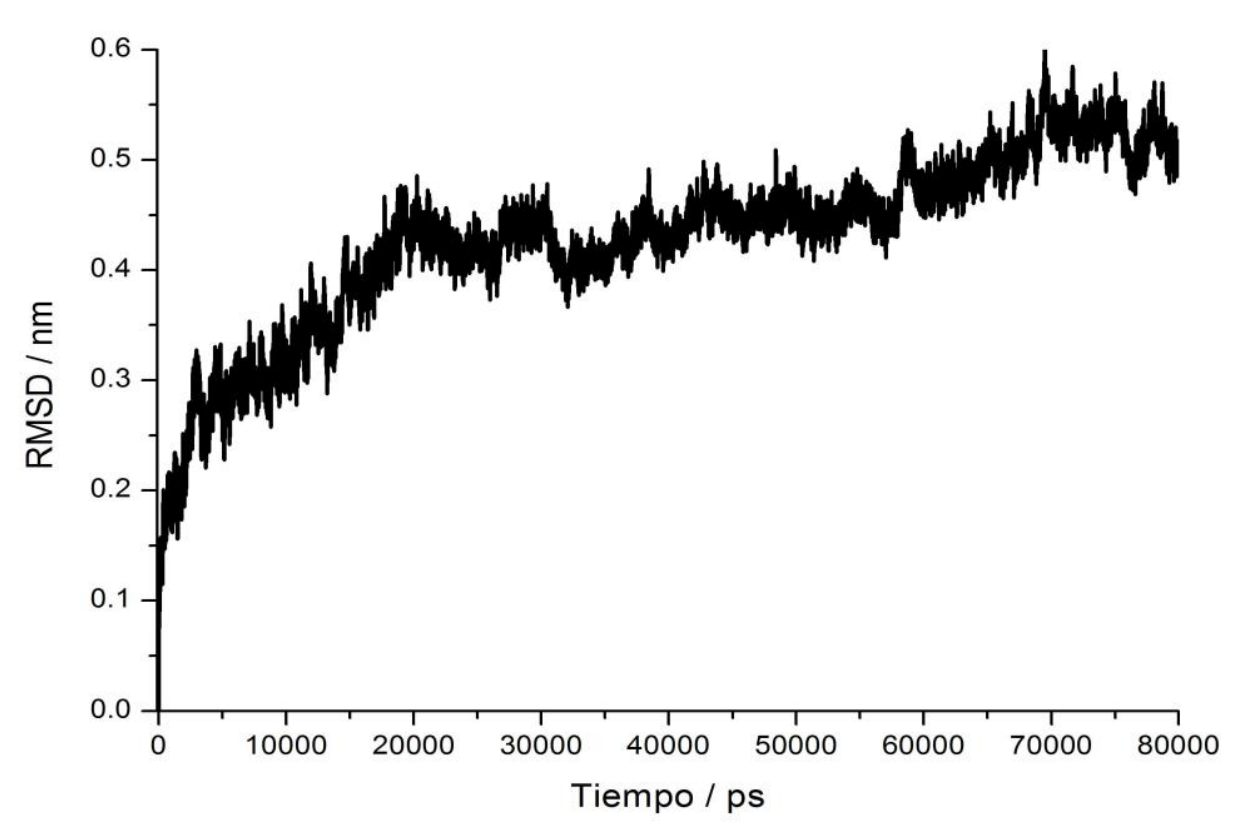

Figura 3-1: Raíz de la Desviación Cuadrática Media (RMSD) de las posiciones de los Carbonos $\alpha$ de la proteína en una corrida de simulación de 80ns en agua SPC/E.

\section{b. Estudios en agua deuterada (modelo SPC/HW)}

Para analizar cómo este comportamiento se ve afectado por la presencia de un solvente más estructurado como lo es el agua pesada, se simuló el mismo sistema utilizando el modelo de agua SPC/HW. Esto se realizó a partir de la estructura obtenida a los 40ns de simulación en agua SPC/E por 40ns más. En la Figura 3-2 se observan los resultados obtenidos. Cabe indicar el crecimiento en el $R M S D$ respecto del correspondiente a agua $\mathrm{SPC} / \mathrm{E}$, lo que muestra un reacomodamiento de la estructura debido a la mayor rigidez de los puentes de deuterio. Luego de este crecimiento, el RMSD mantiene una relativa estabilidad, posiblemente debido a la gran cantidad de puentes disulfuro que posee la proteína y a la rigidización de la estructura por la presencia de los puentes de deuterio. 


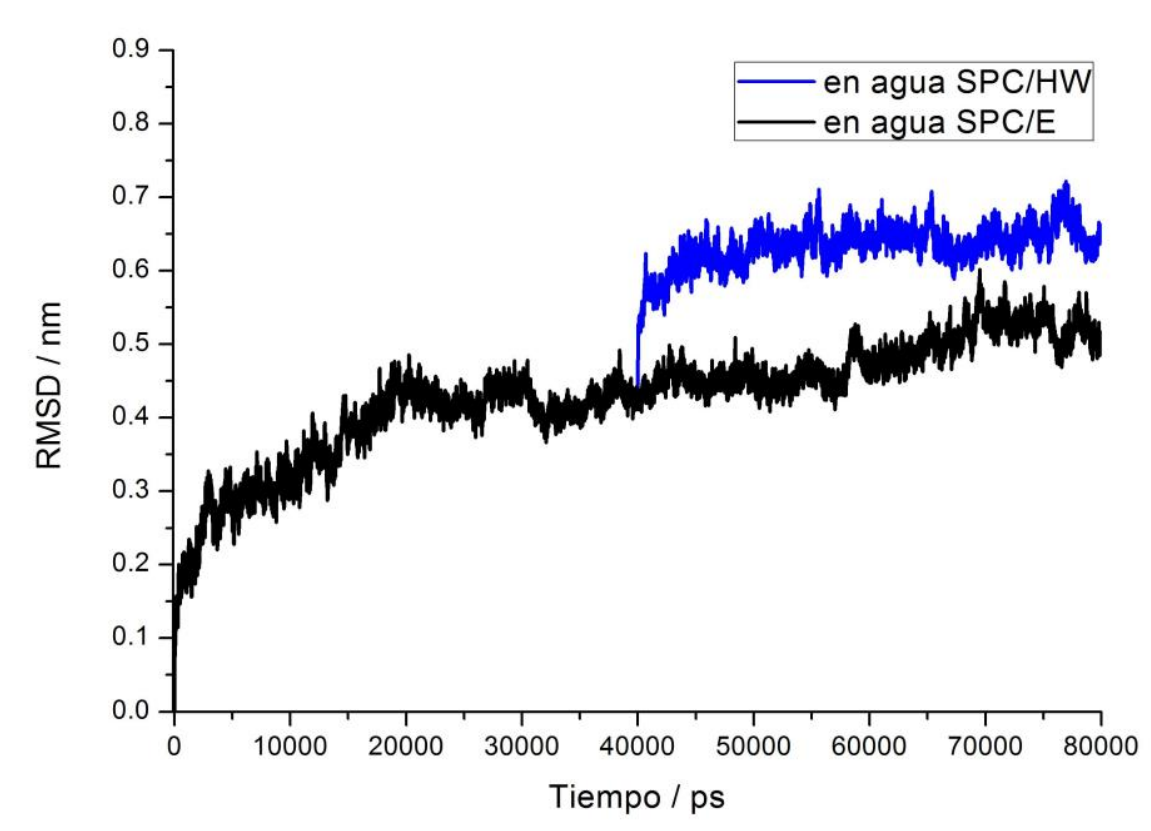

Figura 3-2: RMSD de las posiciones de los Carbonos $\alpha$ de la proteína en una corrida de simulación de 80ns en agua SPC/E (curva negra) y en una corrida de simulación de 40ns en agua pesada SPC/HW a partir de los 40ns (curva azul).

\section{c. Efectos de la Presión Hidrostática}

También se estudiaron los efectos de la presión hidrostática sobre el sistema, llevando la presión a $3 \mathrm{kbar}$ (presión a la cual, como ya se ha mencionado, el agua pierde sus características de líquido estructurado). Esto se realizó a partir de la estructura obtenida a los 30ns y a los 40ns de simulación en agua SPC/E a 1bar. Pueden observarse los resultados obtenidos en la figura 3-3. Allí podemos marcar un efecto similar en ambas corridas, lo que marca la coherencia de los valores de RMSD obtenidos desde dos configuraciones diferentes.

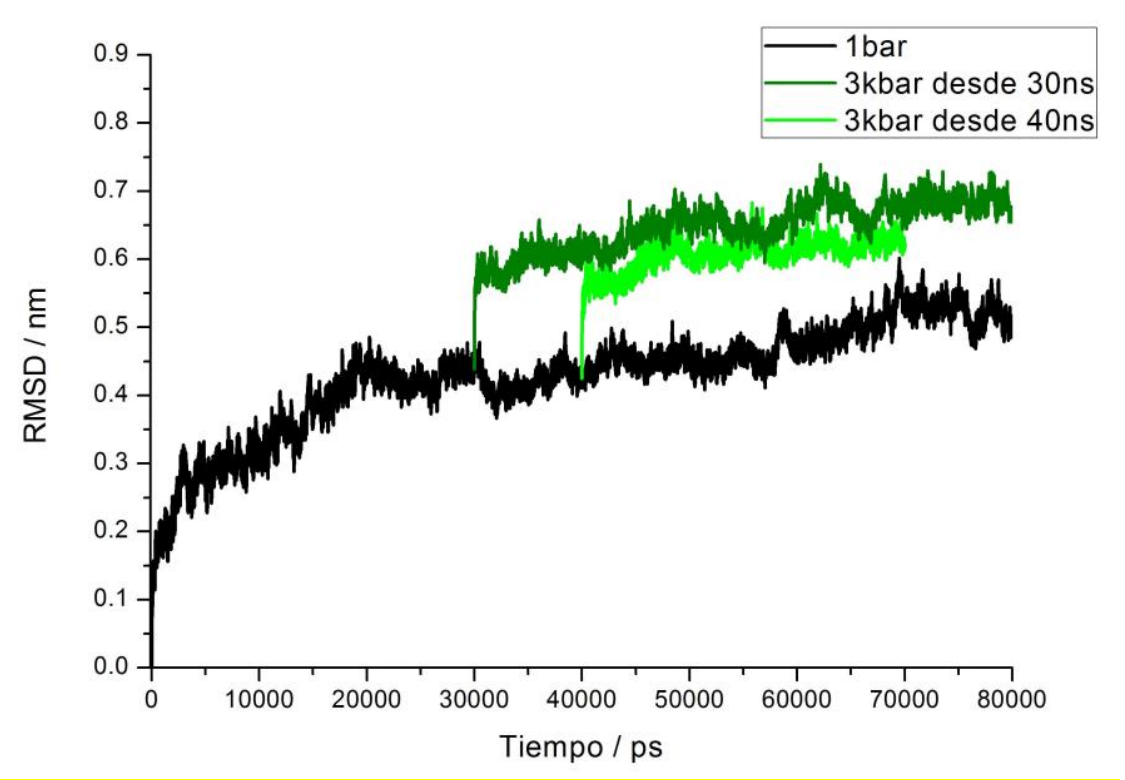

Figura 3-3: RMSD de las posiciones de los Carbonos $\alpha$ de la proteína en una corrida de simulación de 80ns (curva negra) y en dos corridas de simulación a $3 \mathrm{kbar}$ (curvas verdes) en agua SPC/E. 


\section{CAPÍTULO 3}

\section{d. Análisis del Radio de Giro}

Para complementar el análisis realizado a partir del $R M S D$, se realizó para las mismas corridas el estudio del Radio de Giro $\left(\mathrm{R}_{\mathrm{g}}\right)$. Los mismos se presentan en la figura 3-4.

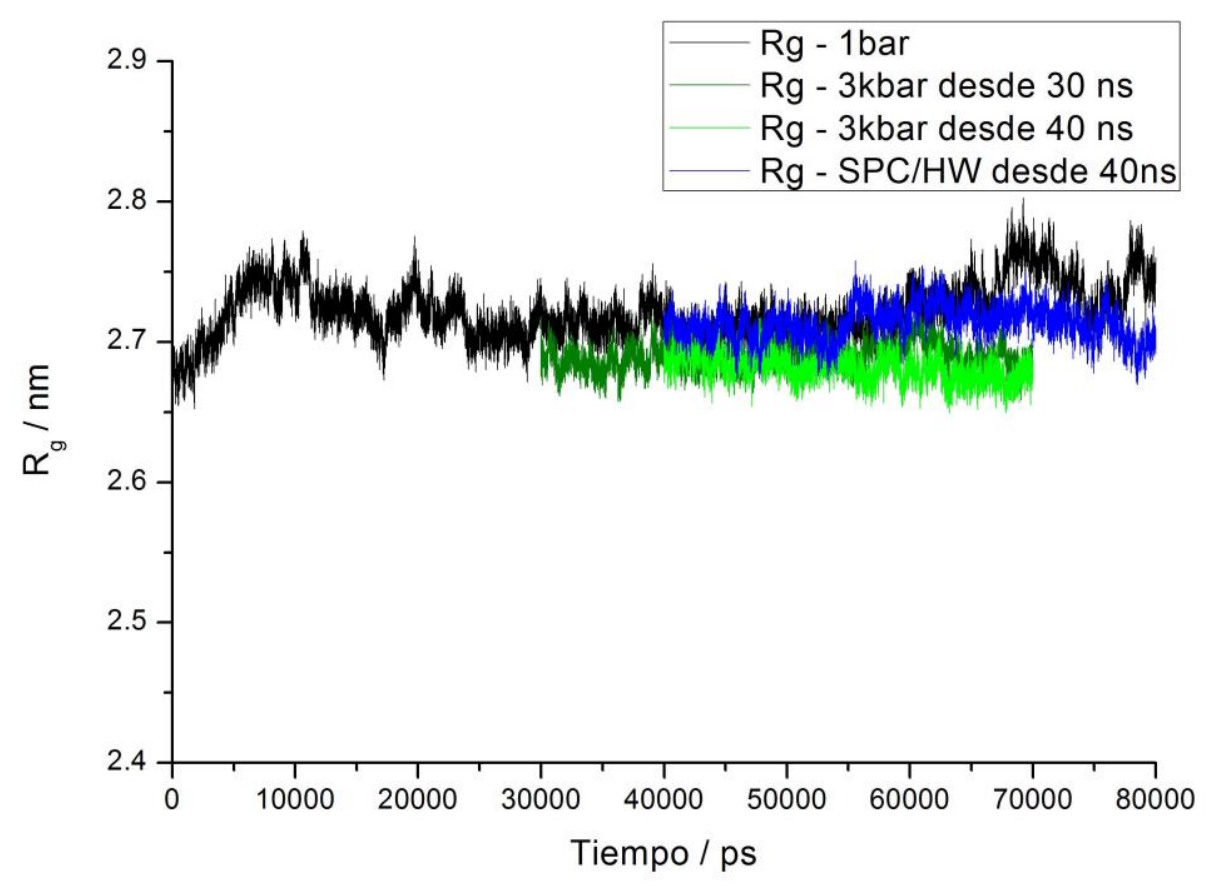

Figura 3-4: Radio de Giro $\mathrm{R}_{\mathrm{g}}$ de la proteína en una corrida de 80ns (curva negra), en dos corridas a $3 \mathrm{kbar}$ (curvas verdes) en agua SPC/E y una corrida en agua pesada $\mathrm{SPC} / \mathrm{HW}$ (curva azul).

Del análisis de la Figura 3-4, podemos concluir que el Radio de Giro de la proteína a una presión de 1 bar es relativamente estable alrededor de un valor medio de 2,72 $\mathrm{nm}$. Para las corridas a $3 \mathrm{kbar}$, en aquella que comienza desde los $30 \mathrm{~ns}$ de la corrida original, el $R_{\mathrm{g}}$ se estabiliza rápidamente en un valor de $2,68 \mathrm{~nm}$, mientras que en la que comienza en los $40 \mathrm{~ns}$ el valor promedio es $2,69 \mathrm{~nm}$.

El valor medio del Radio de Giro para la corrida en agua pesada fue de 2,71 nm.

Vemos de este modo que tanto el aumento en la presión hidrostática como el hecho de reemplazar el solvente por uno con mayor grado de estructuración generan una leve disminución del Radio de Giro de la proteína.

\section{e. Superficie Accesible al Solvente}

Del mismo modo, se estudió la Superficie Accesible al Solvente (SAS), separando la contribución a la misma de zonas Hidrofóbicas e Hidrofílicas, para analizar principalmente el efecto, sobre la primera de estas zonas, del aumento de la presión hidrostática y del cambio del solvente (agua por agua pesada). Para esto se analizó la superficie de la proteína y sus ligandos recorriendo el sistema con una esfera de prueba de $0,14 \mathrm{~nm}$ (radio del solvente utilizado).

Una de las características relevantes y llamativas de esta proteína es el hecho de tener una gran cantidad de residuos hidrofóbicos expuestos al solvente. 
El 54\% de la superficie expuesta al solvente para la estructura inicial de este estudio es Hidrofóbica. Este hecho, que pareciera contradecir lo que usualmente se afirma como verdad absoluta cuando se habla de la conformación de proteínas, indica claramente que la principal función de la Albúmina es ligar y transportar moléculas no polares a través del torrente sanguíneo.

En la Figura 3-5 se representan los promedios de la fracción de superficie hidrofóbica expuesta al solvente, esto es, el cociente entre la superficie hidrofóbica expuesta al solvente y la superficie total expuesta al solvente por nuestro sistema en las condiciones ya descriptas (es decir, en agua SPC/E a 1 bar y $3 \mathrm{kbar}$ y en agua pesada SPC/HW a 1 bar).

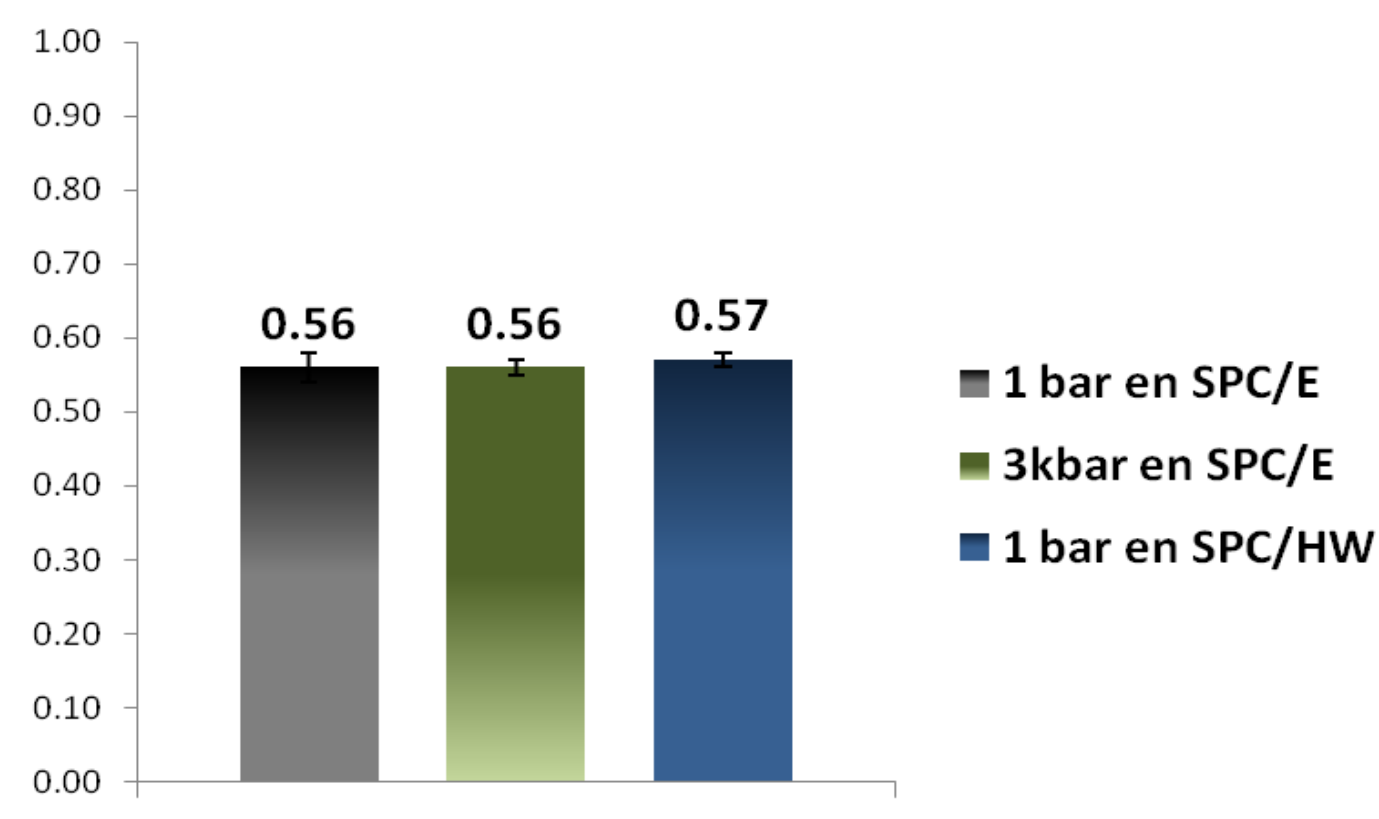

Fracción Hidrofóbica

Figura 3-5: Fracción promedio de superficie hidrofóbica expuesta al solvente en las condiciones estudiadas.

Del análisis de la figura puede verse una notoria estabilidad de la fracción de superficie hidrofóbica expuesta con los importantes cambios producidos tanto en la presión hidrostática como en el solvente acuoso utilizado. Esto nos lleva a concluir que pese a su gran movilidad, esta proteína mantiene una gran estabilidad en diversas condiciones, en parte, seguramente, por la gran cantidad de puentes disulfuro con que cuenta.

También es remarcable el hecho de que la proteína conserva a todos sus ligandos unidos pese a las importantes modificaciones introducidas en su entorno, manteniendo así su función en estas condiciones. 


\section{CAPÍTULO 3}

\section{Simulación de Umbrella Pulling ${ }^{11}$}

Para esta corrida, el análisis de la superficie de la proteína utilizando el programa de visualización VMD 96, permitió elegir la dirección en la cual tirar.

Luego de realizar una serie de corridas para confirmar que los valores estimados para la constante del resorte y la velocidad con que se tira fueran adecuados, se realizaron 30 corridas de $500 \mathrm{ps}$ a un paso de $2 \mathrm{fs}$. La temperatura del termostato fue de $300 \mathrm{~K}$. El valor de la constante del resorte fue $k=1.000 \frac{\mathrm{kJ}}{\mathrm{mol} \cdot \mathrm{nm}^{2}}$ y la velocidad $v=0,01 \frac{\mathrm{nm}}{\mathrm{ps}}$. En la figura 3-6 se grafican las tres componentes de la fuerza aplicada en función del tiempo.
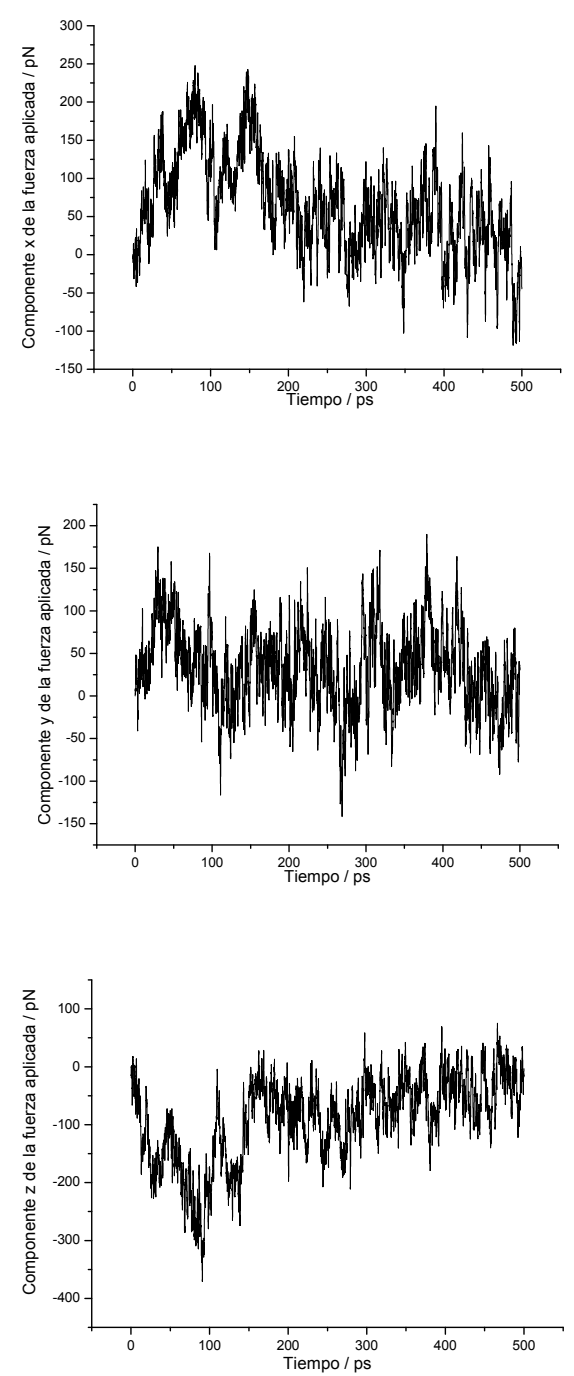

Figura 3-6: Ejemplo de gráficas de las Componentes $x, y$ y $z$, respectivamente de la Fuerza aplicada en función del tiempo. Aquí puede observarse que el desplazamiento según el eje $\mathrm{z}$ fue en el sentido negativo del eje mientras que para $\mathrm{x}$ e y se tiró en el sentido positivo.

\footnotetext{
${ }^{11}$ Esta sección forma parte de la siguiente publicación: Alvarez, H.A., A.N. McCarthy, and J.R. Grigera, A Molecular Dynamics Approach to Ligand-Receptor Interaction in the Aspirin-Human Serum Albumin Complex. Journal of Biophysics, 2012. 2012: p. 7.
} 
Con el propósito de calcular el trabajo realizado, se realizan las gráficas de las componentes de la fuerza en función de la posición de la molécula de la cual se tira. Un ejemplo de estas gráficas se observa en la Figura 3-7. Estas guardan similitud con las obtenidas por otros autores en observaciones experimentales de Microscopía de Fuerza Atómica 97.

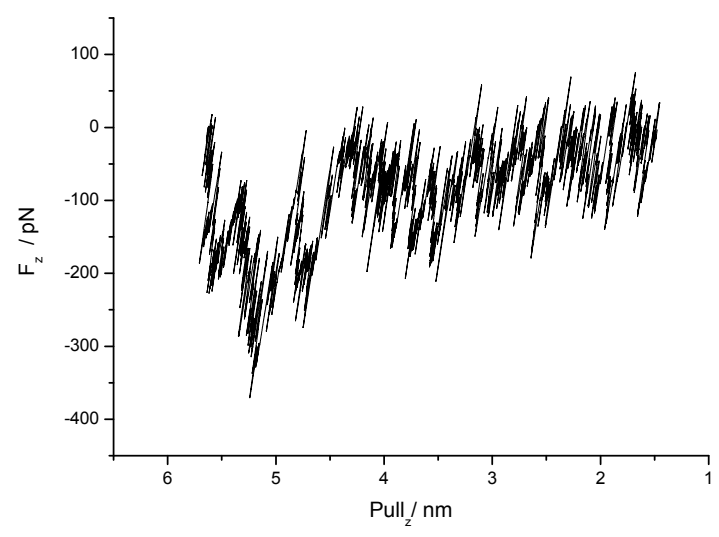

Figura 3-7: Ejemplo de gráfica de componente de la fuerza aplicada en función de la misma componente de la posición de la molécula de la cuál se tira.

Los datos presentados en la Figura 3-8 corresponden al valor medio de la magnitud de la fuerza aplicada sobre el centro de masa de la molécula de ácido acetilsalicílico, como función de la magnitud del desplazamiento del extremo libre del resorte ideal, tanto para el sistema en presencia (líneas negras) y ausencia (líneas rojas) del complejo de la HSA.

Las barras de error muestran la desviación estándar de esos valores. Sólo 80 de estas barras se muestran para una mejor visión. En esta figura, una marcada diferencia entre las curvas se puede observar hasta $4 \mathrm{~nm}$. Después de este punto, la magnitud de la fuerza aplicada es comparable para ambos sistemas, lo que permite considerar fuera del sitio de unión a la molécula de ácido acetilsalicílico.

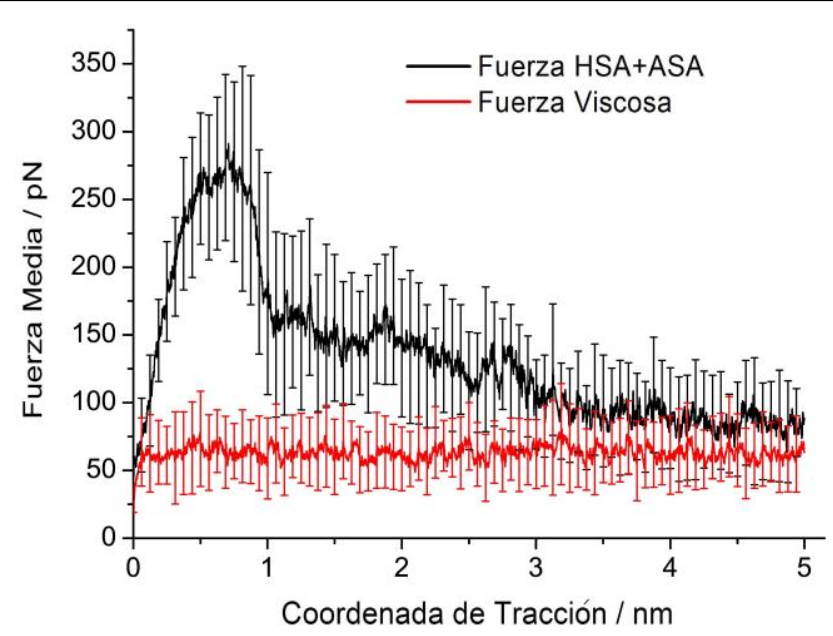

Figura 3-8: Dependencia de la magnitud de la fuerza media aplicada sobre el centro de masas del ASA como función de la magnitud del desplazamiento del resorte (coordenada de tracción o Pull Coordinate), tanto para el sistema en presencia (líneas negras) y ausencia (líneas rojas) del complejo de HSA. Estos valores medios representan la fuerza media en cada paso en treinta corridas de DM para ambos sistemas. Las barras de error son la desviación estándar de los valores (sólo 80 se muestran para una mejor visión). 


\section{CAPÍTULO 3}

En la Figura 3-9 se muestra una representación en histogramas de la distribución del trabajo mecánico realizado, tanto para el sistema en presencia (barras rojas) y ausencia (barras naranjas) del complejo de HSA. A partir de este estudio es interesante observar que las muestras estudiadas de ambos sistemas son lo suficientemente grandes como para distinguir claramente entre las poblaciones.

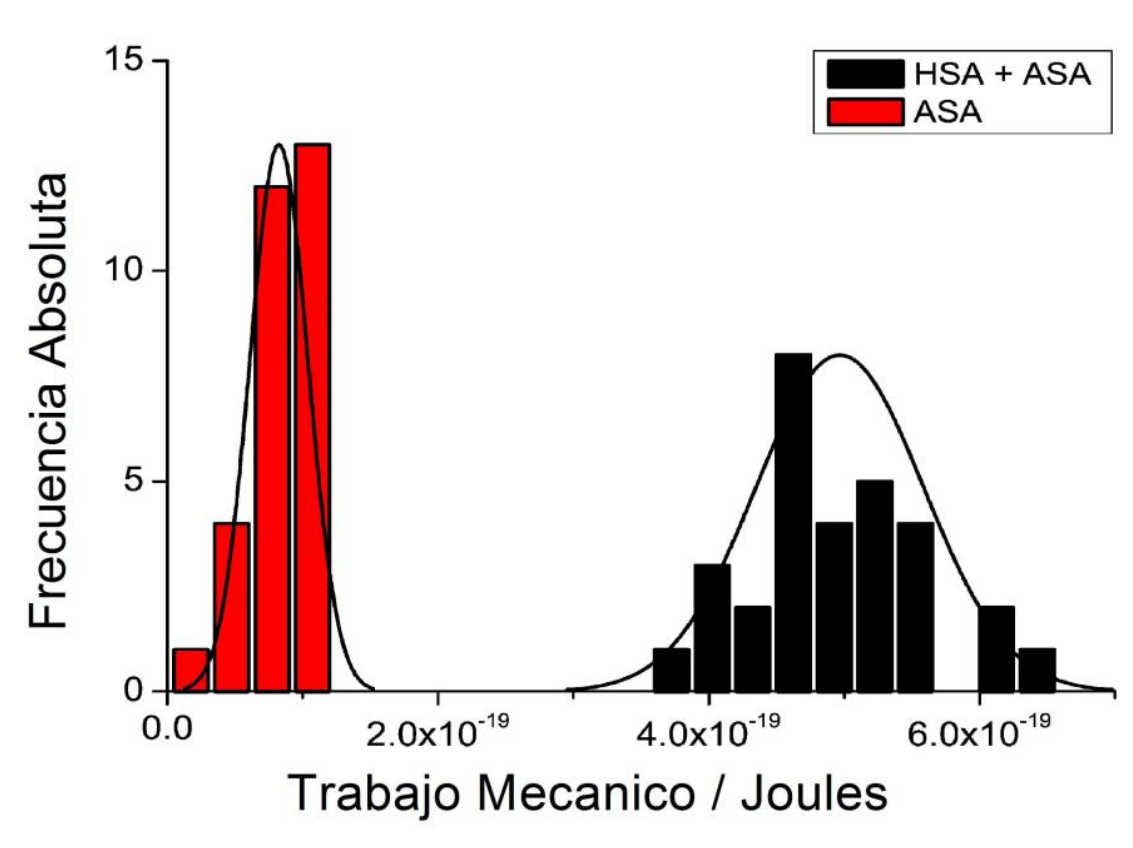

Figura 3-9: Representación en histogramas del trabajo mecánico, tanto para el sistema en presencia (barras negras) como en ausencia (barras rojas) del complejo de HSA. Las líneas continuas son las distribuciones gaussianas para los valores correspondientes de la desviación estándar y el valor medio de cada histograma.

Los valores obtenidos para $W^{a}$ y $W^{x}$, usando las ecuaciones (1.4) y (1.6) respectivamente, son:

$$
\begin{array}{ll}
\mathrm{W}^{a}=(5,0 \pm 0,6) \times 10^{-19} \mathrm{~J} & \text { (Promedio Usual) } \\
\mathrm{W}^{x}=(4,0 \pm 0,6) \times 10^{-19} \mathrm{~J} & \text { (Promedio a la Jarzynski) }
\end{array}
$$

De estos resultados podemos observar que $\mathrm{W}^{x}$ establece una mejor cota superior para $\Delta G$ que $\mathrm{W}^{a}$, de acuerdo con la ecuación (1.7).

Asimismo, el valor medio del Trabajo Viscoso obtenido usando el promedio usual es:

$$
\mathrm{W}^{a}{ }_{\text {viscoso }}=8 \pm 2 \times 10^{-20} \mathrm{~J}
$$

Y el estimador de muestreo finito del valor medio a partir de la igualdad de Jarzynski:

$$
\mathrm{W}^{x}{ }_{\text {viscoso }}=4 \pm 2 \times 10^{-20} \mathrm{~J}
$$


Para el presente caso, el valor obtenido del trabajo viscoso se encuentra dentro del orden de magnitud de la desviación estándar del trabajo de enlace calculado. Sin embargo, esto puede no ser la situación general. Además, a medida que estos métodos computacionales son refinados y aumentan las capacidades de muestreo, este "trabajo viscoso" razonablemente puede convertirse en una fuente más importante de discrepancia con la observación experimental, por lo tanto, esto vuelve obligatoria su evaluación.

Teniendo esto en cuenta, el valor obtenido para $\mathrm{W}^{x}$ sería el siguiente:

$$
\mathrm{W}_{\text {corregido }}^{x}=(3,6 \pm 0,6) \times 10^{-19} \mathrm{~J}
$$

Con respecto a la trayectoria del ligando en este proceso, se pueden distinguir dos regiones: una región interior que corresponde a la circulación en el bolsillo de enlace, donde la dirección de tracción se ve unívocamente determinada por el camino más corto entre la posición original del ligando y el umbral del bolsillo de unión. En esta primera región, donde el camino está determinado conformacionalmente, podemos suponer que la contribución a la media del trabajo total es cercana a la óptima, mientras que en la región exterior se espera poder lograr una mejor optimización de la ruta.

La separación entre ambas regiones se estableció como el punto en el que el centro de masa del ligando cruza el plano formado por los residuos de GLU292, HIS440 y CYS448 (es decir, el umbral del bolsillo de unión), con una coordenada correspondiente de tracción de $1.47 \mathrm{~nm}$.

La primera región representa el $29,4 \%$ del total de la trayectoria, y su contribución al trabajo corregido es de $(1,9 \pm 0,6) \times 10^{-19} \mathrm{~J}$.

\section{Hacia la elección de Caminos}

Una vez identificada la separación entre las dos regiones (interior y exterior), se procedió a estudiar el trabajo realizado en la región exterior tirando en una dirección diferente a la inicial. Se realizaron nuevamente 30 corridas de simulación tomando como configuraciones iniciales las correspondientes a la coordenada de tracción de $1,47 \mathrm{~nm}$.

En la figura 3-10 puede verse una representación en superficie de la Proteína y de la dirección de tracción elegida comparada con la dirección inicial. Esta nueva dirección no pretende ser la óptima, pero sí un camino energéticamente más favorable que la anteriormente estudiada para retirar el residuo una vez que abandona el bolsillo de enlace. 


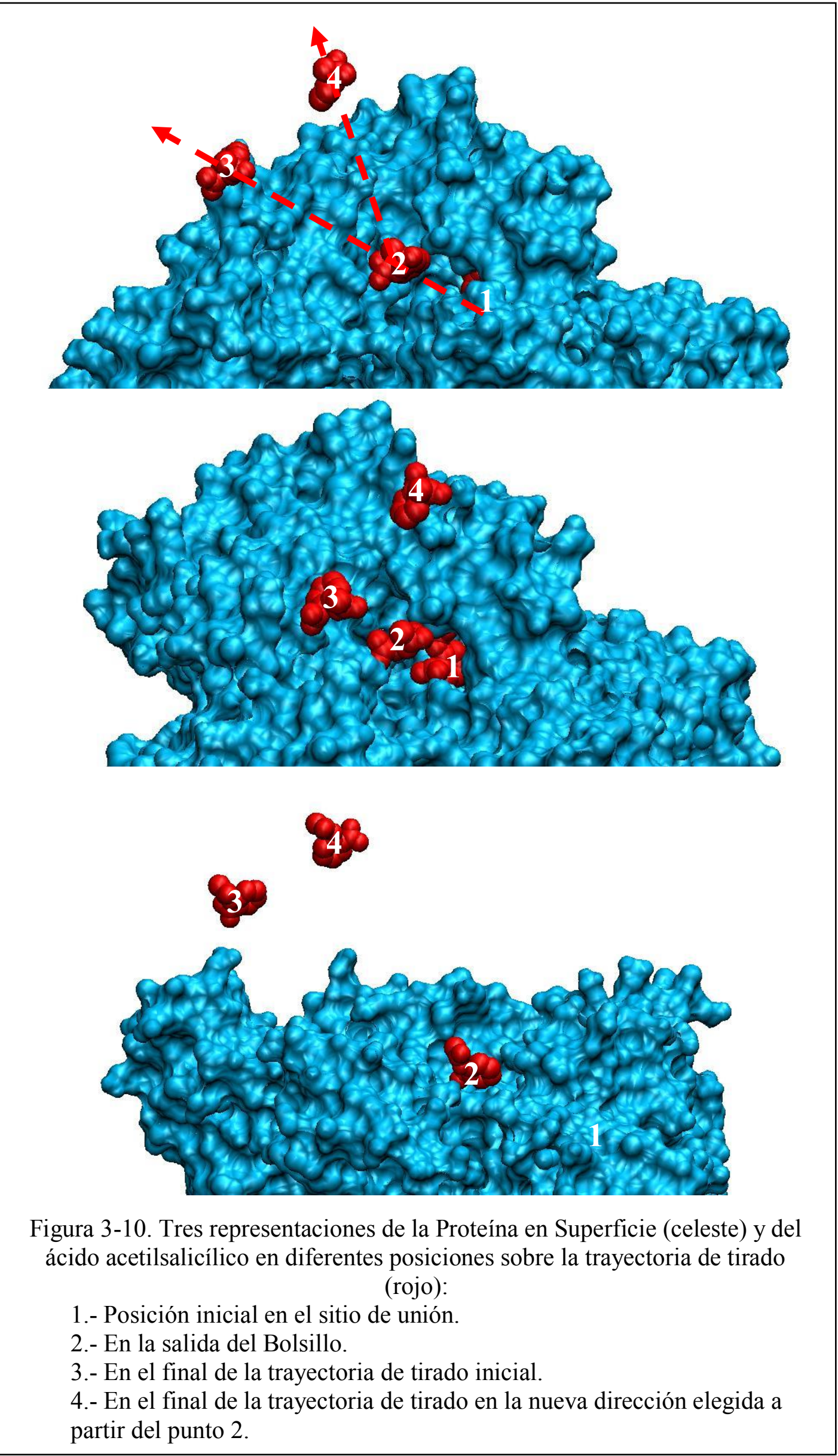


En la Figura 3-11 se representa nuevamente el Módulo de la Fuerza media incorporando la ejercida en el proceso de tirado en otra dirección.

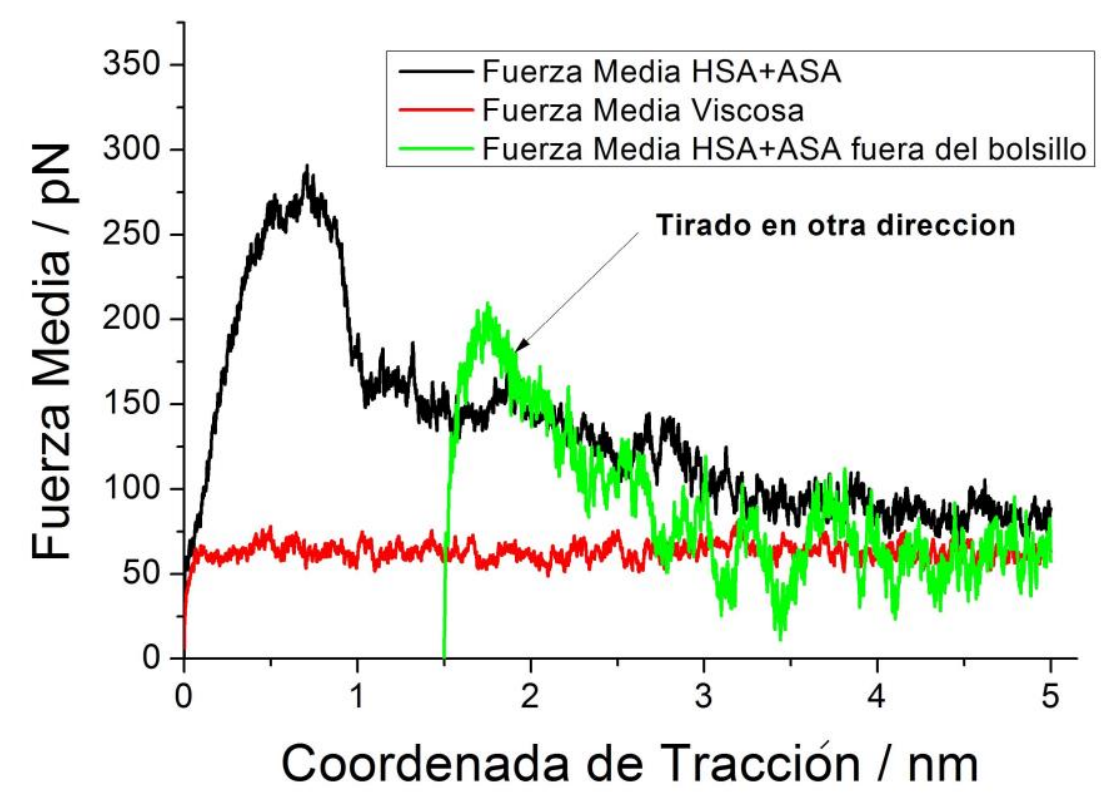

Figura 3-11. Grafícas de Fuerza Media en función de la coordenada de tracción para los sistemas HSA-ASA (negro), Trabajo Viscoso (rojo) y para HSA-ASA tirando en una dirección alternativa (verde).

Se observa en la gráfica que, pese a una mayor fluctuación, la nueva Fuerza Media de tirado se mantiene por debajo de la obtenida para la dirección inicial de tracción. En línea con este resultado, tomando esta contribución en lugar de la inicial para la región exterior del bolsillo, el valor final obtenido para $\mathrm{W}^{x}$ corregido es:

$$
\mathrm{W}_{\text {corregido }}^{x}=(3,5 \pm 0,7) \times 10^{-19} \mathrm{~J}
$$

La constante experimental de afinidad del complejo HSA-aspirina, obtenida por Bojko y colaboradores mediante medidas de extinción de la fluorescencia (quenching fluorescence) 90 es: $\mathrm{K}_{\mathrm{a}}=18,79 \times 10^{3} \mathrm{M}^{-1}$. A partir de este valor, se obtiene el $\Delta \mathrm{G}$ experimental:

$$
\Delta \mathrm{G}=\mathrm{k}_{\mathrm{B}} \mathrm{T} \ln \mathrm{K}_{\mathrm{a}}=4.07 \times 10^{-20} \mathrm{~J}
$$

La cota superior obtenida utilizando el estimador de muestreo finito de la media del trabajo da un mejor valor que la calculada del modo habitual, y puede verse que una aún más adecuada elección del camino de tracción puede mejorar los resultados obtenidos.

Más allá de relativamente recientes comentarios sobre el trabajo de Jarzynski 91, su respuesta es clara y contundente 92, y estos resultados están en línea con lo que clásicamente ha propuesto. 


\section{Mutantes K199A y K199M de Albúmina Sérica Humana}

Adicionalmente, se estudió, utilizando el mismo método, la interacción entre dos mutantes de HSA con sustitución puntual de aminoácidos K199A y K199M, y el ácido acetilsalicílico. En particular la mutante K199A representa la sustitución de un aminoácido básico, polar y cargado como la Lisina 199, por uno más pequeño y neutro como la Alanina, mientras que la mutante K199M representa la sustitución del mismo por uno grande y también neutro como la Metionina.

El objetivo de este estudio fue tener una primera aproximación a la importancia de la Lisina 199 en la interacción de la Aspirina con la Albúmina.

Las mutaciones propuestas son las más utilizadas sobre este residuo. Las mismas han sido empleadas en otras publicaciones para el estudio de la interacción de Albúmina Sérica Humana con Bilirrubina, Halotano y Warfarina, entre otros estudios 98, 99, 100, 101.

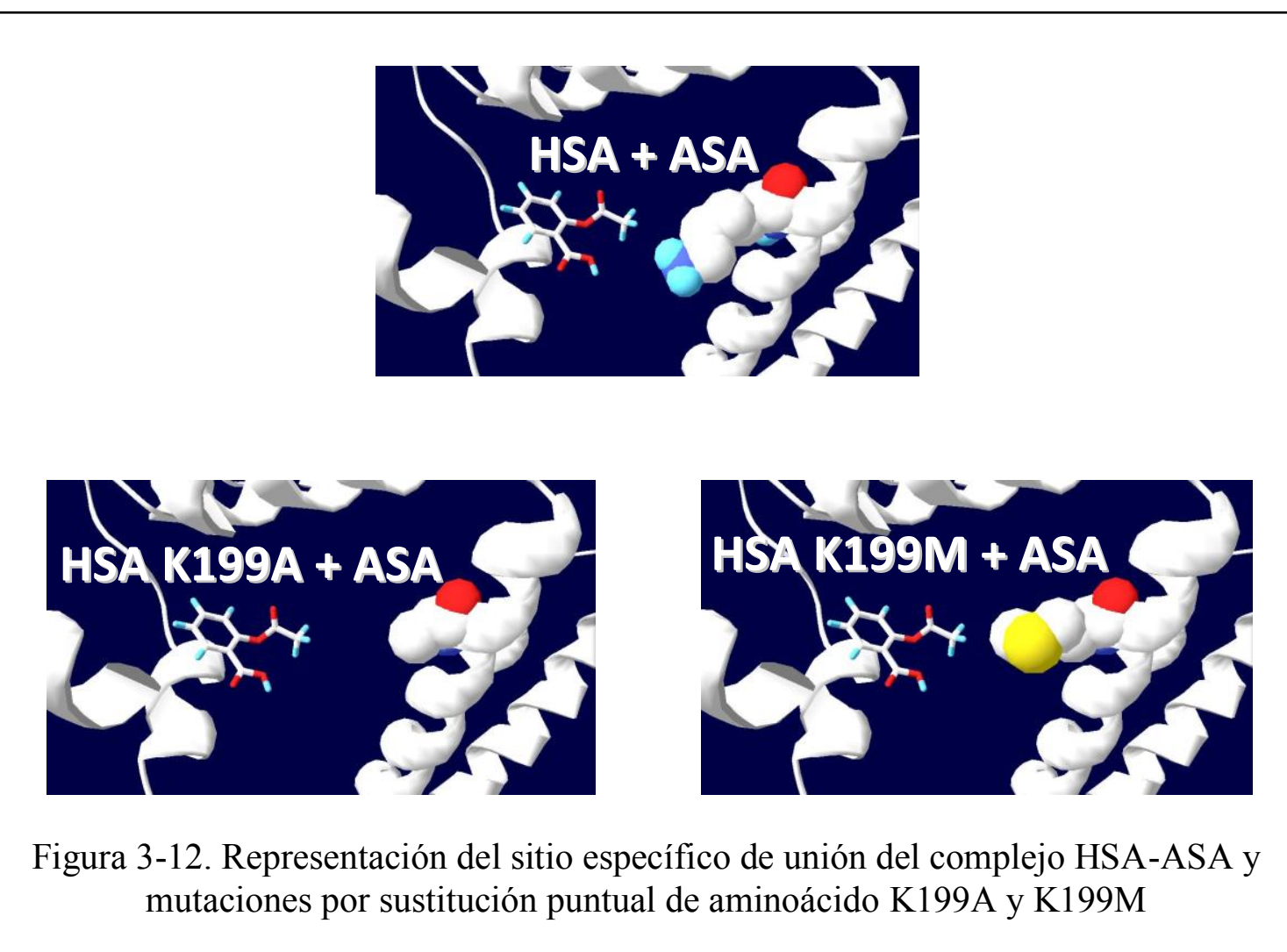

Puede verse claramente en la curva de Fuerza en función de la coordenada de tracción (Figura 3-13) que los trabajos realizados en presencia del residuo de Alanina y del de Metionina son mucho mayores que los promedios obtenidos en presencia de Lisina, siendo además el primero mucho mayor que el segundo.

Podemos indicar en este mismo sentido que ante las mencionadas mutaciones, se modifica la estructura protéica, cerrando de forma notoria la salida del bolsillo donde se encuentra la aspirina. Esto puede apreciarse en la Figura 3-14, donde se ha representado la superficie protéica y se ha ubicado a la aspirina (en representación de van der Waals) posicionada en la dirección de tracción. 


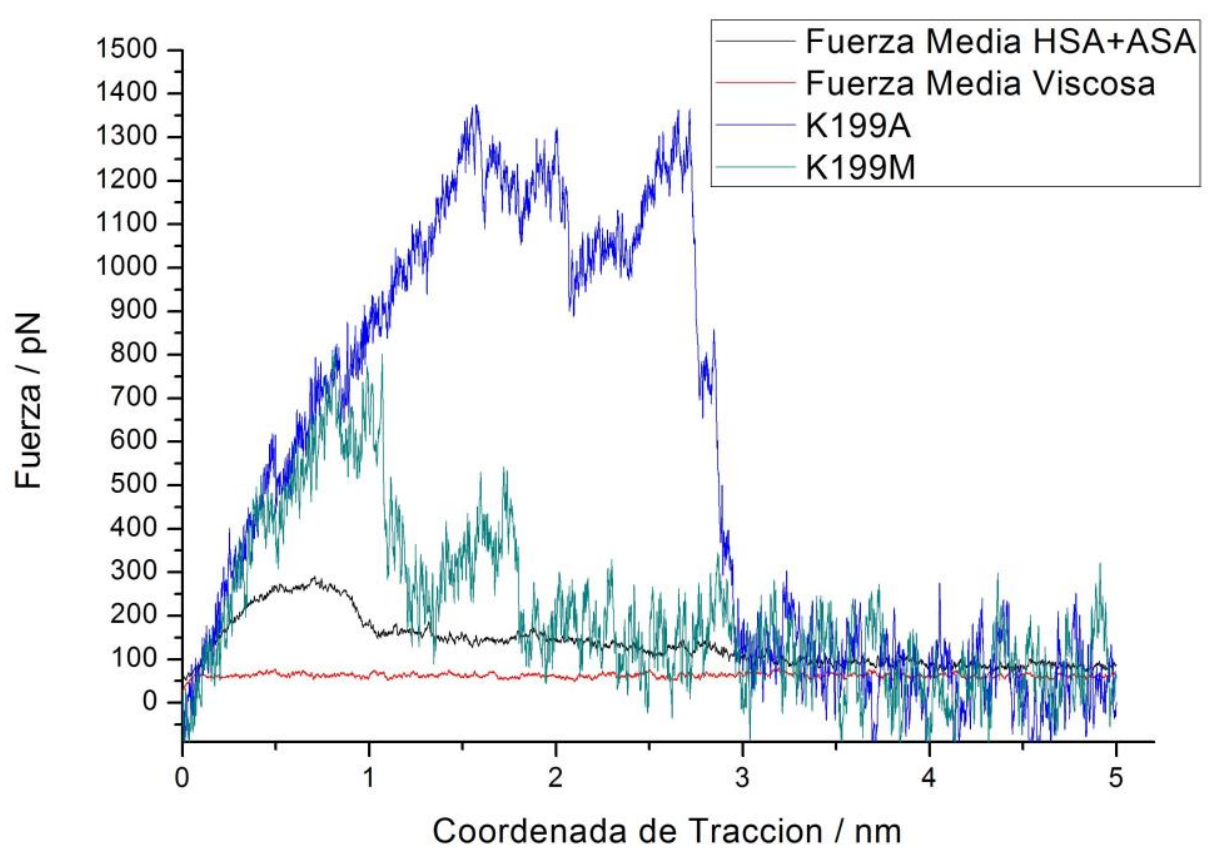

Figura 3-13. Gráficas de Fuerza en función de la coordenada de tracción para los sistemas HSA-ASA (negro), Trabajo Viscoso (rojo), K199A-ASA (azul) y K199M-ASA (verde).

El trabajo calculado para estos sistemas es el siguiente:

$$
\begin{aligned}
& \mathrm{K} 199 \mathrm{~A} \rightarrow \mathrm{W}=2,67 \times 10^{-18} \mathrm{~J} \\
& \mathrm{~K} 199 \mathrm{M} \rightarrow \mathrm{W}=1,00 \times 10^{-18} \mathrm{~J}
\end{aligned}
$$
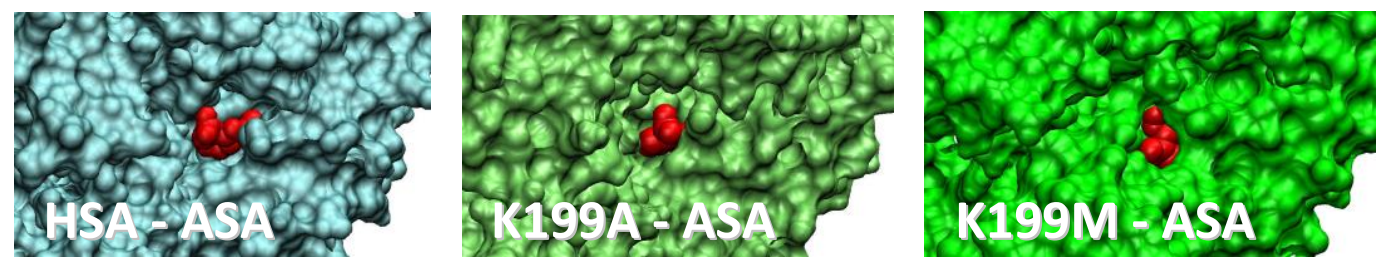

Figura 3-14. Representación de la superficie proteica, y de la Aspirina (rojo) ubicada en el sitio específico de unión y vista en la dirección de tirado para la proteína "silvestre" y sus mutantes. 


\section{CONCLUSIONES}


Página $\mid 72$ 


\section{CONCLUSIONES}

Luego de analizar los resultados obtenidos se puede concluir lo siguiente:

Es necesario destacar la importancia de haber obtenido una estructura estable del complejo que, en ausencia de la fuerza externa utilizada, mantiene a todos sus ligandos en los sitios específicos que se observan en la imagen de Difracción de Rayos X original, a pesar de ser la albúmina una proteína de gran movilidad. Este no es un resultado menor si se tiene en cuenta que la proteína no se hallaba totalmente resuelta a través de la Difracción de Rayos X.

Es posible un análisis a nivel atómico de un sistema tan complejo como la proteína estudiada, mediante las herramientas que provee la Dinámica Molecular, e incluso, con un refinamiento de la técnica podrían obtenerse valores más apropiados. La reducción obtenida para la cota superior de la energía libre de interacción luego de retirar la aspirina en una dirección diferente a la original, habla a las claras de que una mejora en el método de elección de la dirección de tracción, permitiría optimizar los resultados obtenidos.

Se ha obtenido un límite superior promedio para la energía libre de Gibbs de unión del complejo de HSA-ASA que se encuentra a menos de un orden de magnitud por encima del valor experimental.

Es llamativo el resultado obtenido para los sistemas mutantes con grandes diferencias con respecto al comportamiento de la proteína silvestre (wild type). Teniendo en cuenta esto, podemos concluir que la carga negativa de la lisina estabiliza la interacción, a diferencia de lo que ocurre con los aminoácidos neutros. En cuanto a la comparación entre ambas mutantes, podemos decir que el mejor "empaquetamiento" producido por la incorporación de un aminoácido pequeño como la Alanina proporciona un efecto más relevante que el provocado por la Metionina.

En cuanto al comportamiento de los solventes utilizados, se ha podido observar la esperada persistencia de la estructura tetrahédrica en el modelo de agua pesada SPC/HW con respecto al modelo SPC/E. Se analizó cómo esto afecta la estabilidad del complejo estudiado, observando un aumento en el RMSD de la proteína por el reemplazo del agua SPC/E por agua pesada SPC/HW, que se estabiliza en estas condiciones, probablemente debido a la gran cantidad de puentes disulfuro que posee la Albúmina y a la mayor rigidez de los puentes de deuterio respecto a los de hidrógeno.

Algo similar puede decirse del Radio de Giro, que aparentemente indicaría una disminución del volumen de la proteína en presencia de agua pesada SPC/HW.

A partir del estudio de la estabilidad del complejo en función de la presión hidrostática ejercida, se obtiene un aumento comparable del RMSD en ambos puntos de la trayectoria original a partir de los que se estudió la acción de la presión. Este hecho marca que los confórmeros explorados por la proteína no son configuraciones al azar, sino que guardan cierta relación estructural.

Como perspectivas futuras, y para profundizar el análisis de variaciones de energía libre, se planea la obtención de paisajes de energía libre que permitan encontrar el camino más adecuado energéticamente, para la ligadura del sustrato a la proteína. 
También se planea realizar una caracterización de la reacción de hidrólisis, que según sugiere la bibliografía consultada, se produce en el sitio específico en que se une la Aspirina a la Albúmina, mediante la herramienta QM/MM con que cuenta el paquete GROMACS. 
El presente Trabajo de Tesis fue financiado a través de una beca doctoral de CONICET bajo la Dirección del Dr. J. Raúl Grigera y la co-Dirección del Dr. Andrés N. McCarthy en el Instituto de Física de Líquidos y Sistemas Biológicos y del Programa de Retención de Recursos Humanos del Departamento de Ciencias Biológicas - Facultad de Ciencias Exactas - UNLP bajo la Dirección del Dr. J. Raúl Grigera con lugar de trabajo en el Centro de Química Inorgánica Dr. Pedro J. Aymonino. 
Página $\mid 76$ 


\section{REFERENCIAS BIBLIOGRÁFICAS}

1 Equilibrium free-energy differences from nonequilibrium measurements: A master-equation approach. C. Jarzynski

Phys. Rev. E. Volume 56, Number 5: November 1997. pp 5018 - 5035.

2 Nonequilibrium Equality for Free Energy Differences. C. Jarzynski

Physical Review Letters. Volume 78, Number 14: April 1997. pp 2690 - 2693.

3 Systematic errors in free energy perturbation calculations due to a finite sample of configuration space: sample-size hysteresis. Robert $H$. Wood, Wolfgang C. F. Muhlbauer, and Peter T. Thompson

Journal of Physical Chemistry. Vol. 95, No. 17: August 1991. pp $6670-6675$.

4 Theory of a Systematic Computational Error in Free Energy Differences. Daniel M. Zuckerman, and Thomas B.Woolf

Physical Review Letters. Volume 89, Number 18: October 2002.

5 Gromacs: A parallel computer for molecular dynamics simulations. Bekker, H., Berendsen, H. J. C., Dijkstra, E. J., Achterop, S., van Drunen, R., van der Spoel, D., Sijbers, A., Keegstra, H., Reitsma, B., Renardus, M. K. R.

Physics Computing 92 (Singapore, 1993). de Groot, R. A., Nadrchal, J., eds. World Scientific.

6 GROMACS: A message-passing parallel molecular dynamics implementation. Berendsen, H. J. C., van der Spoel, D., van Drunen.

R. Comp. Phys. Comm. 91:43-56, 1995.

7 Gromacs 3.0: A package for molecular simulation and trajectory analysis. Lindahl, E., Hess, B., van der Spoel.

D. J. Mol. Mod. 7:306-317, 2001.

8 GROMACS: Fast, Flexible and Free. van der Spoel, D., Lindahl, E., Hess, B., Groenhof, G., Mark, A. E., Berendsen, H. J. C.

J. Comp. Chem. 26:1701-1718, 2005.

9 Structure of Serum Albumin, en Advances in Protein Chemistry. Carter, D.C. y J.X. Ho; J.T.E.F.M.R.C.B. Anfinsen y S.E. David, Editores.

Academic Press. p. 153-203, 1994.

10 All About Albumin: Biochemistry, Genetics, and Medical Applications. Hassan, M., E. Azzazy y R.H. Christenson.

Theodore Peters, Jr. San Diego, CA: Academic Press, Clin Chem. 43(10), 1997.

11 Crystal structure of human serum albumin at $2.5 \AA$ resolution. Sugio, S., et al. Protein Engineering. 12(6): p. 439-446, 1999.

12 Five recombinant fragments of human serum albumin-tools for the characterization of the warfarin binding site. Dockal, M., et al.

Protein Sci. 9(8): p. 1455-65, 2000. 
13 Atomic structure and chemistry of human serum albumin. He, X.M. y D.C. Carter.

Nature 358(6383): p. 209-215, $1992 .$.

14 Fatty acid binding to plasma albumin. Spector, A.A.

Journal of Lipid Research, 1975. 16: p. 165-179.

15 Crystallographic analysis reveals common modes of binding of medium and long-chain fatty acids to human serum albumin. Bhattacharya, A.A., T. Grüne, y S. Curry.

Journal of Molecular Biology 303(5): p. 721-732, 2000.

16 Crystal structural analysis of human serum albumin complexed with hemin and fatty acid. Zunszain, $P$., et al.

BMC Structural Biology 3(1): p. 6, 2003.

17 Practical Aspects of the Ligand-Binding and Enzymatic Properties of Human Serum Albumin. Kragh-Hansen, U., V.T.G. Chuang, y M. Otagiri.

Biological and Pharmaceutical Bulletin 25(6): p. 695-704, 2002.

18 A reappraisal of what we have learnt during three decades of computer simulations on water. Guillot, B.

Journal of Molecular Liquids 101(1-3): p. 219-260 , 2002.

19 Interaction models for water in relation to protein hydration. Berendsen, H.J.C., et al.

Intermolecular Forces. p. 331-342, 1981.

20 The missing term in effective pair potentials. Berendsen, H.J.C., Grigera, J. R., Straatsma, T. P.

Journal of Physical Chemistry. 91: p. 6269-6271, 1987.

21 Comparison of simple potential functions for simulating liquid water. Jorgensen, W.L., et al.

The Journal of Chemical Physics 79(2), p. 926-935, 1983.

22 Temperature and size dependence for Monte Carlo simulations of TIP4P water. Jorgensen, W.L. and J.D. Madura.

Molecular Physics 56(6): p. 1381-1392, 1985.

23 The melting temperature of the most common models of water. Vega, C., E. Sanz, and J.L.F. Abascal.

J. Chem. Phys. Vol. 122.: AIP. 114507, 2005.

24 A five-site model for liquid water and the reproduction of the density anomaly by rigid, nonpolarizable potential functions. Mahoney, M.W. and W.L. Jorgensen.

J. Chem. Phys. Vol. 112. AIP. 8910-8922, 2000. 
25 A systematic study of water models for molecular simulation: Derivation of water models optimized for use with a reaction field. Spoel, D.v.d., P.J.v. Maaren, and H.J.C. Berendsen,

J. Chem. Phys. Vol. 108. AIP. 10220-10230, 1998.

26 Rationalization of the dielectric properties of common three-site water models in terms of their force field parameters. Höchtl, P., et al.

J. Chem. Phys. Vol. 109. AIP. 4927-4937, 1998.

27 Diffusion constant of the TIP5P model of liquid water. Mahoney, M.W. and W.L. Jorgensen.

J. Chem. Phys. Vol. 114. AIP. 363-366, 2001.

28 Relation between the melting temperature and the temperature of maximum density for the most common models of water. Vega, C. and J.L.F. Abascal.

J. Chem. Phys. Vol. 123. 2005: AIP. 144504.

29 Charge-on-spring polarizable water models revisited: From water clusters to liquid water to ice. Yu, H. and W.F.v. Gunsteren.

J. Chem. Phys. Vol. 121. AIP. 9549-9564, 2004.

30 Existence of a density maximum in extended simple point charge water. Báez, L.A. and P. Clancy.

J. Chem. Phys. Vol. 101. AIP. 9837-9840, 1994.

31 Flexible simple point-charge water model with improved liquid-state properties. $\mathrm{Wu}$, Y., H.L. Tepper, and G.A. Voth

J. Chem. Phys. Vol. 124. AIP. 024503, 2006.

32 Dielectric relaxation in water. Computer simulations with the TIP4P potential. Neumann, M.

J. Chem. Phys. 85(3): p. 1567-1580, 1986.

33 Computer Simulation of the Dielectric Properties of Liquid Water. Strauch, H.J. and P.T. Cummings.

Molecular Simulation 2(1-2): p. 89-104, 1989.

34 The total molecular dipole moment for liquid water. Gubskaya, A.V. and P.G. Kusalik.

J. Chem. Phys. Vol. 117. AIP. 5290-5302, 2002.

35 The dielectric constant of water and heavy water between 0 and 40 degree. Vidulich, G.A., D.F. Evans, and R.L. Kay.

The Journal of Physical Chemistry 71(3): p. 656-662, 1967.

36 Pressure and temperature dependence of self-diffusion in water. Krynicki, K., C.D. Green, and D.W. Sawyer.

Faraday Discussions of the Chemical Society 66: p. 199-208, 1978.

37 MD of H2O, a molecular dynamics study of water. Postma, J.P.M. 
Thesis, University of Groningen., 1985.

38 Water: A matrix of life. Franks, F., Royal Society of Chemistry. 2 edition (September 8, 2000).

39 Density, thermal expansivity, and compressibility of liquid water from $0^{\circ} \mathrm{C}$ to $150^{\circ} \mathrm{C}$. Correlations and tables for atmospheric pressure and saturation reviewed and expressed on 1968 temperature scale. Kell, G.S.

Journal of Chemical \& Engineering Data 20(1): p. 97-105, 1975.

40 The intermolecular dynamics of liquid water. Castner, E.W.J., et al. The Journal of Chemical Physics 102(2): p. 653-659, 1995.

41 Intense depolarized Rayleigh scattering in Raman spectra of acids caused by large proton polarizabilities of hydrogen bonds. Danninger, W. and G. Zundel. The Journal of Chemical Physics 74(5): p. 276, 1981.

42 Femtosecond Dynamics of Hydrogen Bonds in Liquid Water: A Real Time Study. Gale, G.M., et al.

Physical Review Letters 82(5): p. 1068-1071, 1999.

43 Dynamics of Local Substructures in Water Observed by Ultrafast Infrared Hole Burning. Laenen, R., C. Rauscher, and A. Laubereau.

Physical Review Letters 80(12): p. 2622-2625, 1998.

44 Temperature-Dependent Hydrogen-Bond Geometry in Liquid Water. Modig, K., B.G. Pfrommer, and B. Halle

Physical Review Letters 90(7): p. 075502, 2003.

45 Depolarized Rayleigh scattering and hydrogen bonding in liquid water. Montrose, C.J., et al.

The Journal of Chemical Physics 60(12): p. 5025-5029, 1974.

46 X-ray diffraction study of liquid water in the temperature range 4200[degree]C. Narten, A.H., M.D. Danford, and H.A. Levy.

Discussions of the Faraday Society 43: p. 97-107, 1967.

47 Mechanism for vibrational relaxation in water investigated by femtosecond infrared spectroscopy. Nienhuys, H.-K., et al.

The Journal of Chemical Physics 111(4): p. 1494-1500, 1999.

48 Site-site pair correlation functions of water from 25 to $400{ }^{\circ} \mathrm{C}$ : Revised analysis of new and old diffraction data. Soper, A.K., F. Bruni, and M.A. Ricci J. Chem. Phys. Vol. 106. 1997: AIP. 247-254.

49 Femtosecond Mid-IR Pump-Probe Spectroscopy of Liquid Water: Evidence for a Two-Component Structure. Woutersen, S., U. Emmerichs, and H.J. Bakker. Science 278(5338): p. 658-660, 1997. 
50 Molecular dynamics of liquid water probed by neutron scattering. Teixeira, J., M.C. Bellissent-Funel, and S.H. Chen.

Journal of Molecular Liquids 48(2-4): p. 111-121, 1991.

51 A molecular dynamics study of the decane/water interface. van Buuren, A.R., S.J. Marrink, and H.J.C. Berendsen.

The Journal of Physical Chemistry 97(36): p. 9206-9212, 1993.

52 Molecular dynamics simulations of a fully hydrated dipalmitoylphosphatidylcholine bilayer with different macroscopic boundary conditions and parameters. Tieleman, D.P. and H.J.C. Berendsen.

The Journal of Chemical Physics 105(11): p. 4871-4880, 1996.

53 Hydration Thermodynamic Properties of Amino Acid Analogues: A Systematic Comparison of Biomolecular Force Fields and Water Models. Hess, B. and N.F.A. van der Vegt.

The Journal of Physical Chemistry B110(35): p. 17616-17626, 2006.

54 Classic Force Field for Predicting Surface Tension and Interfacial Properties of Sodium Dodecyl Sulfate. Cheng, T., et al.

The Journal of Physical Chemistry B 114(43): p. 13736-13744, 2010.

55 Prediction of the PVT properties of water over wide range of temperatures and pressures from molecular dynamics simulation. Zhang, Z. y Z. Duan, Physics of the Earth and Planetary Interiors 149(3-4): p. 335-354, 2005.

56 A Fixed Point Charge Model for Water Optimized to the Vapor-Liquid Coexistence Properties. Errington, J.R. and A.Z. Panagiotopoulos.

The Journal of Physical Chemistry B 102(38): p. 7470-7475, 1998.

57 Transport and dielectric properties of water and the influence of coarsegraining: Comparing BMW, SPC/E, and TIP3P models. D. Braun, S. Boresch, and O. Steinhauser.

The Journal of Chemical Physics 140 (6), 2014.

58 A Theory of Water and Ionic Solution, with Particular Reference to Hydrogen and Hydroxyl Ions. Bernal, J.D. and R.H. Fowler.

J. Chem. Phys. Vol. 1. AIP. 515-548, 1933.

59 Crossover between tetrahedral and hexagonal structures in liquid water. Chara, O., A.N. McCarthy, and J.R. Grigera.

Physics Letters A 375(3): p. 572-576, 2011.

60 Solvent isotope effect and protein stability. Makhatadze, G.I., G.M. Clore, and A.M. Gronenborn.

Nat. Struct. Mol. Biol. 2(10): p. 852-855, 1995.

61 Effect of Heavy Water on Protein Flexibility. Cioni, P. and G.B. Strambini.

Biophysical Journal 82(6): p. 3246-3253, 2002. 
62 An effective pair potential for heavy water. Grigera, J.R. J Chem Phys, 2001. 114(18): p. 8064-8067.

63 An efficient, box shape independent non-bonded force and virial algorithm for molecular dynamics. Bekker, H., Dijkstra, E. J., Renardus, M. K. R., Berendsen, H. J.

Mol. Sim. 14:137-152, 1995.

64 Gromacs User Manual version 4.6.3, (www.gromacs.org)

D. van der Spoel, E. Lindahl, B. Hess, and the GROMACS development team (2013).

65 Cohesion. Lennard-Jones, J.E.

Proceedings of the Physical Society. 43(5): p. 461, 1931.

66 Diatomic molecules according to the wave mechanics. II. vibrational levels Morse, P. M..

Phys. Rev. 34:57-64, 1929.

67 Cut-off Induced Artifacts in Molecular Dynamics studies of Solvated Peptides. The Reaction Field Method. Schreiber H., y Steinhauser O. Taming.

J.Mol.Biol. 228, 909-923(1992).

68 Berechnung optischer und elektrostatischer Gitterpotentiale. Ewald, P. P. Die Ann. Phys. 64:253-287, 1921.

69 Particle mesh Ewald: An $N-\log (\mathrm{N})$ method for Ewald sums in large systems. Darden, T., York, D., Pedersen, L.

J. Chem. Phys. 98:10089-10092, 1993.

70 A smooth particle mesh ewald potential. Essmann, U., Perera, L., Berkowitz, M. L., Darden, T., Lee, H., Pedersen, L. G.

J. Chem. Phys. 103:8577-8592, 1995.

71 Computer simulation using particles. Hockney, R. W., Eastwood, J. W.

New York: McGraw-Hill. 1981

72 Lattice-sum methods for calculating electrostatic interactions in molecular simulations. Luty, B. A., Tironi, I. G., van Gunsteren, W. F.

J. Chem. Phys. 103:3014-3021, 1995.

73 Computer "experiments" on classical fluids. I. Thermodynamical properties of Lennard- Jones molecules. Verlet, L.

Phys. Rev. 159:98, 1967.

74 Practical algorithms for dynamic simulations. Berendsen, H. J. C. and van Gunsteren, W. F.. En: Ciccotti, G. and Hoover, W., editors, Molecular-Dynamics Simulation of Statistical-Mechanical Systems. North-Holland, Amsterdam (1986).

75 Computer Simulation of Liquids. Allen, M.P. and D.J. Tildesley.

Oxford University Press, USA (1989). 
76 Molecular dynamics with coupling to an external bath. Berendsen, H. J. C., Postma, J. P. M., DiNola, A., Haak, J. R.

J. Chem. Phys. 81:3684-3690, 1984.

77 Polymorphic transitions in single crystals: A new molecular dynamics method. Parrinello, M. and A. Rahman,

Journal of Applied Physics, 1981. 52(12): p. 7182-7190.

78 Canonical sampling through velocity rescaling. Bussi, G., D. Donadio, and M. Parrinello.

J. Chem. Phys. 126(1): p. 014101, 2007.

79 A molecular dynamics method for simulations in the canonical ensemble. Nosé, $\mathrm{S}$. Mol. Phys. 52:255-268, 1984.

80 Canonical dynamics: equilibrium phase-space distributions. Hoover, W. G. Phys. Rev. A 31:1695-1697, 1985.

81 Transport properties computed by linear response through weak coupling to a bath. Berendsen, H. J. C. En: Computer Simulations in Material Science. Meyer, M., Pontikis, V. eds. Kluwer 1991 139-155.

82 Numerical integration of the Cartesian equations of motion of a system with constraints; molecular dynamics of n-alkanes. Ryckaert, J. P., Ciccotti, G., Berendsen, H. J. C.

J. Comp. Phys. 23:327-341, 1977.

83 SETTLE: An analytical version of the SHAKE and RATTLE algorithms for rigid water models. Miyamoto, S., Kollman, P. A.

J. Comp. Chem. 13:952-962, 1992.

84 LINCS: A linear constraint solver for molecular simulations. Hess, B., Bekker, H., Berendsen, H.J.C., Fraaije, J.G.E.M.

J. Comp. Chem. 18:1463-1472, 1997.

85 The interpretation of protein structures: Estimation of static accessibility. Lee, B. and F.M. Richards.

Journal of Molecular Biology. 55(3): p. 379-IN4, 1971.

86 Analytical molecular surface calculation. Connolly, $\mathrm{M}$.

Journal of Applied Crystallography. 16(5): p. 548-558, 1983.

87 The molecular surface package. Connolly, M.L.,

Journal of Molecular Graphics. 11(2): p. 139-141. , 1993

88 A generalized reaction field method for molecular dynamics simulations. Tironi, I. G., Sperb, R., Smith, P. E., van Gunsteren, W. F.

J. Chem. Phys. 102:5451-5459, 1995. 
89 The missing term in effective pair potentials. Berendsen, H. J. C., Grigera, J. R., Straatsma, T. P.

J. Phys. Chem. 91:6269-6271, 1987.

90 Changes of serum albumin affinity for aspirin induced by fatty acid. Bojko, B., et al., International Journal of Biological Macromolecules, 2008. 42(4): p. 314-323.

91 A note on the Jarzynski equality. Cohen, E.G.D. and M. David, Journal of Statistical Mechanics: Theory and Experiment, 2004. 2004(07): p. P07006.

92 Nonequilibrium work theorem for a system strongly coupled to a thermal environment. Jarzynski, C., Journal of Statistical Mechanics: Theory and Experiment, 2004. 2004(09): p. P09005.

93 Biomolecular Simulation: The GROMOS96 manual and user guide. van Gunsteren, W. F., Billeter, S. R., Eising, A. A., Hünenberger, P. H., Krüger, P., Mark, A. E., Scott, W. R. P., Tironi, I. G.

Zürich. Switzerland: Hochschulverlag AG an der ETH Zürich. 1996

94 Effect of human serum albumin on drug metabolism: Structural evidence of esterase activity of human serum albumin. Yang, F., Bian, C., Zhu, L., Zhao, G., Huang, Z., Huang, M.

J.Struct.Biol. v157 pp 348-355, 2007

95 PRODRG - a tool for high-throughput crystallography of protein-ligand complexes. A. W. Schuettelkopf and D. M. F. van Aalten (2004).

Acta Crystallographica. D60, 1355--1363.

96 "VMD - Visual Molecular Dynamics" Humphrey, W., Dalke, A. and Schulten, K., J. Molec. Graphics, vol. 14, pp. 33-38, 1996.

97 Free energy reconstruction from nonequilibrium single-molecule pulling experiments. Gerhard Hummer, Attila Szabo.

PNAS, vol. 98, no. 7, March 27, pp 3658-3661, 2001.

98 Biological characteristics of two lysines on human serum albumin in the highaffinity binding of 4Z,15Z-bilirubin-IX $\alpha$ revealed by phage display. Minomo, A., et al.

FEBS Journal, 2011. 278(21): p. 4100-4111.

99 The Role of Electrostatic Interactions in Human Serum Albumin Binding and Stabilization by Halothane. Liu, R., et al.

Journal of Biological Chemistry, 2002. 277(39): p. 36373-36379.

100 Conformational stability and warfarin-binding properties of human serum albumin studied by recombinant mutants. Watanabe, $\mathrm{H}$., et al.

Biochem. J., 2001. 357(1): p. 269-274.

101 The effect of glycation on the structure, function and biological fate of human serum albumin as revealed by recombinant mutants. Nakajou, K., et al. 
REFERENCIAS BIBLIOGRÁFICAS

Biochimica et Biophysica Acta (BBA) - General Subjects, 2003. 1623(2-3): p. 8897. 
Página | 86 


\section{APÉNDICE \\ Cargas asignadas al Ácido Acetilsalicílico y al Ácido Mirístico}

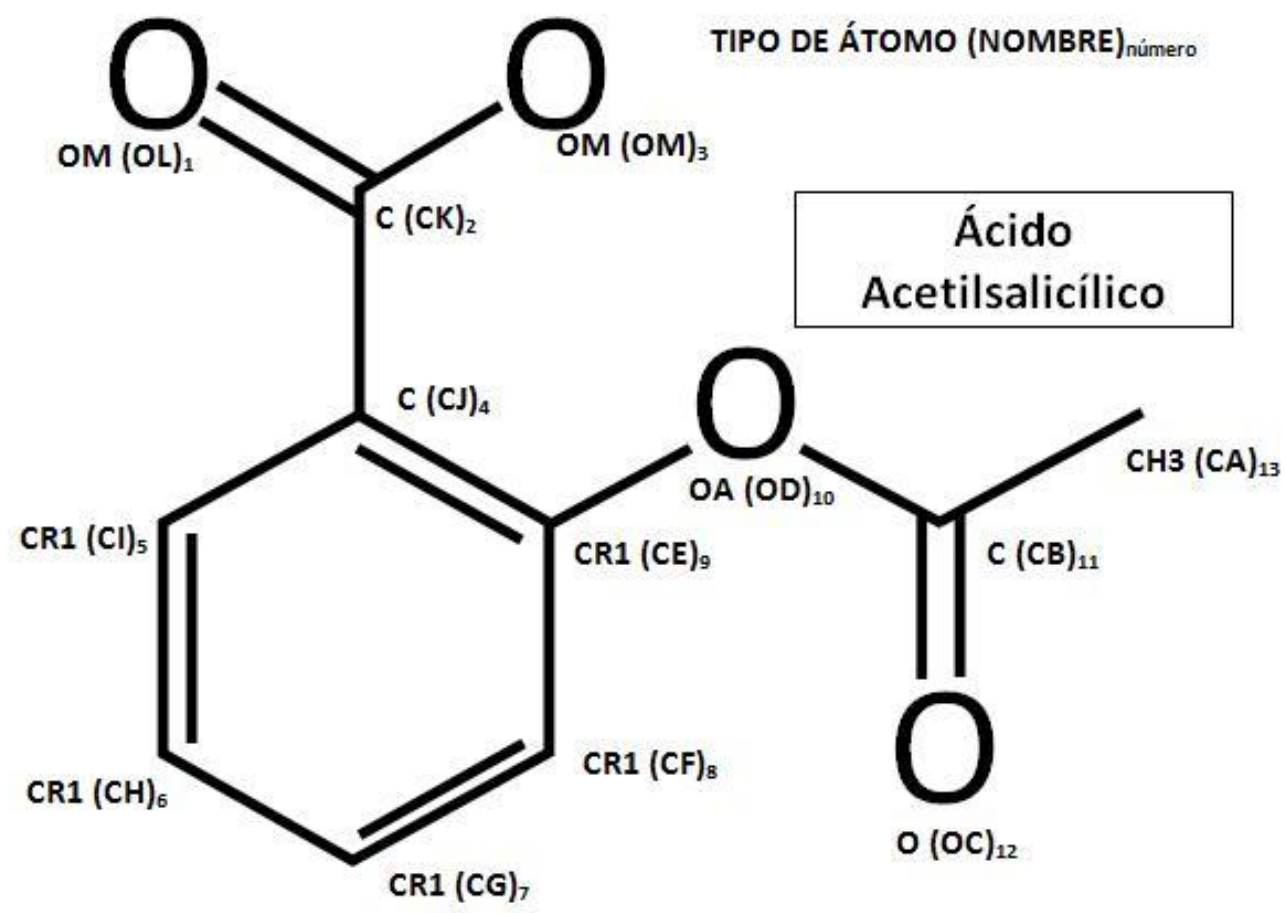

Nombres asignados a los diferentes átomos del ácido acetilsalicílico

\begin{tabular}{|c|c|c|c|c|c|}
\hline $\begin{array}{c}\text { Número } \\
\text { de átomo }\end{array}$ & $\begin{array}{c}\text { Tipo de } \\
\text { átomo }\end{array}$ & Nombre & $\begin{array}{c}\text { Grupo } \\
\text { de carga }\end{array}$ & $\begin{array}{c}\text { Carga } \\
\text { Parcial }\end{array}$ & Masa \\
\hline 1 & OM & OL & 1 & -0.635 & 15.9994 \\
\hline 2 & C & CK & 1 & 0.27 & 12.011 \\
\hline 3 & OM & OM & 1 & -0.635 & 15.9994 \\
\hline 4 & C & CJ & 2 & 0 & 12.011 \\
\hline 5 & CR1 & CI & 2 & 0 & 13.019 \\
\hline 6 & CR1 & CH & 2 & 0 & 13.019 \\
\hline 7 & CR1 & CG & 3 & 0 & 13.019 \\
\hline 8 & CR1 & CF & 3 & 0 & 13.019 \\
\hline 9 & C & CE & 3 & 0 & 12.011 \\
\hline 10 & OA & OD & 4 & 0 & 15.9994 \\
\hline 11 & C & CB & 4 & 0.38 & 12.011 \\
\hline 12 & O & OC & 4 & -0.38 & 15.9994 \\
\hline 13 & CH3 & CA & 5 & 0 & 15.035 \\
\hline
\end{tabular}

Distribución de las cargas asignadas a cada átomo en la construcción de la topología del ácido acetilsalicílico 


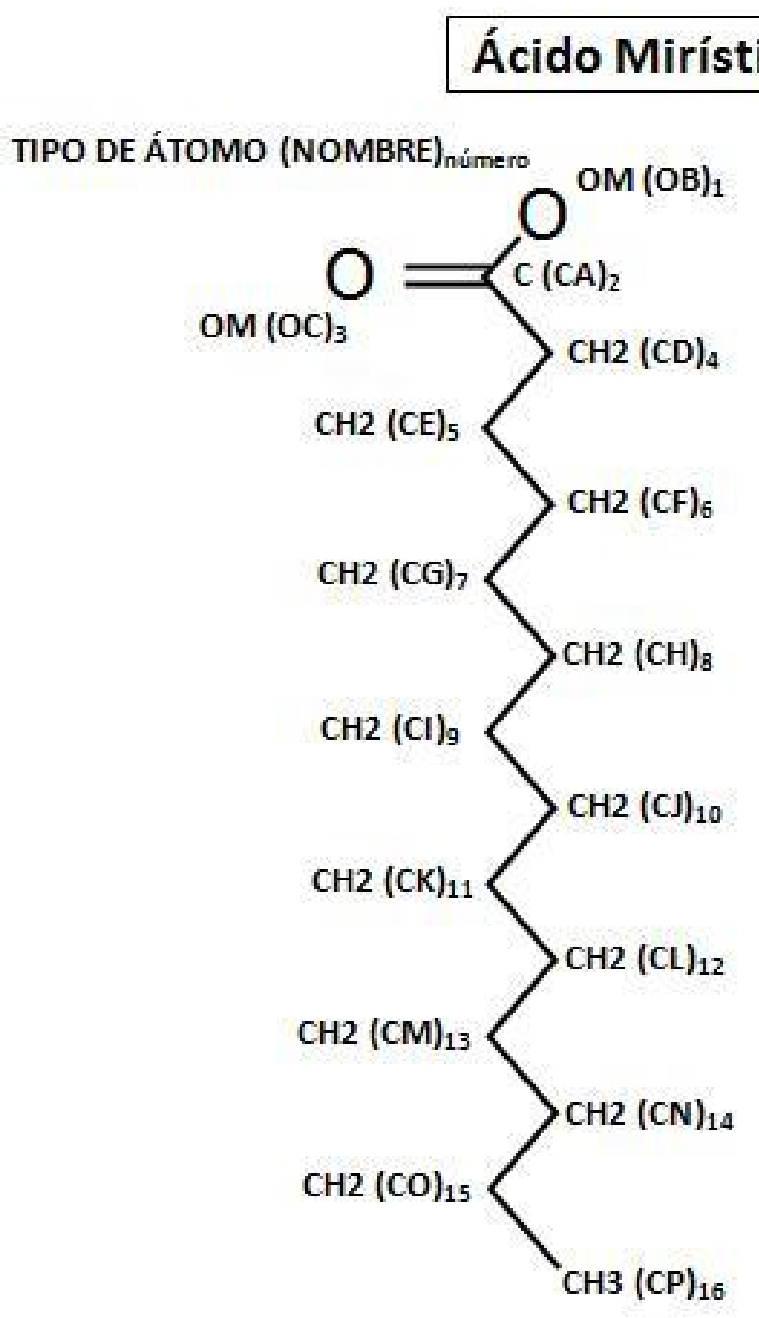

Nombres asignados a los diferentes átomos del ácido mirístico

\begin{tabular}{|c|c|c|c|c|c|}
\hline $\begin{array}{c}\text { Número } \\
\text { de átomo }\end{array}$ & $\begin{array}{c}\text { Tipo de } \\
\text { átomo }\end{array}$ & Nombre & $\begin{array}{c}\text { Grupo } \\
\text { de carga }\end{array}$ & $\begin{array}{c}\text { Carga } \\
\text { Parcial }\end{array}$ & Masa \\
\hline 1 & OM & OB & 1 & -0.635 & 15.9994 \\
\hline 2 & C & CA & 1 & 0.27 & 12.011 \\
\hline 3 & OM & OC & 1 & -0.635 & 15.9994 \\
\hline 4 & CH2 & CD & 2 & 0 & 14.027 \\
\hline 5 & CH2 & CE & 2 & 0 & 14.027 \\
\hline 6 & CH2 & CF & 2 & 0 & 14.027 \\
\hline 7 & CH2 & CG & 2 & 0 & 14.027 \\
\hline 8 & CH2 & CH & 2 & 0 & 14.027 \\
\hline 9 & $\mathrm{CH} 2$ & CI & 2 & 0 & 14.027 \\
\hline 10 & CH2 & CJ & 2 & 0 & 14.027 \\
\hline 11 & $\mathrm{CH} 2$ & CK & 2 & 0 & 14.027 \\
\hline 12 & $\mathrm{CH} 2$ & $\mathrm{CL}$ & 2 & 0 & 14.027 \\
\hline 13 & $\mathrm{CH} 2$ & $\mathrm{CM}$ & 2 & 0 & 14.027 \\
\hline 14 & $\mathrm{CH} 2$ & $\mathrm{CN}$ & 2 & 0 & 14.027 \\
\hline 15 & $\mathrm{CH} 2$ & $\mathrm{CO}$ & 2 & 0 & 14.027 \\
\hline 16 & $\mathrm{CH} 3$ & $\mathrm{CP}$ & 2 & 0 & 15.035 \\
\hline
\end{tabular}

Distribución de las cargas asignadas a cada átomo en la construcción de la topología del ácido mirístico 